UNIVERSIDADE DE SÃO PAULO

ESCOLA DE ENFERMAGEM

TANIA OLIVEIRA LOPES

\title{
AULA EXPOSITIVA DIALOGADA E AULA SIMULADA: \\ COMPARAÇÃO ENTRE ESTRATÉGIAS DE ENSINO NA GRADUAÇÃO EM ENFERMAGEM
}

SÃO PAULO

2012 
TANIA OLIVEIRA LOPES

\section{AULA EXPOSITIVA DIALOGADA E AULA SIMULADA: COMPARAÇÃO ENTRE ESTRATÉGIAS DE ENSINO NA GRADUAÇÃO EM ENFERMAGEM}

Dissertação apresentada ao Programa de Pós-Graduação em Gerenciamento em Enfermagem da Escola de Enfermagem da Universidade de São Paulo para obtenção do título de Mestre em Ciências

Área de Concentração: Fundamentos e Práticas de Gerenciamento em Enfermagem e em Saúde

Orientadora: Prof ${ }^{\underline{a}}$ Dr $^{\underline{a}}$ Heloísa Helena Ciqueto Peres

\section{SÃo PAULO}


AUTORIZO A REPRODUÇÃO E DIVULGAÇÃO TOTAL OU PARCIAL DESTE TRABALHO, POR QUALQUER MEIO CONVENCIONAL OU ELETRÔNICO, PARA FINS DE ESTUDO E PESQUISA, DESDE QUE CITADA A FONTE.

Assinatura:

Data:

\section{Catalogação na Publicação (CIP) Biblioteca "Wanda de Aguiar Horta" Escola de Enfermagem da Universidade de São Paulo}

\section{Lopes, Tania Oliveira}

Aula expositiva dialogada e aula simulada:

Comparação entre estratégias de ensino na graduação em enfermagem. Tania Oliveira Lopes. - São Paulo, 2012.

$126 \mathrm{p}$.

Dissertação (Mestrado) - Escola de Enfermagem da Universidade de São Paulo.

Orientadora: Profa. Dra. Heloisa Helena Ciqueto Peres

Área de concentração: Fundamentos e práticas de gerenciamento em enfermagem e em saúde.

1. Enfermagem-Estudo e Ensino 2. Tecnologia educacional 3. Simulação de Paciente 4. Acidente cerebrovascular 5 Simulação (aprendizagem) I.Título. 
Nome: Tania Oliveira Lopes

Título: Aula Expositiva Dialogada e Aula Simulada: Comparação Entre Estratégias de Ensino na Graduação em Enfermagem

Dissertação apresentada à Escola de Enfermagem da Universidade de São Paulo para obtenção do título de Mestre em Ciências

Aprovado em:

\section{Banca Examinadora}

Prof. Dr.: Instituição:

Julgamento: Assinatura:

Prof. Dr.: Instituição:

Julgamento: Assinatura:

Prof. Dr.: Instituição:

Julgamento: Assinatura: 


\section{Dedicatória}

A Deus, que é a fonte de toda energia que ilumina todos os dias da minha vida e encaminhou-me passo a passo nesta jornada.

A minha mãe Luzia que sempre me incentivou a alcançar vôos mais altos, além do amor e carinho recebido por ela desde meu nascimento.

Ao meu irmão Sidnei companheiro e amigo dos momentos bons e dos não tão bons, como irmão mais velho desbravou os caminhos mais difíceis, tornando - os mais suaves na minha trajetória.

Ao meu querido avô Elias (in memorian), você me acolheu e já me ensinava na minha mais tenra infância o sentido do amor verdadeiro.

Ao amor da minha vida, Marcelo, esposo e companheiro, poder viver ao seu lado é um presente de Deus que recebi.

Ao meu filho Henrique, dádiva divina, fonte de luz e de amor, você deu uma nova cor em minha vida, fez sentir o mais puro amor que um ser humano pode sentir, fez entender o verdadeiro sentido da minha existência nesta jornada terrestre.

Aos meus sogros Mario e Fernanda pelo incentivo à melhoria contínua.

A meu amigo e grande líder Miguel Cendoroglo Neto, você me fez entender que não há limite para sonhar. 


\section{Agradecimento Especial}

\section{À Prof ${ }^{a}$ Dra. Heloisa Helena Ciqueto Peres}

Minha orientadora, amiga, companheira deste trabalho, Dra. Heloísa Helena Ciqueto Peres, você foi fonte de equilíbrio, paz, incentivo e colaborou para meu crescimento profissional, acadêmico e como ser humano.

"A mente que se abre a uma nova idéia jamais voltará a seu tamanho original".

Albert Einstein 


\section{Agradecimentos}

Às Prof. ${ }^{a}$ Dra.Claudia Prado e Prof ${ }^{a}$ Dra. Vera Mira Gonçalves meu reconhecimento pelo carinho, acolhimento e pelas ricas contribuições no exame de qualificação;

Às Prof..$^{a}$ Dra.Claudia Prado e Prof ${ }^{\underline{a}}$ Dra. Vera Mira Gonçalves e ao Dr. José Manuela Rocha Fernandes e a Dra. Gisele Sampaio Silva; seus conhecimentos contribuíram de forma marcante na construção deste trabalho;

Aos funcionários da EEUSP, pela presteza e solicitude no atendimento;

Às amigas e líderes Dra. Olga Farah e Dra. Andreia Molhalem; sem apoio de vocês, este trabalho não teria sido realizado;

Às amigas do Instituto do Cérebro, Dra. Claudia Cristina Ferreiro de Barros, Ms. Maria Angela M. Barreiros Angela e Dra. Patrícia Aguiar, pela parceria e apoio para a minha melhoria contínua;

À secretaria do Departamento de Orientação Profissional, pelo atendimento destes dois anos;

A todos que direta ou indiretamente contribuíram na concretização deste trabalho. 
Lopes TO. Aula Expositiva Dialogada e Aula Simulada: Comparação entre Estratégias de Ensino na Graduação em Enfermagem. [dissertação]. São Paulo: Escola de Enfermagem, Universidade de São Paulo; 2012.

\section{Resumo}

Este estudo teve como objetivo geral analisar a eficácia da aprendizagem dos discentes, imediatamente, 15 e 30 dias após a aula expositiva dialogada e a aula simulada em laboratório de enfermagem. Tratou-se de um estudo longitudinal de abordagem quantitativa, tipo experimento antes e depois, que se constitui de um método experimental verdadeiro para a comparação da apreensão do conhecimento dos alunos na aula expositiva dialogada e na aula simulada no laboratório de enfermagem, tendo hipótese que a aula simulada é mais eficaz do que a aula expositiva dialogada para a apreensão do conhecimento em AVC na enfermagem. A população deste estudo foi composta por 42 alunos do 6o semestre da graduação em enfermagem da Faculdade de Enfermagem do Hospital Israelita Albert Einstein, que foram randomizados estatisticamente em dois grupos, controle e experimental. Foram consideradas como variáveis intervenientes ao processo de ensino e aprendizagem: idade, atuação profissional na área da saúde, média ponderada das notas do primeiro e segundo anos letivos e a nota da avaliação progressiva do conhecimento de 2009. Ambos os grupos foram submetidos a uma aula sobre o reconhecimento dos sinais e sintomas do Acidente Vascular Cerebral (AVC) e suas condutas assistencias. $\mathrm{O}$ grupo controle foi submetido a uma aula dialogada expositiva e o grupo Experimental a uma aula simulada em laboratório de enfermagem. Nas duas intervenções foi utilizado como cenário pedagógico a Teoria da Aprendizagem Significativa. Os resultados da pesquisa demonstram que a estratégia de aula simulada no laboratório de enfermagem é mais eficaz para a apreensão do conhecimento de forma significativa pelos discentes de graduação em enfermagem, com diferença estatística significante de $p<0,05$ do momento pré para o momento imediatamente pós intervenção sobre os sinais e sintomas do $A V C$ e as condutas assistenciais. Dessa forma a hipótese do presente estudo de que a aula simulada é mais eficaz do que a 
aula expositiva dialogada para a apreensão do conhecimento em AVC na enfermagem é verdadeira. Em relação ao seguimento longitudinal após 15 e 30 dias da intervenção, os grupos (controle e experimental) se comportaram de forma muito semelhante ao longo do tempo, ocorrendo um declínio da retenção do conhecimento em ambos os grupos, sem diferenças estatísticas significativas. Entretanto, o grupo experimental comportou-se com nota superior. Quanto a comparação da satisfação dos discentes na aula expositiva dialogada e na aula simulada, o grupo experimental que participou da aula simulada em laboratório de enfermagem evidenciou estar mais satisfeito e motivado para a apreensão do conhecimento sobre AVC. Este fato pôde ser comprovado por meio da comparação da satisfação dos discentes na aula expositiva dialogada e na aula simulada, bem como pelos relatos dos discentes que expressaram a importância da aula para propiciar uma visão real dos objetos de estudo contribuindo para uma aprendizagem significativa. Dessa forma este estudo possibilitou identificar e comparar a eficácia da apreensão do conhecimento na aula simulada em laboratório de enfermagem, bem como propiciou a compreensão da importância do planejamento educacional e da adoção de estratégias de ensino fundamentadas na Teoria da Aprendizagem Significativa, identificando a necessidade da capacitação pedagógica dos docentes de enfermagem.

Descritores: 1. Enfermagem-Estudo e Ensino 2. Tecnologia educacional 3. Simulação de Paciente 4. Acidente cerebrovascular 5 Simulação (aprendizagem) 
Lopes TO. Lecture Through Dialogue and Simulated Classroom: Comparing Teaching Strategies in Undergraduate Nursing [dissertation]. São Paulo: Nursing School, University of São Paulo; 2012.

\section{Abstract}

This study aimed to analyze the effectiveness of students' learning, immediately, 15 and 30 days after the lecture and classroom dialogic simulated nursing lab. This was a longitudinal study of quantitative approach, like before and after the experiment, which consists of an experimental method for comparing the true understanding of students' knowledge in dialogued lecture in class and in simulated nursing lab, and hypothesis a simulated classroom is more effective than lecture dialogued for the apprehension of knowledge in stroke nursing. The study population consisted of 42 students of 6th semester of undergraduate nursing, School of Nursing of the Hospital Albert Einstein, who statistically were randomized into two groups, experimental and control. Were considered as intervening variables to the process of teaching and learning: age, professional activity in health, the weighted average of grades in the first and second school years and note the progressive assessment of knowledge, 2009. Both groups were subjected to a lecture on the recognition of signs and symptoms of stroke (CVA) and assists their conduct. The control group underwent a dialogic classroom expository and experimental group to a classroom in simulated nursing lab. In the two interventions was used as a pedagogic setting the Theory of Meaningful Learning. The survey results show that the strategy of class in simulated nursing lab is more effective for the acquisition of knowledge significantly by undergraduate students in nursing, with statistical significance of $p<0.05$ from pre to the time immediately post intervention on the signs and symptoms of stroke care and conduct. Thus the hypothesis of this study that simulated the lesson is more effective than lecture dialogued for the apprehension of knowledge in stroke nursing is true. In relation to the longitudinal follow-up after 15 and 30 days of the intervention groups (control and experimental) behaved very similarly over time, experiencing a decline in 
knowledge retention in both groups, without statistically significant differences. However, the experimental group behaved with top note. The comparison of the satisfaction of students in the lecture through dialogue and simulated classroom, the experimental group who attended the class in simulated nursing lab showed to be more satisfied and motivated for the apprehension of knowledge of stroke. This fact was proven by comparing the satisfaction of students in the lecture through dialogue and simulated in the classroom as well as by the reports of students who expressed the importance of class to provide a true picture of the objects of study contributing to a meaningful learning. Thus this study allowed to identify and compare the effectiveness of the acquisition of knowledge in the classroom in simulated nursing lab, as well as providing an understanding of the importance of educational planning and the adoption of teaching strategies based on the Theory of Meaningful Learning, identifying the need for pedagogical training of nursing faculty

Descriptor: 1-Nursing-Study and Teaching 2. Educational Technology 3. Patient Simulation 4. Stroke 5 Simulation stroke (learning) 


\section{LISTA DE ILUSTRAÇÕES}

Figura 1 Estrutura de apreensão do conhecimento do aluno baseado na Aula Aprendizagem Significativa- Plataforma Moodle EEUSP- São Paulo, 2011

Figura 2 Faculdade de Enfermagem do Hospital Israelita Albert Einstein (FEHIAE).

Figura 3 Corredores Internos da FEHIAE........................................... 44

Figura 4 Laboratório de Enfermagem FEHIAE................................... 46

Figura 5 Manequim Laboratório de Enfermagem FEHIAE. .................... 46

Figura 6 Pesquisadora orientando os alunos do grupo Controle............ 52

Figura 7 Pesquisadora orientando a temática da aula aos alunos do Grupo Experimental no laboratório de enfermagem FEHIAE.

Figura 8 Pesquisadora apresentando e demonstrando a temática da aula aos alunos do Grupo Experimental no laboratório de enfermagem FEHIAE..

Figura 9 Distribuição do tempo em que os alunos atuam na área da saúde, São Paulo-2010

Figura 10 Distribuição do local de atuação dos alunos que trabalham na área da saúde, São Paulo, 2011.

Figura 11 Distribuição do grupo controle quanto à satisfação na dimensão individual. São Paulo- 2011

Figura 12 Distribuição do grupo experimental quanto a satisfação na dimensão individual. São Paulo- 2011

Figura 13 Distribuição do grupo controle quanto à satisfação na dimensão educacional. São Paulo- 2011

Figura 14 Distribuição do grupo experimental quanto a satisfação na dimensão educacional. São Paulo- 2011. 


\section{LISTA DE QUADROS}

Quadro 1 Distribuição do gênero no grupo controle e grupo experimental, São Paulo-2010

Quadro 2 Distribuição por faixa etária do grupo controle e grupo experimental,São Paulo-2010.

Quadro 3 Distribuição dos alunos que trabalham na área da saúde do grupo controle e grupo experimental, São Paulo-2010 59

Quadro 4 Valores estimados e as comparações sobre sinais e sintomas do AVC entre o grupo controle e experimental nos momentos pré, pós, $15 \mathrm{e}$ 30 dias da intervenção, São Paulo-2010

Quadro 5 Valores estimados e as comparações sobre as condutas assistenciais implementadas ao paciente com AVC entre o grupo controle e experimental nos momentos pré, pós, 15 e 30 dias da intervenção, São Paulo-2010 


\section{SUMÁRIO}

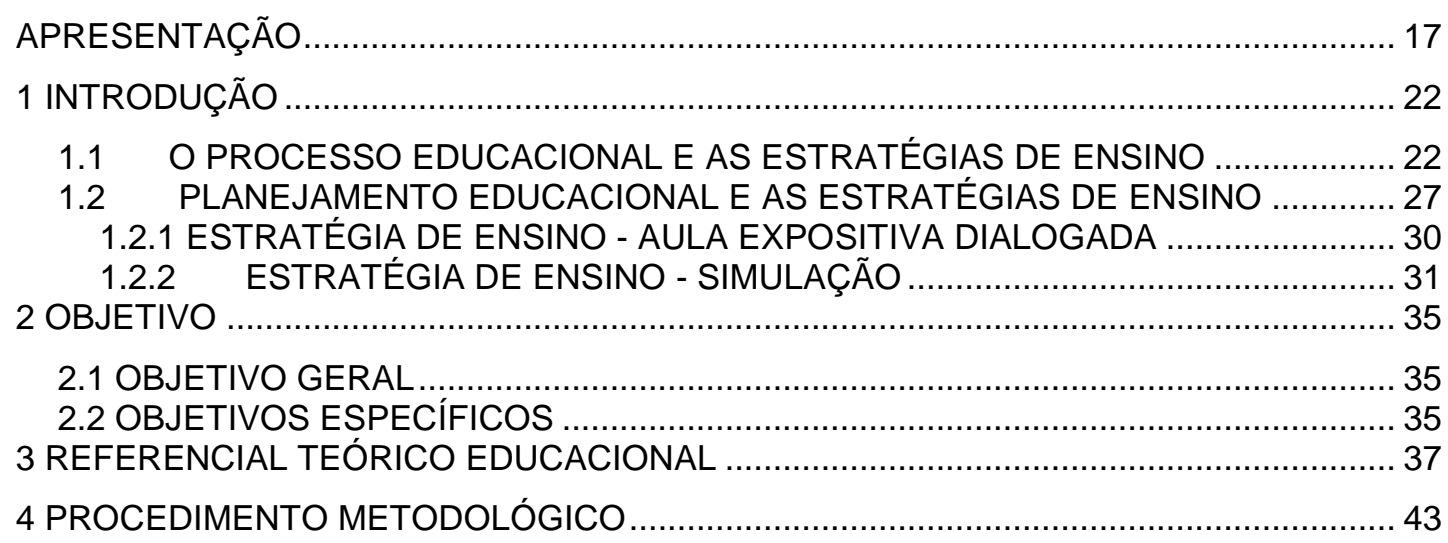

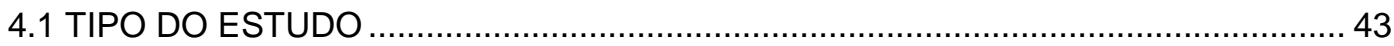

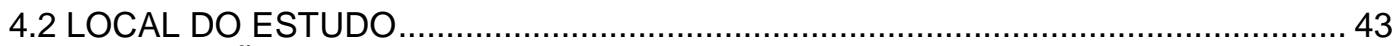

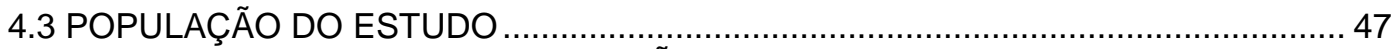

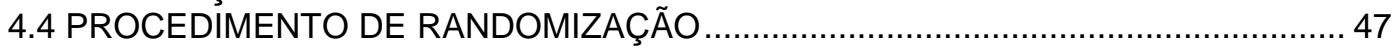

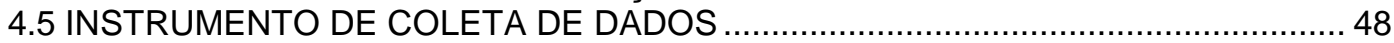

4.6 OPERACIONALIZAÇÃO DA COLETA DE DADOS …....................................... 50

4.6.1 INTERVENÇÃO GRUPO CONTROLE - ESTRATÉGIA DE ENSINO AULA

EXPOSITIVA DIALOGADA ….................................................................. 50

4.6.2 INTERVENÇÃO GRUPO EXPERIMENTAL - ESTRATÉGIA DE ENSINO AULA

SIMULADA EM LABORATÓRIO DE ENFERMAGEM ................................................ 52

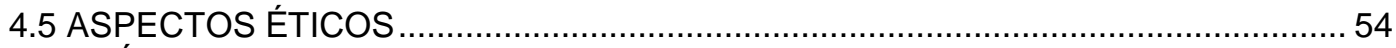

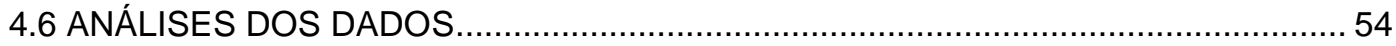

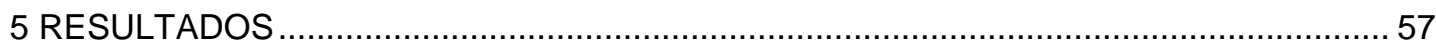

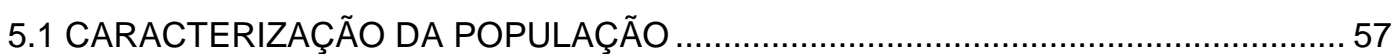

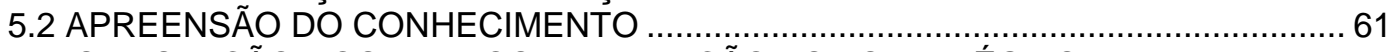

5.3 SATISFAÇÃO DOS ALUNOS EM RELAÇÃO AS ESTRATÉGIAS …......................6 66

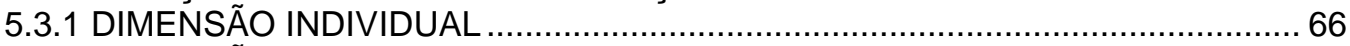

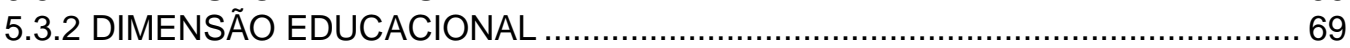

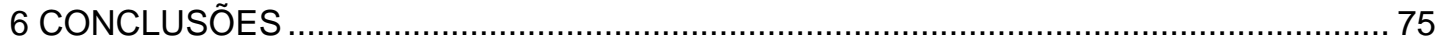

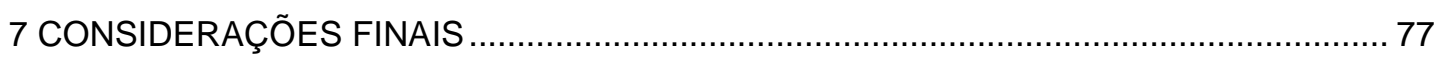

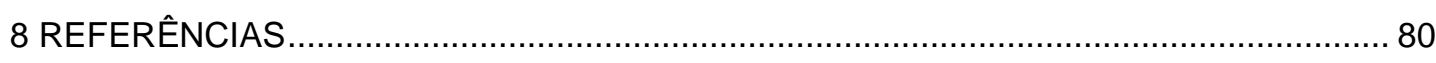

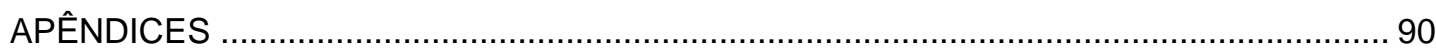

APÊNDICE 1 - TERMO DE CONSENTIMENTO LIVRE E ESCLARECIDO ...................90

APÊNDICE 3 RELATÓRIO DO LABORATÓRIO DE ESTATÍSTICA - PROCESSO DE

RANDOMIZAÇÃO DOS GRUPOS .......................................................................... 93

APÊNDICE 4 - AMOSTRAGEM DA DIVISÃO DOS ALUNOS PROCESSO DE

RANDOMIZAÇÃO PARA MONTAGEM DO GRUPO EXPERIMENTAL E GRUPO

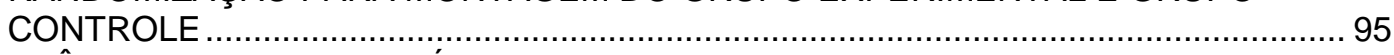

APÊNDICE 5 - QUESTIONÁRIO PARA COLETA DE DADOS …................................. 96

APÊNDICE 6 - QUESTIONÁRIO PARA COLETA DE DADOS- PÓS INTERVENÇÃO ... 98 APÊNDICE 7 - INSTRUMENTO DE AVALIAÇÃO DE SATISFAÇÃO PÓS

INTERVENÇÃO ............................................................................................. 99

APÊNDICE 8- GABARITO DO QUESTIONÁRIO DE COLETA DE DADOS- PRÉ E PÓS

INTERVENÇÃO 
APÊNDICE 9-PLANO DE AULA - INTERVENÇÃO DO GRUPO CONTROLE- AULA

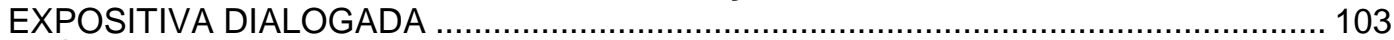
APÊNDICE 10- AULA ELABORADA PARA A INTERVENÇÃO DO GRUPO CONTROLE ANEXOS

ANEXO 1 - CARTA DE APROVAÇÃO DO PROJETO PELO COMITÊ DE ÉTICA EM PESQUISA.

ANEXO 2 - SOLICITAÇÃO AO CEP DA EMENTA 


\section{LISTA DE ABREVIATURAS E SIGLAS}

\begin{tabular}{|c|c|}
\hline AVC. & Acidente Vascular Cerebral \\
\hline CTI.... & Centro Terapia Intensiva \\
\hline CNPq... & $\begin{array}{l}\text { Conselho Nacional de Desenvolvimento Científico } \\
\text { e Tecnológico }\end{array}$ \\
\hline CAAE... & Certificado de Apresentação para Apreciação Ética \\
\hline CEP.. & Comissão Ética em Pesquisa \\
\hline CMC... & Clínica Médico e Cirúrgica \\
\hline EEUSP.. & $\begin{array}{l}\text { Escola de Enfermagem da Universidade de São } \\
\text { Paulo }\end{array}$ \\
\hline ENADE.. & Exame Nacional de Desempenho dos Estudantes \\
\hline FEO.. & Faculdade de Enfermagem e obstetrícia \\
\hline FEHIAE. & $\begin{array}{l}\text { Faculade de Enfermagem do Hospital Israelita } \\
\text { Albert Einstein }\end{array}$ \\
\hline GEPETE. & $\begin{array}{l}\text { Grupo de estudos e Pesauisa de Tecnologias da } \\
\text { Informação nos Processos de Enfermagem }\end{array}$ \\
\hline HIAE... & Hospital Israelita albert Einstein \\
\hline INEP... & Instituto Nacional de estudos e Pesquisas \\
\hline IIRS & Instituto Israelita de responsabilidade Social \\
\hline IIEP.. & Instituto Israelita de Ensino e Pesquisa \\
\hline SPSS. & Statistical Package for the Social Sciences \\
\hline SBIBAE.. & Sociedade Benefeciente Israelita Brasileira Albert \\
\hline TAS ........ & Teoria da Aprendizagem Significatica \\
\hline USP.. & ..Universidade de São Paulo \\
\hline
\end{tabular}


Apresentação 


\section{APRESENTAÇÃO}

Em 1989 ingressei no Curso de Graduação em Enfermagem e Obstetrícia de Adamantina (FEO), mas acredito que a minha trajetória profissional havia começado na infância.

Por volta dos 10 anos, naquela época ainda com as bonecas nas mãos, houve um grande problema familiar: a minha avó paterna, que por sinal morava conosco, era diabética e seu tratamento era à base de dieta, controles médicos e também usava um antiglicemiante oral, mas a doença agravou-se e havia necessidade de introduzir no seu tratamento o uso de insulina humana.

Morávamos longe de um centro de saúde, a minha avó não tinha coragem de se auto aplicar insulina e o local mais próximo para realizar o tratamento era uma farmácia, mas o custo da aplicação diária era alto.

$\mathrm{Na}$ época, a farmacêutica sugeriu que alguém da família treinasse e se tornasse responsável por este cuidado. Diante deste impasse, onde todos se recusaram a aprender, eu me ofereci para aplicar a injeção....Foi um espanto: como uma criança, com os brinquedos na mão, poderia ter coragem de administrar uma injeção?

Acredito que foi neste momento que compreendi o que seria no futuro e hoje entendo que a minha primeira paciente foi a minha avó. Fui aprender a técnica na farmácia, treinei na laranja, e por anos seguidos, antes de ir para a escola, administrava a insulina em minha avó.

Após algum tempo, com a progressão da doença, veio uma úlcera venosa, e também era eu quem realizava as trocas diárias do curativo. Não tive dúvidas na hora de escolher a minha profissão, o que eu queria ser...e sou uma enfermeira!

Entrei para a faculdade, que ficava na cidade de Adamantina (interior de São Paulo), e a cada semestre me apaixonava mais e mais pela profissão escolhida, mas eu sonhava em ser uma enfermeira de um grande hospital, e já nesta época dizia que seria enfermeira do Albert Einstein. Ora, 
que pretensão a minha, mas sonhar é dar asas a imaginação e foi assim que fiz.

Terminei a faculdade e imediatamente mudei-me para São Paulo, onde meu primeiro trabalho foi no Hospital das Clínicas de São Paulo, no Centro de Terapia Intensiva (CTI) de Queimados. Comecei a profissão em uma área extremamente árdua, mas agradeço até hoje, pois foi neste local que aprendi de verdade o que é ser "enfermeira" e cuidar de pacientes, os quais, na sua grande maioria, já não estão neste plano terrestre.

Após dois anos, mais precisamente no dia do aniversário da minha mãe, realizei o meu grande sonho, passei no processo seletivo do Hospital Israelita Albert Einstein (HIAE). Foi uma felicidade sem fim. Iniciei a minha trajetória no HIAE na clínica médica e cirúrgica neurológica, uma área totalmente distinta da minha experiência profissional até então.

Não tenho palavras para descrever o quanto aprendi com este grupo de pacientes, que na sua grande maioria apresentava incapacidades físicas, emocionais e muitas vezes mentais. Considero que ser diferente, muitas vezes, é sinônimo de exclusão social, profissional e familiar, e esse é um dos grandes desafios do processo de cuidar em neurologia, pelo qual sou muito motivada.

Com o passar dos anos na instituição fui convidada a implantar o primeiro Centro de Atendimento ao Paciente com Acidente Vascular Cerebral (AVC). Em 2004, passei de enfermeira assistencial para Coordenadora Técnica da Neurologia. O meu maior desafio foi desenvolver o projeto do Centro de AVC, oferecendo aos pacientes um tratamento baseado nos melhores protocolos assistenciais, assim como prezando pela continuidade efetiva de sua assistência nas diversas áreas em que ele poderia estar dentro da instituição, ou seja, um atendimento personalizado e diferenciado.

Foi um trabalho extenuante, mas após três anos a instituição recebeu um selo de qualidade internacional que conferia o status de terceiro centro de atendimento ao paciente com AVC do mundo, fora do território 
americano, a ter este selo de qualidade. Foi um momento profissional inesquecível!

Neste mesmo ano, em 2007, tive a maior alegria da minha vida: a chegada do meu filho Henrique, foi muita emoção em apenas um ano.

Com o meu envolvimento neste projeto, era convidada a dar muitas aulas sobre a temática do AVC. Então, no ano de 2008 houve uma oportunidade de atuar como docente da Faculdade de Enfermagem do Hospital Israelita Albert Einstein.

Com este novo projeto profissional, o curso de Pós Graduação "Strictu Sensu" se tornou uma necessidade para a minha evolução enquanto docente. Como já participava do Grupo de Estudos e Pesquisas de Tecnologias da Informação nos Processos de Trabalho em Enfermagem (GEPETE), vinculado à Escola de Enfermagem da Universidade de São Paulo (USP) e ao Conselho Nacional de Desenvolvimento Científico e Tecnológico (CNPq), senti-me fortemente motivada a desenvolver um projeto educacional inovador, onde fosse capaz de responder aos questionamentos sobre quais as estratégias educacionais que fossem mais significativas para 0 ensino-aprendizagem da temática do AVC, considerando que o preparo deste aluno é extremamente importante para seu bom desempenho profissional no cuidado do paciente neurológico.

Nessa perspectiva, a proposta deste estudo situa-se na análise das estratégias de ensino e de aprendizagem em resposta às seguintes indagações: A utilização da aula simulada promove uma aprendizagem significativa? As estratégias de aula expositiva dialogada e aula simulada podem favorecer a apreensão do conhecimento? Quais dessas estratégias de ensino corroboram para o ensino significativo do reconhecimento de sinais e sintomas do Acidente Vascular Cerebral e das condutas clínicas preconizadas para o tratamento dessa doença?

A busca pelas respostas a esses questionamentos e a incipiente experiência da enfermagem na utilização e avaliação de estratégias da aula simulada incentivou a realização deste estudo, tendo como tema de aprendizagem o reconhecimento de sinais e sintomas do AVC e suas 
condutas assistenciais.

Diante do exposto, o presente estudo tem como hipótese que a aula simulada é mais eficaz do que a aula expositiva dialogada para a apreensão do conhecimento em AVC na enfermagem. 
Introdução 


\section{INTRODUÇÃO}

\subsection{O PROCESSO EDUCACIONAL E AS ESTRATÉGIAS DE ENSINO}

$\mathrm{Na}$ trajetória histórica do processo educacional, isto é, nos primórdios dos tempos, desde a antiguidade e bem antes do processo de colonização, não existiam escolas, não havia professores e todos os adultos ensinavam o que sabiam aos seus filhos, ou seja, o processo de ensino e aprendizagem acontecia informalmente, e se iniciava a partir das experiências e a preleção dos mais velhos. Desta forma, o aprender e o fazer se tornavam inseparáveis, isto é, o saber e o trabalho eram reproduzidos a partir de um modelo não formal de educação e que tinham influência de uma aprendizagem significativa ${ }^{1}$.

Na Idade Média, mais especificamente na Europa, surgem as escolas da nobreza, onde um conjunto de pessoas (em grande parte religiosa) especializou-se na transmissão de conteúdos focados na moral, na religião e no domínio da palavra e do saber abstrato, que passou a ter espaço físico isolado do mundo dos adultos e sem qualquer relação com a vida cotidiana. Assim, as crianças da elite européia eram educadas neste modelo de educação que passou a servir também à burguesia que estava, nesta época, em ascensão ${ }^{1}$.

As demais crianças, filhos da classe operária e as pessoas das classes mais pobres, desde a mais tenra infância, aprendiam a prática de um ofício, no dia a dia com seus pais e irmãos mais velhos, ou seja, a educação não formal partia do seio familiar a partir de modelos desempenhados pelos mais velhos.

A escola da nobreza sobreviveu até que as estruturas do mundo feudal, rígidas e hierarquizadas se fragmentaram a partir do movimento da revolução industrial da época, surgindo duas escolas, a da burguesia e a dos operários. A coexistência deste modelo foi reforçada pelo movimento industrial, onde os objetos dos saberes estavam ancorados em fornecer o mínimo de cultura necessária para a integração sócio-cultural da classe operária ${ }^{1,2}$.

No Brasil, o primeiro o modelo formal de ensino baseado na estratégia 
da oratória surgiu a partir do modelo jesuítico de educação amplamente utilizado no início da colonização pelos portugueses. Nesse modelo o professor seguia um manual denominado Ratio Studiorum- datado de 1599, estruturado em três passos ${ }^{2}$ :

1-Preleção do conteúdo pelo professor.

2-Levantamento de dúvidas dos alunos.

3-Exercícios de fixação.

Refletindo sobre este modelo identifica-se que o ensino, nesta época, foi baseado na preleção e oratória, estratégias ainda muito aplicadas no ensino atual e que vem sendo adotadas desde os primórdios da colonização em nosso país ${ }^{2}$.

Quando o docente reproduz o modelo jesuítico, percebemos que os conteúdos abordados não apresentam significado para os alunos, que não ocorrem conexões entre as experiências vividas e a prática profissional. Esta concepção pedagógica tradicional está fundamentada na memorização, replicando os conteúdos sem a preocupação da mobilização dos saberes e os determinantes históricos, sociais e científicos, promovendo a fragmentação dos conteúdos ministrados pelos docentes.

É fato notável que nos últimos anos o mundo passou por profundas transformações sociais, políticas, econômicas e culturais, que foram ditadas e podem ser explicadas pelo processo de globalização instaurado no novo século. Essas mudanças vêm reestruturando o mercado de trabalho e elevando a complexidade das estruturas organizacionais, exigindo assim profundas reflexões na educação.

O processo de globalização tem sido impulsionado pela alta demanda dos processos comunicacionais entre os países no final do século $X X$ e início do século XXI. O marco deste período foi a utilização dos recursos tecnológicos, como a internet, para facilitar e agilizar o processo de comunicação entre as pessoas ${ }^{3}$.

O novo perfil comunicacional, estabelecido neste novo século, facilitou a integração e as relações humanas e favorece a comunicação síncrona e assíncrona apoiada pelos recursos tecnológicos, fomentando e direcionando a produção do conhecimento, favorecendo a implementação de 
recursos tecnológicos na educação, para que possa acompanhar todo este fenômeno das mudanças mundiais ${ }^{4}$.

Neste contexto, as estratégias educacionais apoiadas pelas tecnologias vêm impactando a educação, exigindo estruturas e recursos educacionais adequados ao novo cenário, bem como capacitação tecnológica e pedagógica dos docentes e alunos para que possam atuar profissionalmente no mundo globalizado da informação que requer habilidades para trabalhar em redes e para resolução de problemas ${ }^{3-6}$.

Diante do mundo globalizado da informação não é mais possível privilegiar a memorização, mas a socialização, a construção coletiva do conhecimento, a tomada de decisão e a gestão compartilhada da informação. Nesse sentido, o processo ensino-aprendizagem requer a adoção de novos modelos e estratégias educacionais mais interativas e integrativas, que rompem as barreiras limitadoras do tempo e do espaço, permitindo a re-significação e a construção de novos modelos educacionais ${ }^{7}$.

Ressalta-se que as estratégias de ensino apoiadas nas novas tecnologias devem estar aliadas a propostas pedagógicas emancipadoras, a fim de possibilitar o aprendizado significativo. Para isso destacam-se cinco pressupostos básicos para o fazer pedagógico significativo:

1- Comunicação

2- Interação

3- Avaliação

4- Mediação

5- Colaboração

Estes pressupostos devem estar presentes no fazer pedagógico, a fim de mobilizar os saberes e promover as mudanças paradigmáticas no processo ensino-aprendizagem como a autonomia, confiança, criatividade e criticidade entre os alunos ${ }^{2,8-10}$.

A nova prática educacional deve estar fundamentada no contexto social e nas mudanças atitudinais dos professores e alunos a fim de experimentar novas estratégias como instrumentos do saber, devendo sempre estar aderida a uma proposta pedagógica significativa ${ }^{7}$. 
Nesse processo é importante estabelecer a diferença entre aprender e apreender, embora nos dois verbos exista a relação entre os sujeitos e o conhecimento. $O$ verbo aprender significa tomar conhecimento, fixar na memória, receber uma informação. O verbo apreender vem do latim apprehendere, tendo um significado de segurar, prender, entender, compreender, demonstrando uma forma ativa do aluno ${ }^{9}$.

Hoje o termo apreender pode ser definido também como um processo evolutivo onde os conteúdos se encadeiam, se permutam, promovendo o desenvolvimento dos processos cerebrais responsáveis pelas aptidões. Para que ocorra o processo cerebral, é necessário que aconteçam os estímulos do meio ambiente, entendendo-se assim que a postura do docente seja encarada como um mediador do processo ensino-aprendizagem podendo-se utilizar as estratégias educacionais para a promoção da mobilização dos saberes $^{1,2,10}$.

Nessa perspectiva é essencial considerar o novo papel do professor e do estudante no processo de aprendizagem, pois a ação de apreender não é passiva e exige do estudante ação constante e consciente de informar-se, exercitar-se, instruir-se. O assistir ou dar aulas precisa ser substituído pela ação conjunta do fazer aulas. Nesse fazer aulas é que surgem as necessárias formas de atuação do professor com o estudante sobre o objeto de estudo e a definição, escolha e efetivação de estratégias diferenciadas que facilitem esse novo fazer ${ }^{9}$.

Entretanto, destaca-se que um ou mais fatores podem corroborar para melhorar ou piorar apreensão do objeto de ensino como as diferenças individuais, motivação para a aprendizagem, limiar de concentração do indivíduo, reação ao objeto de estudo apresentado pelo professor, memorização e a síncrese do conhecimento ${ }^{11}$.

Desta forma, a estratégia de ensino desvela-se como uma ferramenta facilitadora do processo ensino-aprendizagem, ou seja, como o docente pode utilizar alguns meios ou caminhos para tutorar os alunos para a melhor apreensão do saber.

Corroborando com o apresentado, o conteúdo associado à estratégia de ensino pode afetar a forma de ensinar. Buchman (1994) revela ${ }^{12}$ : 
..."conhecer algo nos permite ensiná-lo; e conhecer um conteúdo com profundidade significa estar mentalmente organizado e bempreparado para ensiná-lo de uma forma geral"...

$\mathrm{Na}$ enfermagem, pelas características profissionais, eminentemente práticas, que se configuram na relação assistencial entre o enfermeiro e 0 paciente é preciso superar o aprender, que se baseia na memorização e na perpetuação de procedimentos e técnicas, na direção do apreender, assimilar, compreender e estabelecer o raciocínio clínico.

As Diretrizes Curriculares Nacionais dos Cursos de Graduação em Enfermagem, aprovadas em 2001, definem os princípios, os fundamentos, as condições e os procedimentos da formação dos enfermeiros, estabelecendo a necessidade do desenvolvimento de habilidades técnicas e comportamentais, relacionadas à liderança, comunicação, relacionamento interpessoal e tomada de decisão no exercício profissional ${ }^{13,14}$.

Destaca-se, assim, que a formação do enfermeiro deve ser apoiada por estratégias diferenciadas e ativas, objetivando o desenvolvimento de competências que envolvem a comunicação verbal e não verbal e as habilidades de escrita e leitura, bem como a interação multiprofissional ${ }^{15}$.

O grande desafio da formação do enfermeiro é a apropriação de estratégias educacionais que impulsionem os saberes de forma significativa e ofereça instrumentos que permitam transformar os aspectos da realidade em objetos de estudo, constituindo-se em elementos chave neste novo perfil educacional exigido na prática profissional.

Desta forma é imprescindível o uso de estratégias de ensino que ampliem e potencializem as trocas e as colaborações entre os professores e alunos e entre alunos e alunos criando um novo caráter de rede social educacional, desenvolvendo inteligência coletiva, por permitir as trocas dos saberes entre os envolvidos no processo educacional ${ }^{15,16}$.

Neste sentido a estratégia de aula simulada, em ambientes tecnológicos controlados como os laboratórios de enfermagem, oferece oportunidade de experimentar, realizar técnicas práticas e desenvolver saberes de forma compartilhada adequada aos valores humanos. 
No ensino da enfermagem, as estratégias educacionais devem ser utilizadas com o objetivo de formar profissionais de excelência, propiciando oportunidades para aprendizagem significativa, em um processo no qual os discentes possam tomar decisões e desenvolver habilidades, comportamentos e atitudes, garantindo a qualidade do cuidado e a segurança do paciente no processo assistencial.

Diante desses desafios educacionais surgiram diversos questionamentos e indagações referentes à utilização de estratégias no ensino de enfermagem, especificamente, a aula expositiva dialogada e a aula simulada, tendo como objeto da aprendizagem o tema Acidente Vascular Cerebral (AVC).

A temática norteadora deste estudo será o reconhecimento dos sinais e sintomas do Acidente Vascular Cerebral e as condutas clínicas preconizadas para este paciente devido a sua relevância e impacto na vida do indivíduo.

\subsection{PLANEJAMENTO EDUCACIONAL E AS ESTRATÉGIAS DE ENSINO}

O planejamento educacional é destacado por Mattos (1960) ${ }^{17}$ como uma etapa fundamental para o sucesso do processo ensino aprendizagem, considerando:

"Os dois grandes males que debilitam o ensino e
restringem seu rendimento são: a rotina, sem
inspiração nem objetivos; a improvisação
dispersiva, confusa e sem ordem. O melhor
remédio contra esses dois males é o
planejamento..."

As atividades do trabalho do docente iniciam-se bem antes da aula propriamente dita, ou seja, o planejamento da disciplina depende da experiência prévia do professor ${ }^{18}$. 
Para Libâneo (1994) ${ }^{19}$, o planejamento de ensino é uma atividade didática exclusiva do docente e existem três modalidades de planejamento, que têm uma profunda relação entre si:

1- Planejamento da Escola- descreve o plano pedagógico e administrativo da unidade escolar, onde explicita a concepção pedagógica adotada pelos docentes que ali atuam.

2- Plano de Ensino- pode ser definido como um roteiro organizado das unidades didáticas para uma disciplina num determinado tempo.

3- Plano de aula- Este é um detalhamento do plano de ensino, as unidades a serem desenvolvidas pelos alunos são descritas, assim como os objetivos a serem alcançados, matérias a serem utilizadas, descrição das estratégias de ensino para o desenvolvimento do objeto educacional proposto no plano de aula.

Reforçando a idéia da importância do planejamento de ensino, Gil (1997) ${ }^{20}$, relaciona-o à Teoria Geral dos Sistemas, onde descreve os quatro elementos básicos necessários para a compreensão de um bom planejamento: processo, eficiência, eficácia e metas ${ }^{21}$.

A partir destes quatro conceitos entende-se que 0 planejamento de ensino possa abarcar a dimensão do ser humano nas suas necessidades educacionais, bem como o alcance das metas estabelecidas $^{18,19}$.

Gil $(1997)^{20}$ destaca, ainda, que um bom planejamento deve respeitar três fases:

1- Fase da preparação- precede a formulação dos objetivos; é a previsão de todas as fases necessárias para garantir a concretização do objetivo.

2- Fase de acompanhamento - depois que o plano é colocado em prática, acompanhando a evolução da ação educativa proposta pelo professor, e como o aluno está evoluindo dentro do objeto de estudo. Esta fase é muito importante pois dá ao planejamento de ensino o caráter dinâmico do processo ensino aprendizagem, o 
que é fundamental para a retroalimentação da fase do aprimoramento.

3- Fase do aprimoramento- é a fase final do planejamento, envolve o processo de avaliação do professor frente os objetivos propostos. É uma etapa muito importante e servirá de base para novas alterações no planejamento.

O plano de ensino descreve detalhadamente os objetos de estudos abordados, os objetivos educacionais, as estratégias de ensino adotadas, o tempo de cada aula e os resultados educacionais a serem atingidos pelos alunos ${ }^{22}$.

Embora o planejamento seja extremamente importante no processo ensino aprendizagem, uma das críticas versa sobre a primazia do planejamento em detrimento do sucesso da aprendizagem, ou seja, um bom planejamento não garante por si só a apreensão do objeto de estudo. O papel do professor, a relação dialógica entre professor-aluno, a mobilização da estrutura cognitiva do aluno, o ambiente escolar favorável à aprendizagem significativa são alguns dos fatores que contribuem para a apreensão do conhecimento.

O planejamento educacional envolve a escolha de estratégia de ensino que melhor se adapte ao desenvolvimento de uma temática escolhido pelo professor, favorecendo assim uma aprendizagem significativa.

Neste contexto a estratégia de ensino desvela-se como uma ferramenta facilitadora do processo ensino aprendizagem, ou seja como o docente pode utilizar alguns meios, ou caminhos para tutoriar os alunos para a melhor apreensão do saber ${ }^{9}$.

Existem inúmeras estratégias de ensino, porém destacamos a aula expositiva dialogada e aula simulada que foram escolhidas como estratégias para esta pesquisa e são, freqüentemente, utilizadas pelos docentes na graduação de enfermagem. 


\subsubsection{ESTRATÉGIA DE ENSINO - AULA EXPOSITIVA DIALOGADA}

A estratégia de ensino "aula expositiva dialogada" pode ser descrita como uma exposição de conceitos, com a participação ativas dos alunos, onde o conhecimento prévio é extremamente importante, devendo ser considerado este o ponto de partida. O professor leva os alunos a questionarem, discutirem, interpretarem o objeto de estudo apresentado por ele, reconhecendo e contextualizando este objeto com as situações das realidades que podem ser levantadas pelos alunos ${ }^{2,11}$

O diálogo deve ser a ferramenta chave desta estratégia, favorecendo a análise crítica, a produção de novos conhecimentos e propondo aos alunos a superação da passividade e da falta de mobilidade intelectual.

Nesta estratégia, as operações do pensamento mobilizadas são a obtenção e organização de dados, interpretação crítica do objeto de estudo apresentado, decisão, comparação, resumo e aplicabilidade do objeto de estudo na atividade profissional.

Para isso a dinâmica do uso desta estratégia deve seguir alguns passos importantes ${ }^{19,20}$.

1- Planejamento do objeto do estudo: o professor elabora o processo ensino aprendizagem de forma pontual, escolhe a melhor estratégia de ensino para o objeto de estudo definido no plano de ensino, determina os limites do objeto de ensino e o tempo disponível para a apresentação do tema, bem como planeja os recursos materiais e tecnológicos necessários para a condução da estratégia.

2- Apresentação do objeto do estudo: o professor apresenta o objeto do estudo para os alunos, a fim de mobilizar as estruturas mentais, e despertar as informações semelhantes de outros objetos aprendidos, levando os alunos a uma mobilização do conhecimento prévio.

3- Exposição do tema: deve ser bem planejada a fim de oferecer 
oportunidade para os alunos fazerem conexões entre as experiências vivenciadas previamente e os novos conceitos. $O$ professor deve promover um ambiente de respeito e diálogo, para que o aluno consiga apresentar seus questionamentos, críticas, resolver suas dúvidas e, principalmente, realizar a síntese integradora do objeto estudado. Nesta etapa deve ser possível a participação de todos os alunos de forma colaborativa.

Ressalta-se que, essas etapas do processo de construção da aula expositiva dialogada vêm substituir a proposta tradicional da aula expositiva ou da oratória, onde o professor profere sobre o objeto de estudo e os alunos "apenas" ouvem passivamente o tema proposto, não promovendo o diálogo entre professor-aluno.

Quando o professor consegue promover um clima favorável ao diálogo, esta estratégia favorece a apreensão do objeto do estudo proposto, mobilizando o conjunto de experiências prévias do aluno e facilitando a ancoragem de novos objetos de estudo dialogados.

Neste contexto esta estratégia se torna mais eficiente à medida que 0 professor amplia sua comunicação e integração com os alunos, promovendo um clima favorável ao diálogo e trocas educacionais entre o grupo, mobilizando a estrutura cognitiva dos alunos e, conseqüentemente, os conceitos prévios sobre o objeto de estudo apresentados pelo professor, facilitando a síncrese do conhecimento, retroalimentando os conceitos modelados neste momento pela interação ativa e dinâmica entre alunos e o professor ${ }^{19,20}, 23$.

Destaca-se, ainda, que a aula expositiva possui características importantes como flexibilidade e baixo custo, fatores que se adequam ao cenário real da educação brasileira ${ }^{20}$.

\subsubsection{ESTRATÉGIA DE ENSINO - SIMULAÇÃO}

A simulação é relatada nas abordagens da evolução educacional desde os princípios dos tempos. No decorrer da evolução histórica observase que mesmo quando não havia a escola formal, a família supria a 
necessidade da educação dos seus filhos, ensinando na prática os afazeres domésticos e o ofício.

A simulação foi descrita como técnica de aprendizagem em documentos encontrados da era medieval, onde se utilizavam de bonecos de panos para o treinamento dos combates da época ${ }^{24}$.

Estudos relatam, também, a simulação em laboratórios com o uso de animais em treinamentos das habilidades médicas, mais especificamente, para desenvolver habilidades cirúrgicas ${ }^{25}$.

$\mathrm{Na}$ era industrial o uso da simulação se tornou uma prática educacional empregada no mundo do trabalho, a fim de suprir a necessidade de recursos humanos, oferecendo treinamento simulado para os jovens aprendizes ${ }^{25}$.

Entre meados dos anos 60 e 70, esta estratégia de ensino aparece ligada à Teoria da Aprendizagem Significativa (TAS), onde explora a questão da significação dos objetos de estudo no processo educacional.

Desta forma, a estratégia da simulação pode ser conceituada como uma série de ações planejadas que simulam o ambiente real, levando o aluno a desempenhar papéis em uma situação, expressando habilidades e atitudes, mobilizando o conhecimento e favorecendo a reflexão e a retenção do objeto de estudo ${ }^{20}$.

A simulação engloba várias estratégias de ensino como a demonstração, estudo de caso e dramatização.

Atualmente, na era do conhecimento, da globalização e do rápido avanço da tecnologia, a simulação está associada a programas computacionais que reproduzem o objeto da temática de estudo, tanto na educação formal quanto nas capacitações de profissionais que desempenham funções de alto risco como os profissionais da saúde, pilotos de aeronaves, entre outros ${ }^{16,26}$.

$\mathrm{Na}$ enfermagem a utilização da estratégia da simulação em laboratório assume um papel marcante na formação do enfermeiro, diante da oportunidade do aluno exercitar técnicas, procedimentos e desenvolver o raciocínio clínico em ambientes controlados, minimizando riscos, erros e eventos adversos e promovendo a segurança e a qualidade da assistência 
prestada ao futuro paciente.

Entretanto Faro (2011) descreve que a utilização de aula simulada no laboratório de enfermagem requer uma intencionalidade pedagógica do docente e uma avaliação contínua, a fim de identificar os pontos facilitadores e as fragilidades, visando fortalecê-lo como um espaço privilegiado de aprendizagem, e bem estruturado para a formação inicial do futuro profissional da saúde ${ }^{27}$.

$\mathrm{Na}$ literatura alguns trabalhos reforçam, ainda, a questão do uso do laboratório de enfermagem com a utilização da estratégia simulada de casos e técnicas, por favorecer a interação entre alunos e professores, criar ambiente dialógico, tendo como resultado uma aprendizagem de conceitos e habilidades e não apenas um espaço restrito ao desenvolvimento de técnicas ${ }^{28}$.

Diante do Exposto a finalidade deste estudo é analisar a eficácia da aprendizagem dos discentes na aula expositiva dialogada e na aula simulada em laboratório de enfermagem, fundamentadas na Teoria da Aprendizagem Significativa (TAS). Para tanto, considera-se a eficácia da aprendizagem o alcance os objetivos cognitivos, que referem-se ao discente que seja capaz de identificar os sinais e sintomas do AVC e reconhecer as condutas assistenciais a serem instituídas mediante 0 paciente com AVC. 
Objetivo 


\section{OBJETIVO}

\subsection{OBJETIVO GERAL}

- Analisar a eficácia da aprendizagem dos discentes na aula expositiva dialogada e na aula simulada em laboratório de enfermagem.

\subsection{OBJETIVOS ESPECÍFICOS}

- Identificar e comparar a eficácia da aprendizagem dos discentes imediatamente, 15 e 30 dias após participarem na aula expositiva dialogada ou aula simulada.

- Comparar a satisfação dos discentes na aula expositiva dialogada e na aula simulada. 


\section{Referencial Teórico Educacional}




\section{REFERENCIAL TEÓRICO EDUCACIONAL}

A busca pelo referencial teórico educacional proporcionou 0 conhecimento de diferentes concepções pedagógicas e teorias de aprendizagem que fundamentam o processo de ensino e aprendizagem.

Neste estudo, a Teoria da Aprendizagem Significativa (TAS) de David Ausubel, foi considerada a que mais se adequou ao alcance dos objetivos e às indagações do estudo.

David Ausubel, filho de imigrantes judeus refugiados dos conflitos que assolavam a Europa, no final do século XIX e início século XX, fixou residência em Nova York. Para que os pais pudessem trabalhar, Ausubel foi para a escola menino, onde foi massacrado por um ensino reacionário e violento que desconsiderou seus valores morais e religiosos, bem como desrespeitou sua individualidade e ignorou suas experiências de vida ${ }^{29,30}$.

$\mathrm{Na}$ década de 60, ele iniciou os seus primeiros trabalhos sobre a TAS, a partir da observação das influências do "rock" na geração de adolescentes, que alterava os costumes e passou a ter grande significado para este grupo, proporcionando maior facilidade de aprender músicas ${ }^{23}$.

Ao postular a Teoria da Aprendizagem, Aususbel, descreve que o ser humano compreende, transforma e armazena as informações, idéias e conceitos adquiridos no dia a dia. A aprendizagem ocorre a partir das experiências prévias ${ }^{31}$.

Corroborando com a idéia de Ausubel, Novak e Hanesian (1982) descrevem que o resultado das experiências de aprendizagem constitui a estrutura cognitiva do aluno, formando o conjunto de idéias, conceitos e a visão que o aluno mostra sobre uma temática educacional ${ }^{32,33}$.

Desta forma, Ausubel descreve a grande crítica ao modelo de ensino construtivista, pois acredita que o indivíduo precisa partir de uma base préestabelecida, pois se isto não ocorrer o aprendizado torna-se mecânico, dificultando a retenção da aprendizagem.

A TAS possui três conceitos centrais: Organizadores Prévios, Diferenciação Progressiva e Reconciliação Integrativa.

Os Organizadores Prévios correspondem a estrutura cognitiva 
existente nos indivíduos, construída a partir das relações sociais, vivências e conhecimentos prévios, que ficam em um grau de abstração e/ou generalidade e facilitam a integração de novas idéias e conceitos, funcionando como pontes cognitivas ${ }^{34}$.

A Diferenciação Progressiva caracteriza a aprendizagem significativa como um processo contínuo que se inicia a partir do conhecimento abrangente e amplo para o específico, que são progressivamente detalhados construindo elos entre as idéias e conceitos ${ }^{35}$.

A Reconciliação Integradora é o processo pelo qual a pessoa reconhece novas relações entre os conceitos que até então eram vistos isoladamente ${ }^{25}$.

A estrutura cognitiva do indivíduo é definida como o conteúdo organizado, hierarquizado das idéias, conceitos e preposições sobre um determinado tema, apresentado ao indivíduo ao longo da sua vida conforme apresentado esquematicamente na Figura 1.

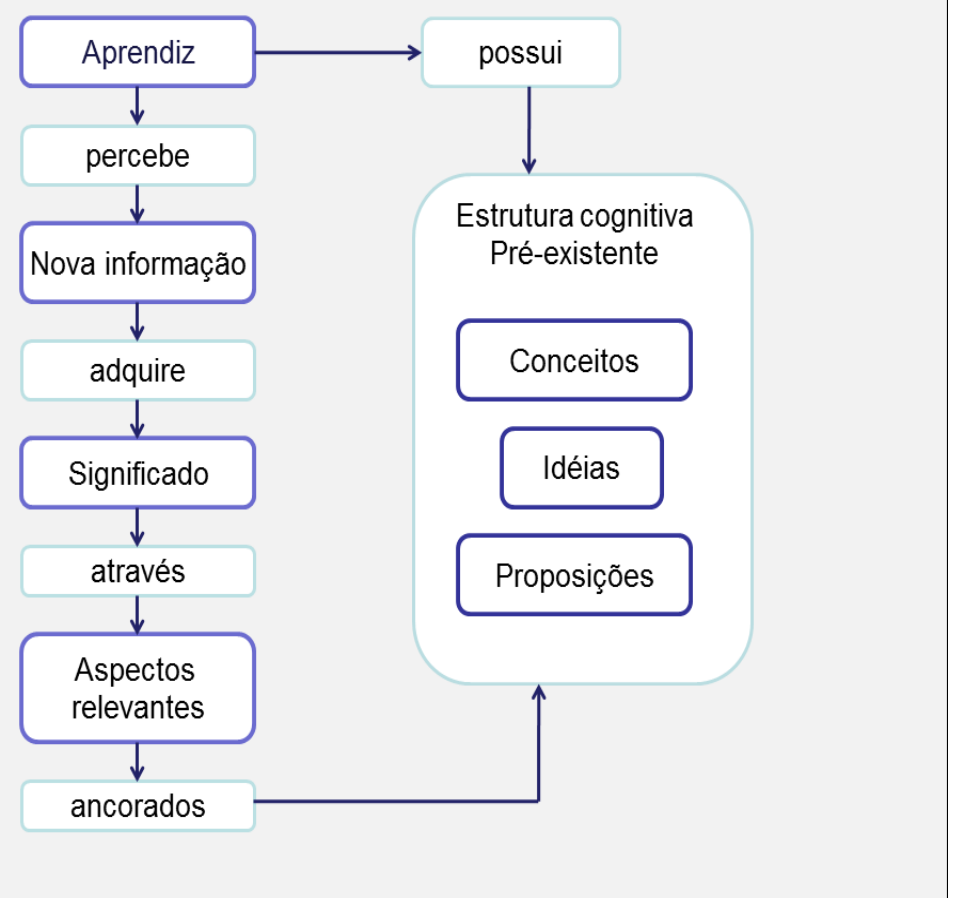

Figura 1 Estrutura de apreensão do conhecimento do aluno baseado na Aula Aprendizagem Significativa- Plataforma Moodle EEUSP- São Paulo, 2011

Ausubel identifica quatro tipos de aprendizagem ${ }^{34}$ :

1. Aprendizagem Significativa por Recepção - o aprendedor 
recebe conhecimentos e consegue relacionar-se com os conhecimentos da estrutura cognitiva prévia.

2. Aprendizagem Significativa por Descoberta - o aluno chega por si só ao conhecimento e consegue relacionar-se com os anteriores.

3. Aprendizagem Mecânica por Recepção - o aluno recebe os conhecimentos e não os relaciona com a estrutura cognitiva prévia.

4. Aprendizagem Mecânica por Descoberta - o aluno chega ao conhecimento por si só e não consegue relacionar-lo com os conhecimentos adquiridos

Para que a aprendizagem significativa ocorra, Ausubel aponta como fatores determinantes a predisposição do sujeito para aprender, ou seja, a motivação para a aprendizagem e materiais educativos que sejam potencialmente significativos para os alunos ${ }^{34,36}$.

$\mathrm{Na}$ perspectiva da TAS, a situação-problema pode ser entendida como um tipo de simulação, onde o docente pode utilizá-la como estratégia de ensino em sua prática docente para conduzir os alunos a um processo da apreensão do conhecimento de forma significativa.

O ser humano, desde os primórdios dos tempos, sempre enfrentou situações-problema, que permitiram sua sobrevivência e o desenvolvimento de suas potencialidades, ajustando-se às necessidades de cada época até chegar à época atual. A situação-problema, ao impulsionar e mobilizar recursos internos para a solução de problemas e superação de obstáculos, proporciona uma aprendizagem significativa por descoberta, possibilitando alterar hábitos e construir novos conhecimentos ${ }^{37}$.

A vida cotidiana da era do conhecimento está repleta de obstáculos, onde o indivíduo se depara com tarefas a serem realizadas que o desafia a aprender a aprender, onde o saber fazer é extremamente relevante na atuação profissional de profissões como a enfermagem.

Assim, a situação-problema é definida como recorte de um domínio complexo, onde a realização implica mobilizações de recursos para a tomada de decisão e o desenvolvimento de esquemas complexos de 
pensamentos ${ }^{38}$.

A situação-problema é uma didática na qual se propõe ao sujeito uma tarefa que ele não pode realizar sem uma aprendizagem precisa, e esta se constitui como o objetivo da situação problema, que se dá ao vencer o obstáculo na realização de uma atividade ${ }^{34}$.

Assim, a estratégia de resolução de problemas contempla categorias presentes nos processos de construção do conhecimento, quando estimula e amplia a significação dos elementos aprendidos em relação a realidade, ou área profissional, podendo ser encarada também como uma versão da simulação ${ }^{9,38}$.

Na formação do enfermeiro, a utilização da estratégia de solução de problemas fundamentada na TAS, propicia o desenvolvimento de estruturas cognitivas, que serão a base para a apreensão do conhecimento e promoção da ancoragem de idéias e conceitos, que o aluno possa aplicar em sua vida profissional, promovendo ações e decisões profissionais eficazes e eficientes.

Dessa forma a situação-problema leva o aluno a vivenciar o cotidiano profissional da enfermagem de forma simulada, oportunizando a segurança e qualidade da assistência que prestará aos seus futuros pacientes.

Para Zabala $(1998)^{39}$ para que ocorra o processo de ensino aprendizagem, podemos encontrar quatro tipos de conteúdos:

1-Conteúdos factuais - conhecimento de fatos, acontecimentos, fenômenos concretos e singulares, que muitas vezes são colocados de lado pelo docente, mas indispensáveis para a formação da ancoragem, entendendo-se assim que seria a base de uma aprendizagem significativa.

2-Conteúdos procedimentais - que pode ser definido como o conjunto de normas e rotinas, ou ainda ações práticas para o estudo de um objeto.

No contexto da enfermagem e da saúde, as ações práticas simuladas oferecem aos alunos a oportunidade de experimentar e realizar técnicas e procedimentos com fundamentação teórico-científica que serão, posteriormente, executados na prática profissional.

Assim, as ações práticas podem ser contextualizadas nos laboratórios de enfermagem, com a simulação de ambientes reais, a fim de levar o aluno 
a uma imersão prática das técnicas e das ações profissionais, bem como ao raciocínio clínico. Desta forma o aluno pode ser preparado para vivenciar situações da prática profissional antes de se deparar com as experiências reais do cuidado e da gestão de enfermagem em ambientes de saúde reais $^{40}$.

3- Conteúdos atitudinais - podem ser entendidos como o conjunto de comportamentos esperados para a realização de uma ação ou uma atividade; para isso é necessário oferecer aos alunos situações simuladas da prática em saúde, a fim de desenvolver algumas habilidades e competências para o exercício da profissão enfermagem, como demonstra a própria legislação do exercício profissional. Para isso pode-se utilizar das estruturas físicas dos laboratórios de enfermagem.

4- Aprendizagem de conceitos- pode ser definido como o conjunto de princípios, leis e regras que produzem um fato ou situação, possibilitando a elaboração da construção pessoal das interpretações e transferências destes nas situações práticas. 


\section{Procedimento}

Metodológico 


\section{PROCEDIMENTO METODOLÓGICO}

\subsection{TIPO DO ESTUDO}

Trata-se de um estudo longitudinal de abordagem quantitativa, dividido em dois momentos.

O primeiro momento da pesquisa tipo experimento antes e depois, constitui-se de um método experimental verdadeiro para a comparação da apreensão do conhecimento dos alunos na aula expositiva dialogada e na aula simulada no laboratório de enfermagem, tendo como hipótese nula a não relação entre as variáveis independentes e dependentes.

O desenho da pesquisa experimental é utilizado em estudos em que 0 pesquisador deseja testar relações de causa e efeito. $O$ experimento verdadeiro possui três propriedades de identificação: randomização, controle e manipulação ${ }^{41,42}$.

A randomização ou encaminhamento aleatório para um grupo envolve a distribuição de indivíduos, para um grupo experimental ou para um grupo controle em uma base puramente aleatória ${ }^{42}$.

No controle, o experimentador introduz controles sobre a situação experimental, incluindo o uso do grupo controle ${ }^{42}$.

Na manipulação, o experimentador faz alguma coisa aos participantes do estudo ${ }^{42}$.

No segundo momento da pesquisa foi aplicado um instrumento de avaliação de satisfação pós intervenção. Este instrumento foi aplicado em ambos os grupos (grupo controle e grupo experimental)

\subsection{LOCAL DO ESTUDO}

O estudo foi desenvolvido na Faculdade de Enfermagem do Hospital Israelita Albert Einstein (FEHIAE), instituição privada de ensino vinculada a um Hospital Privado no município de São Paulo. 


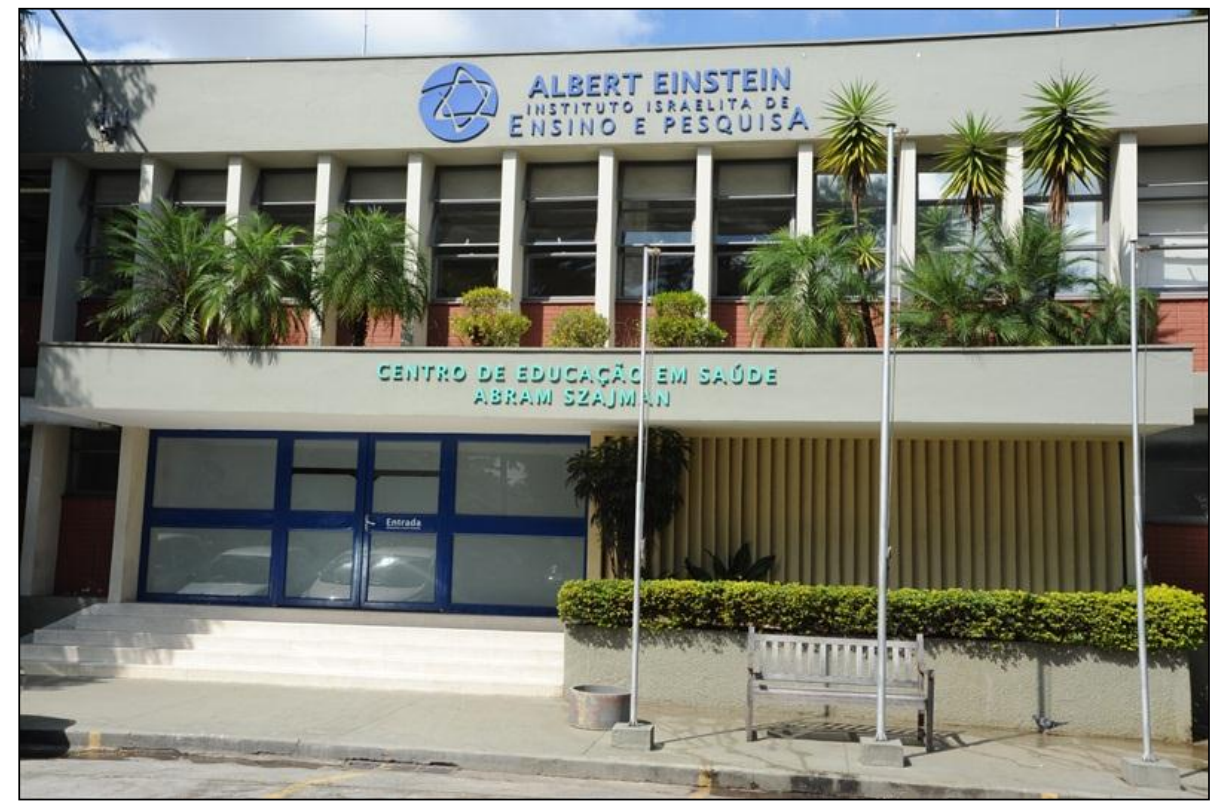

Figura 2 Faculdade de Enfermagem do Hospital Israelita Albert Einstein (FEHIAE).

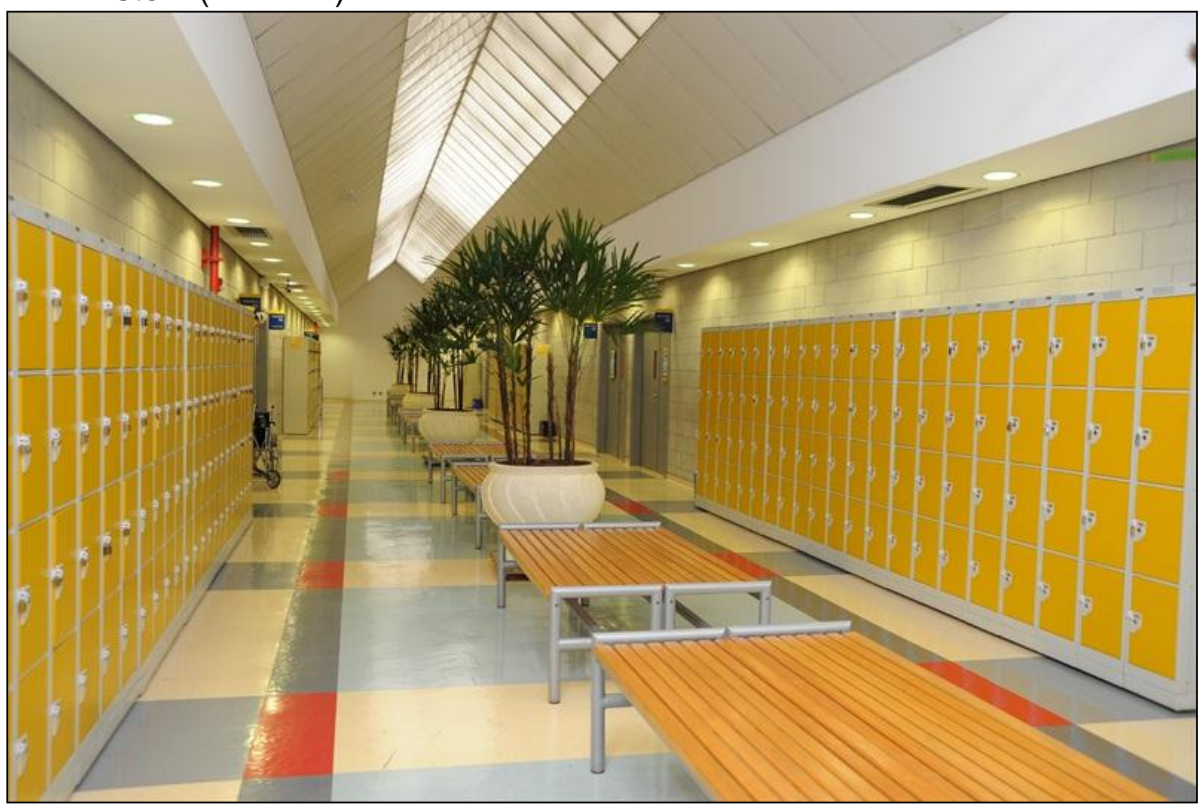

Figura 3

Corredores Internos da FEHIAE.

O Hospital é caracterizado como geral e de grande porte, localizado no município de São Paulo e foi inaugurado em 28 de julho de 1971. A instituição cresceu e se desenvolveu, consolidando-se em um importante centro hospitalar de alta complexidade e se tornou referência nacional em saúde, denominado Sociedade Beneficente Israelita Albert Einstein, composta por três pilares: Hospital Albert Einstein (HIAE), o Instituto de Responsabilidade Social (IIRS) e o Instituto de Ensino e Pesquisa (IIEP), do 
qual faz parte a Faculdade de Enfermagem do Hospital Israelita Albert Einstein (FEHIAE) ${ }^{43}$.

A Faculdade de Enfermagem do Hospital Israelita Albert Einstein deu início às suas atividades letivas em $1^{\circ}$ de março de 1989 e seu reconhecimento deu-se em 1992, conforme Portaria do Ministério da Educação nำ1855, de 18 de dezembro de 1992.

O ensino de graduação em enfermagem prevê o desenvolvimento de competências (conhecimentos, habilidades e atitudes) que possibilitem ao graduando a sua interação e atuação multidisciplinar, oferecendo aos seus alunos uma infra-estrutura física capaz de desenvolver todas as competências necessárias para a formação do futuro profissional.

Desta forma tem como beneficiários os indivíduos e a comunidade, provendo a saúde para todos. As competências a serem desenvolvidas na FEHIAE são:

- Atenção à Saúde

- Tomada de Decisão

- Comunicação

- Liderança

- Administração e Gerenciamento

- Educação Permanente

O curso de graduação em enfermagem tem entrada anual pelo vestibular da Pontifícia Universidade Católica de São Paulo selecionando 60 estudantes.

Desta forma, os docentes desta instituição prezam pelo mais alto grau de qualidade no ensino, oferecendo aos discentes uma sólida formação conceitual, aliada à capacidade de aplicar os conhecimentos científicos em sua área de atuação, e uma estrutura física adequada para esta formação.

A seleção das áreas temáticas do conteúdo programático do Curso de Graduação em Enfermagem da FEHIAE contempla as seguintes áreas:

- Bases Biológicas e Sociais de Enfermagem

- Fundamentos de Enfermagem

- Assistência de Enfermagem 
- Administração de Enfermagem

- Trabalho de Conclusão de Curso

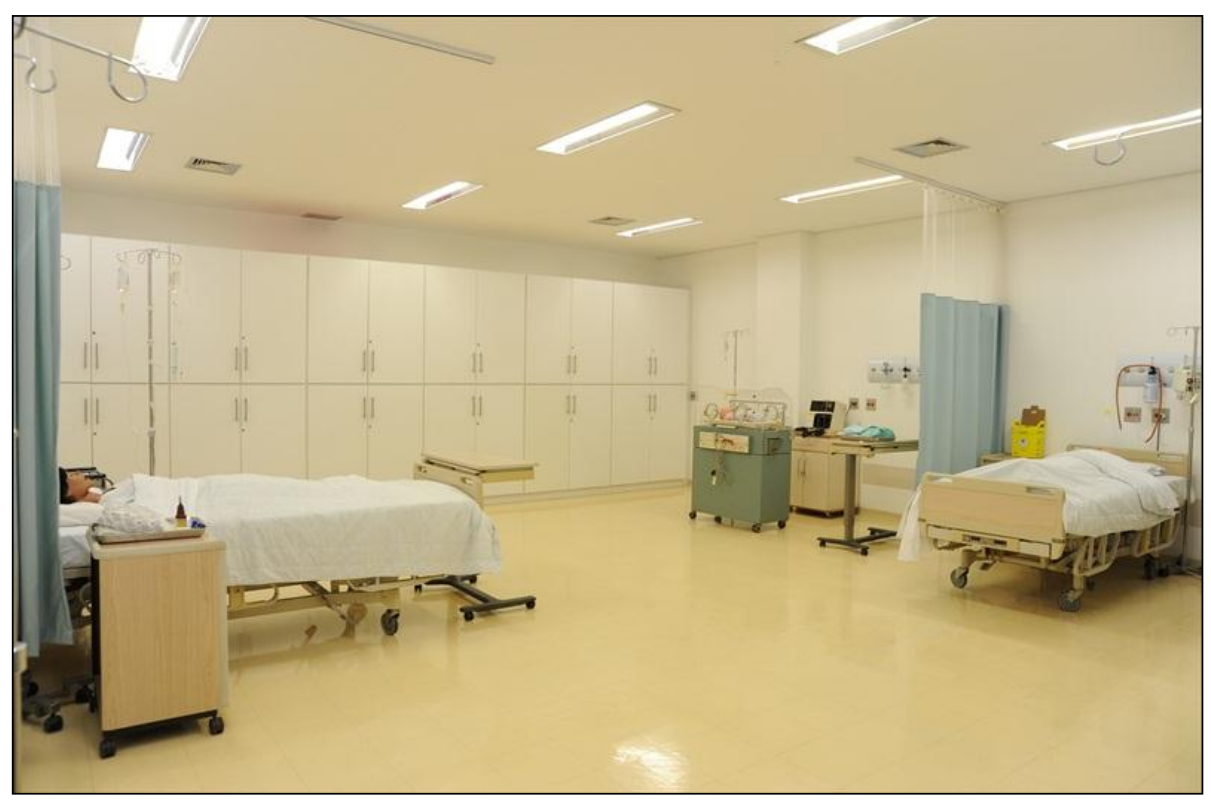

Figura 4 Laboratório de Enfermagem FEHIAE

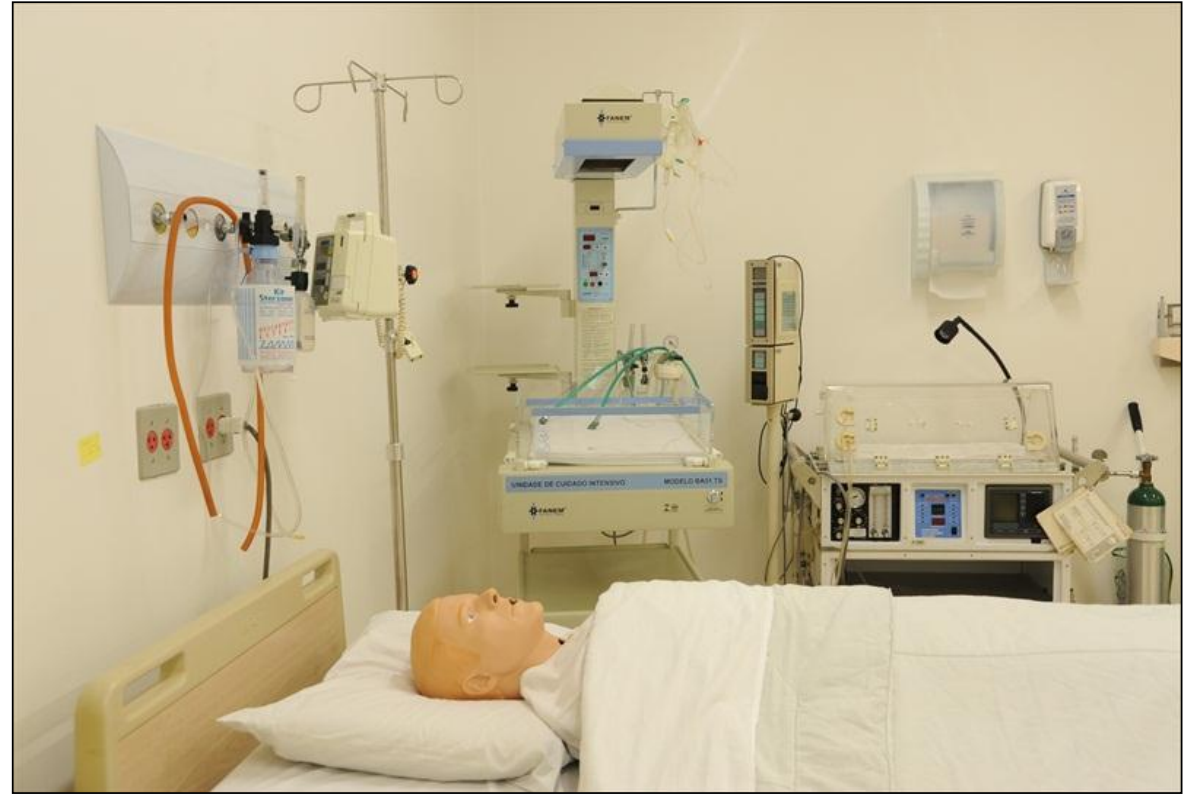

Figura 5 Manequim Laboratório de Enfermagem FEHIAE. 


\subsection{POPULAÇÃO DO ESTUDO}

A população desse estudo foi composta por todos os 44 discentes do $6^{\circ}$ semestre de 2010 da Graduação em Enfermagem da FEHIAE, distribuídos em dois grupos pelo processo de randomização, grupo controle e grupo experimental.

A escolha dos sujeitos justificou-se pela grade curricular proposta pela FEHIAE, onde em várias disciplinas que antecedem a esta, os discentes já tiveram contato com algumas disciplinas que possuem familiaridade com a temática do estudo.

Todos os discentes foram convidados a participar do estudo e foram esclarecidos sobre os objetivos e as finalidades da pesquisa, bem como $o$ respeito à privacidade e ao anonimato de todos os participantes, assegurando os aspectos éticos e garantindo que não teriam prejuízo no desenvolvimento educacional. Os discentes que aceitaram participar da pesquisa preencheram o Termo de Consentimento Livre e Esclarecido, perfazendo um total de 41 participantes (apêndice 1). A população deste estudo recebeu tratamento estatístico para ser considerada apropriada para o estudo experimental.

\subsection{PROCEDIMENTO DE RANDOMIZAÇÃO}

Para o processo de randomização da amostra foram consideradas como variáveis intervenientes ao processo de ensino e aprendizagem: idade, atuação profissional na área da saúde, média ponderada das notas do primeiro e segundo anos letivos e a nota da avaliação progressiva do conhecimento de 2009.

Estes dados foram extraídos do LYCYUM $^{\circledR}$ que é um sistema de gerenciamento educacional da FEHIAE. A pesquisadora compilou estes dados em uma planilha de Excel $^{\circledR} \mathrm{e}$, posteriormente, esta planilha foi encaminhada para o estatístico que analisou e separou os alunos em dois grupos com as variáveis controladas (apêndice 2). 
Estes dados foram encaminhados para a análise estatística visando o controle das variáveis, para que os grupos ficassem homogeneamente parecidos. Para isso foi realizada a comparação das médias das notas entre os dois grupos, verificando a similaridade das médias. Visando comparar as médias, utilizou-se o teste-t e foi necessário verificar a normalidade dos dados pelo teste de Kolmogorov-Smirnov e a homogeneidade das variâncias (apêndice 3).

O relatório com a composição das médias das notas dos alunos foi utilizado para a distribuição dos discentes nos grupos de pesquisa, sendo que a pesquisadora não teve qualquer manipulação para a composição de ambos os grupos (apêndice 4).

\subsection{INSTRUMENTO DE COLETA DE DADOS}

Para contemplar o alcance dos objetivos desta pesquisa, foram elaborados dois instrumentos de coleta de dados.

O primeiro instrumento do tipo questionário pré e pós intervenção foi estruturado especialmente para este estudo e o segundo instrumento foi construído para avaliar a satisfação dos alunos pós intervenção educacional. Os instrumentos foram aplicados em ambos os grupos da pesquisa (apêndice 5,6).

Os instrumentos pré e pós intervenção utilizados nesta pesquisa foram avaliados em sua forma e conteúdo por uma comissão de juízes composta por:

02 Enfermeiras docentes da Escola de Enfermagem da Universidade de São Paulo.

01 Médico neurointensivista do Hospital das Clínicas de São Paulo.

01 Médico Gerente do Programa de Neurologia do Hospital Israelita Albert Einstein.

Destaque-se que para a elaboração desses instrumentos foi considerada a orientação pedagógica e o conteúdo sobre a temática do AVC fundamentado nos protocolos assistenciais reconhecidos nacionalmente e internacionalmente - Los Angeles Pré Hosptial Stroke Scale, adotados na instituição do estudo ${ }^{44}$. 
Os instrumentos pré e pós intervenções apresentam as mesmas questões, com exceção da caracterização do perfil dos alunos onde foram identificadas: idade, gênero, tempo de formação profissional somente no instrumento de pré intervenção.

Os questionários pré e pós Intervenção foram compostos por duas questões sobre a temática escolhida. A primeira questão avalia se os discentes conseguem descrever os sinais e sintomas do AVC e a segunda questão aborda, por meio de um caso clínico, quais as condutas assistenciais adequadas a serem adotadas frente a um paciente com suspeita de AVC.

Para a coleta de dados relacionada à satisfação dos alunos construiuse um instrumento utilizando a metodologia de LIKERT, incluindo questões que envolvem as dimensões individuais e educacionais, além de uma questão aberta sobre a vivência do aluno no processo de aprendizagem. (apêndice 7)

O Instrumento de avaliação de satisfação foi aplicado em ambos os grupos de discentes, imediatamente após o término das intervenções educacionais, tanto da aula expositiva dialogada quanto da aula simulada, visando avaliar a satisfação dos discentes em relação ao uso das estratégias de ensino e identificar os aspectos que foram marcantes em ambas as estratégias educacionais.

Os questionários foram classificados de acordo com o número de matrícula do discente na FEHIAE visando garantir o anonimato e propiciar o acompanhamento longitudinal dos discentes. Em ambos os grupos foi aplicado o mesmo instrumento após 15 e 30 dias da intervenção inicial.

A pesquisadora elaborou um gabarito para a correção dos questionários atribuindo valores numéricos para a análise estatística. As respostas descritas no gabarito estão respaldadas pelo Primeiro Consenso Brasileiro do Tratamento da Fase Aguda do Acidente Vascular Cerebral. (Apêndice 8)

Ressalta-se que não foi atribuída uma média ponderada de corte para análise dos resultados encontrados nessa pesquisa, considerando as diferenças individuais dos estudantes para a apreensão do conhecimento. 


\subsection{OPERACIONALIZAÇÃO DA COLETA DE DADOS}

Após a autorização da Comissão de Ética e Pesquisa do HIAE, foi iniciada a operacionalização da coleta de dados da pesquisa que ocorreu nos dias 27 e 28 de setembro do ano letivo de 2010, junto à disciplina de Práticas Atuais de Enfermagem, para os alunos do 6으 semestre da Graduação de Enfermagem, perfazendo dois dias para a conclusão da coleta dos dados.

Todos os discentes do 6ำ semestre da graduação de enfermagem da FEHIAE foram encaminhados para a sala de aula, onde foram convidados a participar da pesquisa e informados sobre os objetivos, no que consistia a sua participação, seu caráter voluntário e a garantia do anonimato. Foi ressaltada aos discentes a total liberdade para questionamento sobre a pesquisa, bem como a possibilidade de desistir de participar a qualquer momento sem nenhum prejuízo em suas atividades escolares.

Após os esclarecimentos sobre a pesquisa foi entregue aos discentes o Termo de Consentimento Livre Esclarecido (TCLE). Somente depois da assinatura do Termo a pesquisadora informou a composição dos grupos. $O$ grupo controle foi composto por 20 alunos e o grupo experimental foi composto por 21, totalizando 41 discentes que aceitaram participar desta pesquisa. Desta forma no dia 27 de setembro 2010 ocorreu a intervenção no grupo controle e os alunos do grupo experimental foram dispensados das atividades escolares e foram convidados para comparecer no dia seguinte no laboratório de enfermagem.

\subsubsection{INTERVENÇÃO GRUPO CONTROLE - ESTRATÉGIA DE ENSINO AULA EXPOSITIVA DIALOGADA}

As atividades pedagógicas propostas para o grupo controle foram planejadas minuciosamente, detalhando os objetivos da aula, recursos e 
estratégias de ensino conforme descrito no Plano de Aula (apêndice 9). A pesquisadora construiu uma aula em slide de power point $\circledast$ a ser apresentada aos alunos deste grupo (apêndice 10).

O grupo controle participou de uma aula sobre a temática do AVC com duração de 80 minutos. A pesquisadora utilizou a estratégia de ensino aula expositiva dialogada.

A condução da aula foi da seguinte forma:

1- A pesquisadora solicitou aos alunos do grupo controle o preenchimento do questionário pré intervenção (10 minutos).

2- A pesquisadora conduziu a aula expositiva dialogada, com os alunos dispostos em um semicírculo, a fim de facilitar a integração do grupo e favorecer o ambiente dialógico, colaborativo e interativo. Foi projetada uma série de slides sobre os sinais e sintomas de alerta do AVC e a tomada de condutas assistenciais preconizadas no atendimento deste paciente por meio de um hardware, utilizando o editor de apresentações gráficas PowerPoint da Microsoft $®$. Destaca-se que durante a projeção dos slides, a pesquisadora provocava e ao mesmo tempo dialogava com os alunos, tendo como cenário de fundo a proposta pedagógica da TAS (40 minutos).

3- A pesquisadora propôs ao grupo o estudo de caso sobre AVC, onde os alunos deveriam discutir as condutas clínicas adequadas, ancorando os conceitos anteriormente apresentados e discutidos sobre a temática. Esta discussão foi mediada pela pesquisadora (15 minutos).

4- Imediatamente após esta intervenção, os alunos preencheram o questionário pós-intervenção e o instrumento de avaliação de satisfação pós intervenção (15 minutos). 


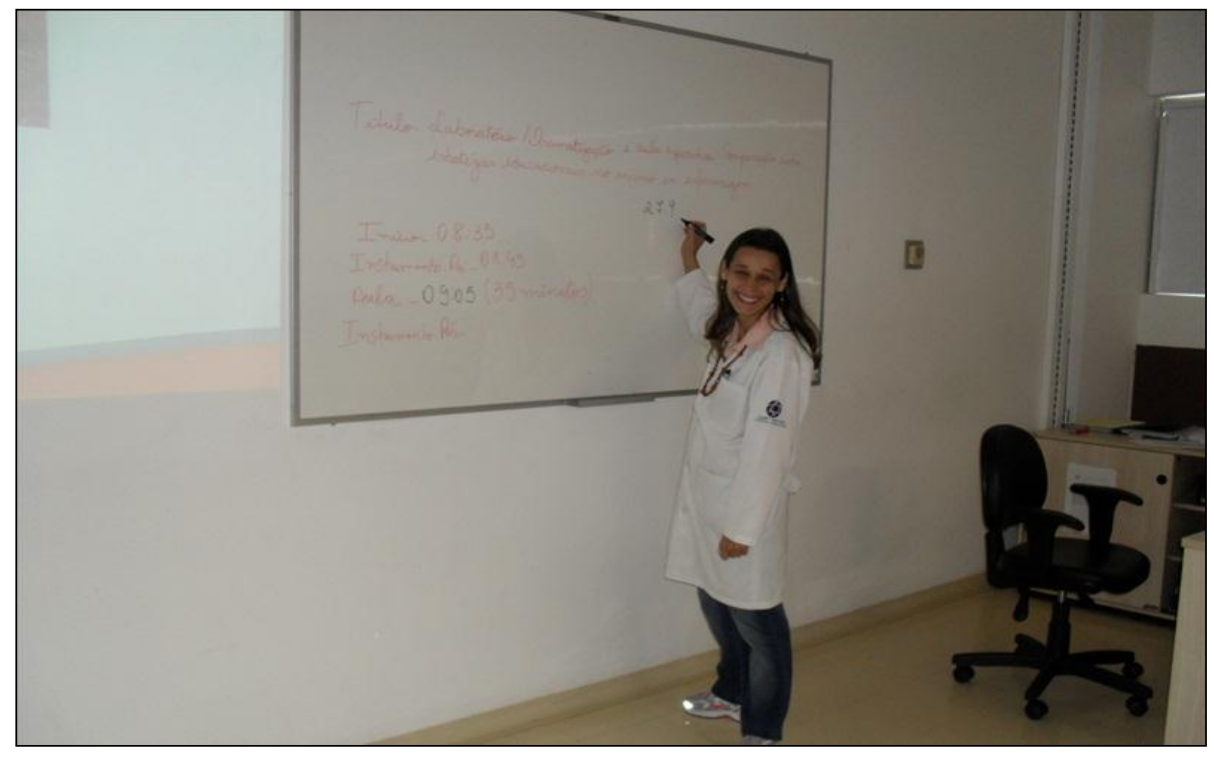

Figura 6 Pesquisadora orientando os alunos do grupo Controle

\subsubsection{INTERVENÇÃO GRUPO EXPERIMENTAL - ESTRATÉGIA DE ENSINO AULA SIMULADA EM LABORATÓRIO DE ENFERMAGEM}

O segundo dia da coleta de dados foi reservado à intervenção junto ao grupo experimental. As atividades pedagógicas propostas para este grupo tiveram uma duração de 80 minutos e também foram planejadas minuciosamente, detalhando os objetivos da aula, recursos e estratégias de ensino, conforme descrito no Plano de Aula. (apêndice 11). Os alunos deste grupo foram encaminhados para o laboratório de procedimentos de enfermagem da FEHIAE.

A condução da aula foi realizada da seguinte forma:

1- A pesquisadora solicitou aos alunos do grupo experimental o preenchimento do questionário pré intervenção (10 minutos).

2- No laboratório de enfermagem de procedimentos, a pesquisadora conduziu a aula simulada, com os alunos dispostos em semicírculo ao redor de um cenário simulado composto por um leito hospitalar e um manequim. A pesquisadora conduziu a temática proposta, simulando no manequim os sinais e sintomas de alerta do AVC e as condutas clínicas preconizadas no atendimento deste paciente de maneira dialógica, favorecendo um ambiente 
colaborativo e interativo tendo como cenário de fundo a proposta pedagógica da TAS (40 minutos).

3- A pesquisadora propôs ao grupo um estudo de caso sobre AVC, onde os alunos deveriam discutir e simular as condutas clínicas adequadas a um atendimento do paciente com suspeita de AVC, utilizando manequim e materiais hospitalares que foram oferecidos no laboratório de procedimentos de enfermagem, e aplicando os conceitos anteriormente apresentados, discutidos e simulados no ambiente laboratorial. Esta discussão foi mediada pela pesquisadora (15 minutos).

4- Imediatamente após esta intervenção, os alunos preencheram o questionário pós-intervenção e o instrumento de avaliação de satisfação pós intervenção (15 minutos).

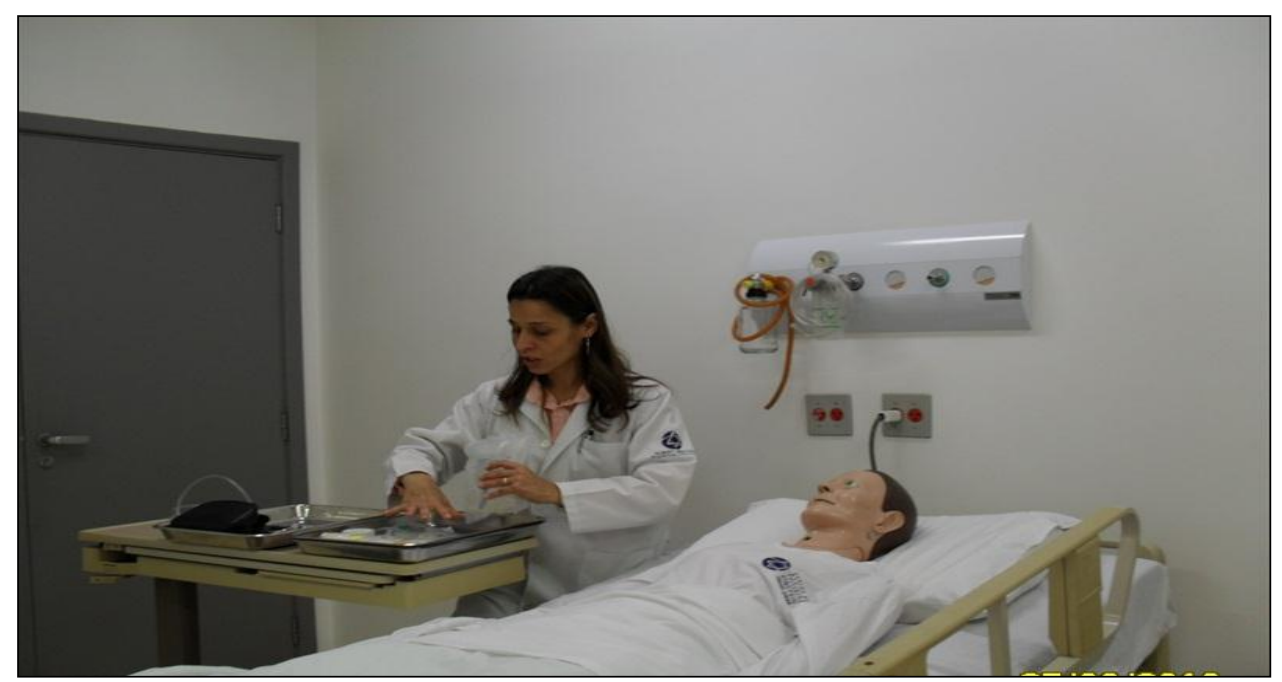

Figura 7 Pesquisadora orientando a temática da aula aos alunos do Grupo Experimental no laboratório de enfermagem FEHIAE. 


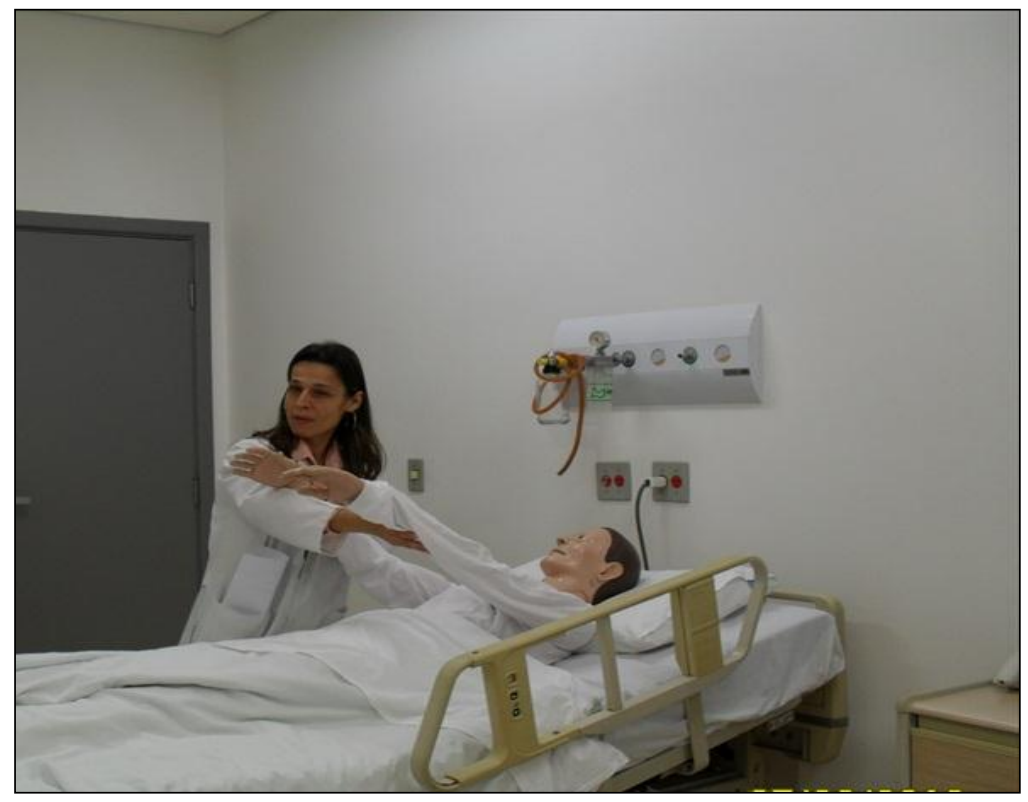

Figura $8 \quad$ Pesquisadora apresentando e demonstrando a temática da aula aos alunos do Grupo Experimental no laboratório de enfermagem FEHIAE.

\subsection{ASPECTOS ÉTICOS}

O projeto foi aprovado pelo Comitê de Ética e de Pesquisa do HIAE, sob o no CAAE 0137.0.028.000-10, em agosto de 2010 e seguiu os preceitos ético-legais de pesquisas que envolvem Resolução 1996/96, bem como as normas e as rotinas estabelecidas pela instituição. Os dados foram coletados somente após a aprovação deste projeto. (anexo 1)

Ressaltamos que, como ocorreu mudança do local da coleta de dados que tinha sido estabelecida no projeto aprovado pelo referido Comitê, a pesquisadora solicitou ao CEP da instituição do estudo a ementa I, ou seja, nova aprovação do projeto, que foi deferindo positivamente (anexo 2).

\subsection{ANÁLISES DOS DADOS}

Para a organização dos dados foi construído um banco de dados no programa Microsoft Exce ${ }^{\circledR}$.

As características dos alunos foram descritas em médias e desvios padrões, no caso das variáveis quantitativas, e em freqüências absolutas e porcentagens, no caso das variáveis qualitativas ${ }^{45}$.

As notas obtidas nas duas questões dos questionários pré e pós intervenção foram descritas por meio de gráficos de perfis médios com 
barras de erros padrão e as comparações entre os diferentes grupos e momentos foram realizadas por meio de um modelo linear de efeitos mistos (efeitos fixos e aleatórios), em que a dependência entre as notas obtidas pelo mesmo aluno é contemplada ${ }^{46}$.

Por meio destes modelos de análise estatística, testaram-se os efeitos de grupo, de tempo e da interação entre o tempo e os diferentes grupos, sendo que, mais especificamente, na interação entre grupo e tempo, foram aplicados testes estatísticos para as comparações múltiplas dentro dos modelos ajustados, aplicando-se a correção de Bonferroni.

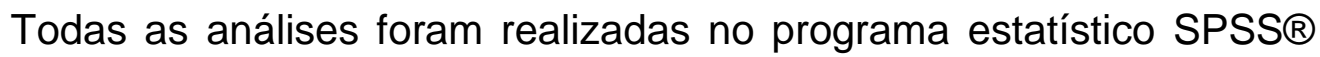
(versão 17), considerando estatisticamente significantes os valores-p menores que 0,05 .

Para a análise da satisfação dos discentes foi realizada primeiramente uma leitura das sugestões escritas pelos discentes, dando início à organização de forma a agrupar as frases de acordo com as dimensões da satisfação individual e educacional dos discentes previamente estabelecidas. 
Apresentação e Análise dos Resultados 


\section{RESULTADOS}

\subsection{CARACTERIZAÇÃO DA POPULAÇÃO}

Dos 41 discentes que participaram desta pesquisa, pelo processo de randomização, 21 (51,3\%) compuseram o grupo experimental e 20 (48,7\%) o grupo controle.

Em relação ao gênero na amostra total encontramos a distribuição de $37(90,3 \%)$ dos alunos do gênero feminino e $4(9,7 \%)$ de alunos do gênero masculino (Tabela 1).

Quadro 1 Distribuição do gênero no grupo controle e grupo experimental, São Paulo-2010

\begin{tabular}{|c|c|c|c|c|}
\hline \multirow{2}{*}{ Grupo } & \multicolumn{2}{|c|}{ Feminino } & \multicolumn{2}{|c|}{ Masculino } \\
\hline & $\mathbf{N}$ & $\%$ & $\mathbf{N}$ & $\%$ \\
\hline Grupo Controle & 19 & 95,0 & 1 & 5,0 \\
\hline Grupo Experimental & 18 & 85,7 & 4 & 9,8 \\
\hline Total & 37 & 90,3 & 4 & 9,7 \\
\hline
\end{tabular}

Os dados da Tabela 1, mostram a distribuição dos alunos segundo a sua participação evidenciando que tanto no grupo experimental quanto no grupo controle a maioria dos alunos foram do gênero feminino.

Estudo realizado pelo Instituto Nacional de Estudos e Pesquisas Educacionais Anísio Teixeira (INEP) em conjunto com os Ministérios da Saúde e da Educação 'demonstra que $83,6 \%$ dos alunos ingressantes nos Cursos de Graduação na Área da Saúde são do gênero feminino mais, especificamente, no Curso de Enfermagem. Segundo os relatórios-síntese do ENADE (2007), realizados pelo INEP, nos anos de 2006 e 2007, os ingressantes foram $84,4 \%$ do gênero feminino ${ }^{47,48}$.

Em relação a idade, observa-se que esta variou de 19 a 45 anos, com predomínio da faixa etária de 21 a 25 anos. 
Quadro 2 Distribuição por faixa etária do grupo controle e grupo experimental,São Paulo-2010

\begin{tabular}{c||c|c|c|c}
\hline \multirow{2}{*}{ Faixa Etária } & \multicolumn{2}{||}{ Grupo Controle } & \multicolumn{2}{c}{ Grupo Experimental } \\
\cline { 2 - 5 } & $\mathbf{N}$ & $\%$ & $\mathbf{N}$ & $\%$ \\
\hline \hline 15 a 20 & 5 & 25,0 & 6 & 28,5 \\
\hline 21 a 25 & 12 & 60,0 & 7 & 33,3 \\
\hline \hline 26 a 30 & 1 & 5,0 & 4 & 19,0 \\
\hline \hline 31 a 35 & 0 & 0,0 & 2 & 9,5 \\
\hline 36 a 40 & 2 & 10,0 & 1 & 4,8 \\
\hline \hline T0 & 0 & 0,0 & 1 & 4,9 \\
\hline \hline Total & 20 & 100,0 & 21 & 100,0 \\
\hline \hline
\end{tabular}

De acordo com os dados apresentados na Tabela 2, a faixa etária de 21 a 25 anos foi predominante no grupo controle e no grupo experimental.

Corroborando com os dados achados, o relatório - síntese do ENADE, elaborado pelo INEP demonstra que a maioria dos estudantes ingressantes na Graduação de Enfermagem possui faixa etária até 24 $\operatorname{anos}^{48,49}$.

No estado de São Paulo um estudo demonstrou que a faixa etária, predominante, dos alunos de graduação de enfermagem corresponde a 17 a 20 anos, sendo considerada alta a procura deste curso por jovens em busca de uma profissão que seja capaz de inseri-los rapidamente no mundo do trabalho ${ }^{50}$.

Com relação a questão sobre a atuação dos alunos na área da saúde, verificou-se que a grande maioria, $34(83,0 \%)$ alunos, não trabalha na área da saúde, o único contato com o ambiente hospitalar é durante os estágios supervisionados que fazem parte da grade curricular do curso de Enfermagem. Os 7 (17,0\%) alunos que trabalham na área da saúde, são técnicos de enfermagem (Tabela 3). 
Quadro 3 Distribuição dos alunos que trabalham na área da saúde do grupo controle e grupo experimental, São Paulo-2010

\begin{tabular}{c|c||c||c|c}
\hline \multirow{2}{*}{ Trabalha na área da saúde } & \multicolumn{2}{|c||}{ Grupo Controle } & \multicolumn{2}{c}{ Grupo Experimental } \\
\cline { 2 - 5 } & $\mathbf{N}$ & $\%$ & $\mathbf{N}$ & $\%$ \\
\hline \hline Sim & 2 & 10,0 & 5 & 23,8 \\
\hline \hline Não & 18 & 90,0 & 16 & 76,2 \\
\hline \hline Total & 20 & 100,0 & 21 & 100,0 \\
\hline \hline
\end{tabular}

De acordos com os dados da Tabela 3, verificou-se que no grupo controle e no grupo experimental o predomínio foi de alunos que não trabalham na área da saúde.

Ressalta-se que a maioria dos alunos se dedica integralmente ao curso de graduação da FEHIAE, que oferece oportunidades extracurriculares para os alunos atuarem como monitores no ambiente hospitalar da instituição.

Estes dados podem ser justificados pela predominância da faixa etária jovem, que busca no curso de enfermagem uma formação profissional única.

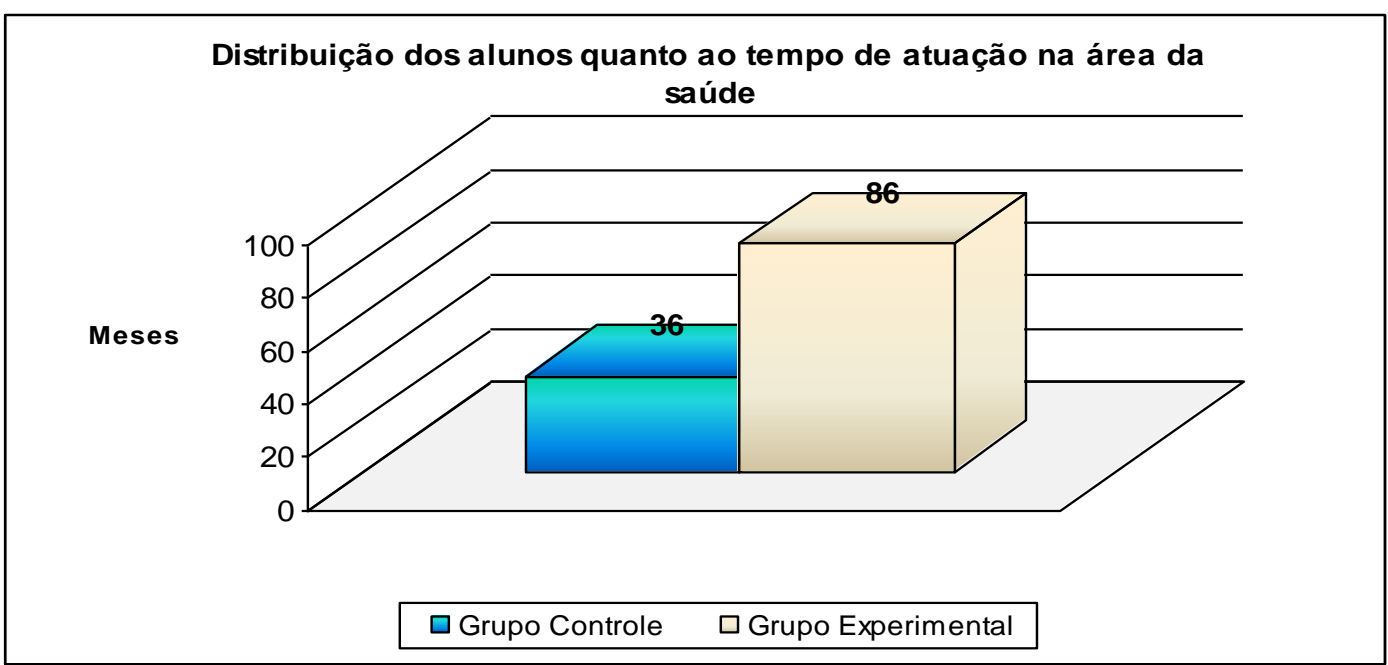

Figura 9 Distribuição do tempo em que os alunos atuam na área da saúde, São Paulo-2010

A média do tempo de atuação dos alunos que trabalham na área da saúde é de 36 meses para o grupo controle e 86 meses no grupo experimental. 


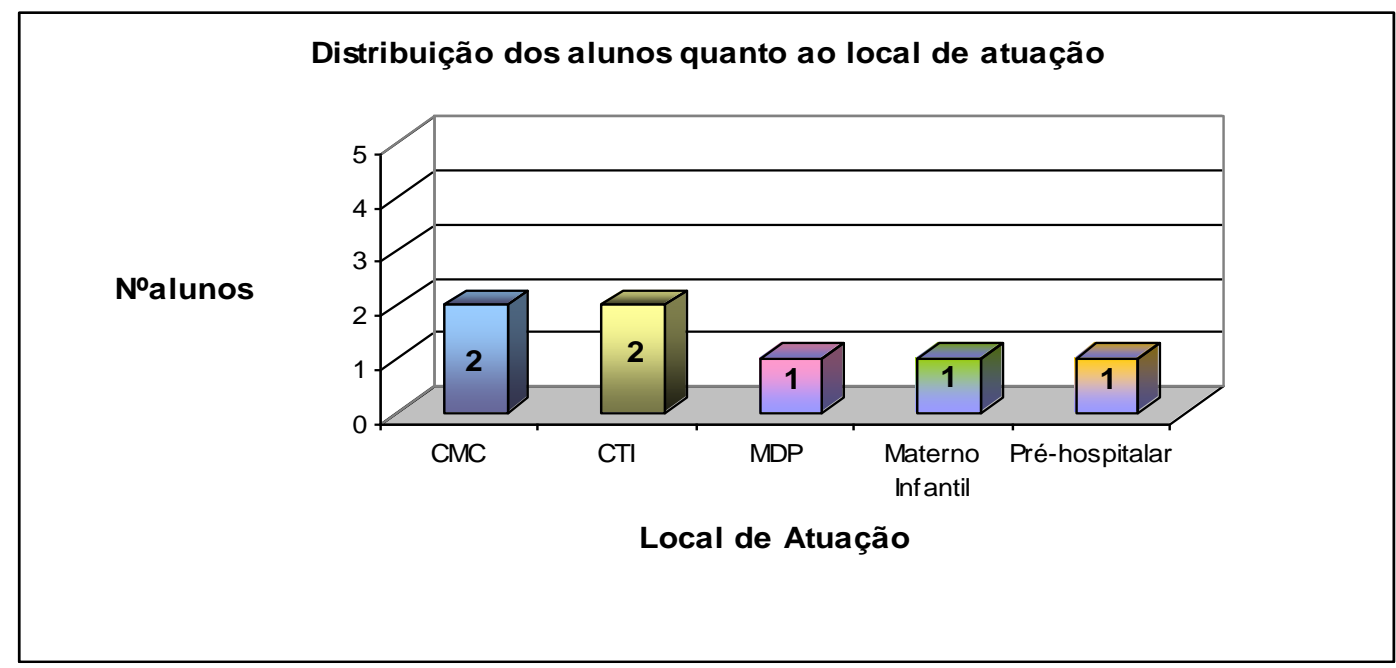

Figura 10 Distribuição do local de atuação dos alunos que trabalham na área da saúde, São Paulo, 2011

Dos alunos que são técnicos de enfermagem e trabalham na área da saúde, 2 (28,5\%) atuam na área de Clinica Médico e Cirúrgica (CMC), 2 $(28,5 \%)$ na área do Centro de Terapia Intensiva (CTI). As áreas de Medicina Diagnóstica e Preventiva, Materno-Infantil e Pré-Hospitalar como moto girl socorrista apresentam, respectivamente, 1(14,0\%) atuação em cada área. $O$ vínculo empregatício da maioria, 6 (86,0\%) alunos, é a Sociedade Beneficente Israelita Brasileira Albert Einstein (SBIBAE) e 1 (14,0\%) aluna trabalha no Corpo de Bombeiros do Estado de São Paulo.

A SBIBAE, reconhecida pela sua qualidade de atendimento no seguimento da saúde, nos últimos anos desenvolveu um plano de expansão da área física da Unidade Morumbi, gerando grande demanda da abertura de novas posições de trabalho na saúde, bem como estimulando seus colaboradores à melhoria contínua, fato que justifica a maioria dos técnicos de enfermagem atuar na própria instituição.

A Instituição apresenta várias possibilidades de melhoria contínua a todos os colaboradores, por meio de políticas de recursos humanos. É oferecido apoio financeiro para o desenvolvimento profissional dos colaboradores, bem como os técnicos de enfermagem são estimulados a ingressarem no curso de graduação de enfermagem da FEHIAE, sendo estabelecida pareceria entre o departamento de recursos humanos do hospital e a graduação de enfermagem. 


\subsection{APREENSÃO DO CONHECIMENTO}

A comparação da apreensão do conhecimento sobre AVC entre o grupo experimental e o controle nos momentos de pré e pós-intervenção, bem como retenção ao longo do tempo, após 15 e 30 dias da intervenção serão apresentados a seguir:

Quadro $4 \quad$ Valores estimados e as comparações sobre sinais e sintomas do AVC entre o grupo controle e experimental nos momentos pré, pós, 15 e 30 dias da intervenção, São Paulo-2010

\begin{tabular}{ccccc}
\hline \multirow{2}{*}{ Grupo } & \multicolumn{5}{c}{ Momento } \\
\cline { 2 - 5 } & Prés & Pós & 15 dias & 30 dias \\
\hline Controle & $3,8(2,9 ; 4,7)$ & $8,6(7,9 ; 9,3) \#$ & $6,1(5,1 ; 7,1) \# \&$ & $5,4(4,4 ; 6,4) \# \&$ \\
Experimental & $5,1(4,2 ; 6,0){ }^{*}$ & $8,4(7,7 ; 9,1) \#$ & $7,1(6,2 ; 8,1) \#$ & $6,7(5,7 ; 7,7) \# \&$ \\
\hline Valores médios estimados pelo modelo (Intervalo de confiança 95\%) & Sinais e sintomas \\
*: $p<0,05$ quando comparado ao grupo controle \\
\#: $p<0,05$ quando comparado ao momento pré \\
$\&: p<0,05$ quando comparado ao momento pós
\end{tabular}

A tabela 4 demonstra que apesar do grupo experimental apresentar valores médios maiores que os do grupo controle nos momentos pós, $15 \mathrm{e}$ 30 dias da intervenção, a única diferença significante observada foi no momento de pré intervenção. Assim, evidencia-se que o grupo experimental apresenta desempenho superior ao do grupo controle, em relação a apreensão do conhecimento referente ao reconhecimento de sinais e sintomas do acidente vascular cerebral.

Para os dois grupos, os valores médios de nota nos momentos pós, 15 e 30 dias são maiores que os do momento pré, indicando que ambas estratégias são eficazes para a retenção do conhecimento. Para o grupo controle há um decréscimo da nota entre o momento pós e 15 dias, sendo que as notas em 15 e 30 dias são semelhantes.

Em relação ao grupo experimental, as notas no pós e em 15 dias são semelhantes e o decréscimo na nota ocorre após 15 dias. 
Quadro 5 Valores estimados e as comparações sobre as condutas assistenciais implementadas ao paciente com AVC entre o grupo controle e experimental nos momentos pré, pós, 15 e 30 dias da intervenção, São Paulo-2010

\begin{tabular}{ccccc}
\hline \multirow{2}{*}{ Grupo } & \multicolumn{5}{c}{ Momento } \\
\cline { 2 - 5 } & Pré & Pós & 15 dias & 30 dias \\
\hline Controle & $1,2(0,6 ; 1,7)$ & $8,2(7,0 ; 9,4) \#$ & $3,7(2,3 ; 5,0) \# \&$ & $3,1(1,7 ; 4,4) \&$ \\
Experimental & $0,0(0,0 ; 0,6)^{*}$ & $7,1(6,0 ; 8,3) \#$ & $4,5(3,1 ; 5,8) \# \&$ & $4,5(3,2 ; 5,9) \# \&$ \\
\hline Valores médios estimados pelo modelo (Intervalo de confiança 95\%) - Condutas assistenciais \\
*: $p<0,05$ quando comparado ao grupo controle \\
\#: $p<0,05$ quando comparado ao momento pré \\
$\&: p<0,05$ quando comparado ao momento pós
\end{tabular}

Em relação à apreensão do conhecimento referente à questão sobre as condutas assistenciais implementadas pelo enfermeiro ao paciente com $A V C$, o grupo experimental apresentou valores médios menores que os do grupo controle no momento da pré intervenção e valores maiores que o do grupo controle em 15 e 30 dias, porém esta diferença não foi estatisticamente significativa.

Para os dois grupos, os valores médios de nota nos momentos pós, 15 e 30 dias são maiores que os do momento pré e há um decréscimo da nota entre o momento pós e 15 dias. Entretanto, nesses momentos, o grupo experimental manteve-se com média superior ao grupo controle.

Destaca-se que ocorreu diferença significativa na apreensão do conhecimento sobre o reconhecimento dos sinais e sintomas do AVC e as condutas assistenciais com o valor de $p<0,05$ da pré-intervenção para a pósintervenção inicial em ambos os grupos de alunos (controle e experimental).

Observa-se, também, que no seguimento longitudinal após 15 e 30 dias da intervenção, os grupos (controle e experimental) se comportaram de forma muito semelhante ao longo do tempo, ocorrendo um declínio da retenção do conhecimento em ambos os grupos, sem diferenças estatísticas significativas. Entretanto, o grupo experimental comportou-se com nota superior.

Para análise dos dados é importante ressaltar que a pesquisadora aplicou as duas estratégias de ensino seguindo todos os passos preconizados para o bom preparo e condução das intervenções educacionais descritas nos planos de aula, tendo como proposta pedagógica 
a teoria da aprendizagem significativa. Considera-se que esta proposta pedagógica foi um fator interveniente para que ocorresse a apreensão do conhecimento tanto na estratégia da aula expositiva quanto na aula simulada.

Desse modo, apesar das estratégias de ensino terem sido diferentes (aula expositiva e aula simulada), os resultados do estudo indicaram que as estratégias foram eficazes e que os objetivos propostos no plano de aula foram alcançados.

A aula expositiva dialogada vem sendo amplamente utilizada e modificada, ao longo do tempo, acompanhando as transformações do ensino e as relações professor-aluno. Esse estudo demonstra a sua efetividade, quando planejada de forma a incorporar um cenário pedagógico dialógico que respeita e valoriza a estrutura cognitiva do aluno e as suas experiências prévias.

A aula simulada tem grande contribuição no processo ensino aprendizagem e, especialmente, na enfermagem, pois envolve o saber fazer, criando ambiente semelhante à prática profissional, oportunizando assim ao aluno vivenciar de forma simulada situações práticas do cotidiano.

O uso de laboratório de enfermagem com recursos materiais, equipamentos e a infra-estrutura, apesar de envolver investimentos, proporciona a aprendizagem significativa.

Quando o professor escolhe a simulação em laboratórios no ensino de graduação em enfermagem, deve considerar o custo-efetividade desta estratégia em relação aos benefícios e aos resultados educacionais esperados $^{51}$.

Uma pesquisa experimental em educação de enfermagem comparou a estratégia da simulação no ensino do processo de preparo e administração medicamentosa de forma segura, identificando as prováveis falhas deste processo em duas áreas de saúde (materno infantil e médico cirúrgica) numa amostra de 54 estudantes. Este estudo concluiu que a simulação pode contribuir para a diminuição de erros no processo de medicação ${ }^{52}$.

De fato, oferecer ao enfermeiro durante o processo de formação uma oportunidade para que vivencie uma situação clínica com a temática AVC é 
de fundamental importância, pois esta condição de saúde apresenta uma alta incidência e prevalência, causando a morte de milhares de pessoas ${ }^{53,54}$.

Outra característica muito importante sobre esta doença é que seu tratamento é tempo dependente, ou seja, quanto mais precoce for o reconhecimento dos sinais e sintomas do AVC, maior será a chance deste paciente recuperar as incapacidades advindas deste processo. Além disso, esta doença está intimamente ligada a fatores de risco, o que torna alguns grupos de pacientes mais susceptíveis à doença, como por exemplo, a unidade de CMC, mais especificamente a cardiologia, geriatria e ortopedia $^{55,56}$.

A estratégia da simulação propicia ao aluno a reflexão conceitual e permite a tomada de decisão clínica, ficando marcante a oportunidade de exercitar condutas assistenciais em um ambiente controlado.

A tomada de decisão é uma competência importante para a prática profissional do enfermeiro, que em seu dia a dia se depara a todo o momento com situações que exigem escolhas que devem ser pautadas em valores éticos e conhecimentos teórico-científicos.

Esta competência é extremamente complexa, pois envolve a construção de saberes, de atitudes frente a situações e de conceitos teóricos. Acredita-se que a construção desta competência inicia-se na graduação, visando preparar o futuro profissional para prática assistencial.

Dessa forma, nesse estudo pode-se observar que os alunos do grupo experimental exercitaram a tomada da decisão assistencial de forma simulada, reconhecendo os sinais e sintomas, e demonstraram com auxílio de manequins as condutas assistenciais de um paciente com AVC.

Corroborando com este achado e entendendo que o tratamento do AVC é uma situação de emergência, encontra-se na literatura que o saber técnico específico e o saber fazer com desenvolvimento de habilidade motora, são fundamentais na execução de procedimentos ou de técnicas, sendo que o enfermeiro deve saber aplicar as condutas assistenciais seguindo uma prioridade lógica no atendimento, conforme o preconizado pelos protocolos de saúde ao paciente vítima de AVC ${ }^{57,58}$. 
$\mathrm{Na}$ área da saúde, vem ocorrendo uma renovação das estratégias de ensino e aprendizagem, oferecendo aos graduandos uma participação mais ativa na incorporação de conhecimentos e habilidades, incluindo o uso de novos recursos e técnicas, bem como de simuladores de pacientes para o desenvolvimento de habilidades necessárias à prática assistencial em enfermagem ${ }^{59,60}$.

Em estudo onde se compararam duas estratégias de ensino sobre reanimação cardio respiratória (leitura e caso-problema) usando um método experimental de pesquisa numa amostra de 71 alunos de enfermagem, concluiu-se que apesar de não haver diferença estatística significante entre os grupos, o grupo experimental (caso-problema) mostrou-se mais motivado durante as intervenções ${ }^{61}$.

A revisão sistemática sobre simulação em enfermagem aponta que essa estratégia deve ser fundamentada em Teorias de Aprendizagens para guiar as simulações, visando proporcionar uma aprendizagem significativa e aumentar as oportunidades dos estudantes desenvolverem habilidades e conhecimentos ${ }^{62,63}$.

Destaca-se, também, que o processo do cuidar em enfermagem requer o desenvolvimento de habilidades técnicas, e é fundamental na formação desse profissional oferecer aos futuros enfermeiros recursos tecnológico e estrutura física para que estes possam desenvolver a competência do saber fazer ${ }^{64}$.

Neste sentido, o desenvolvimento de procedimentos técnicos e habilidades por meio do treinamento em laboratório, com o uso de simuladores está crescendo, por se tratar de uma ferramenta tecnológica que oferece aos alunos um ambiente simulado, que pode facilitar a construção de uma aprendizagem significativa, aprimorar a qualidade da assistência prestada, minimizar os erros e oferecer maior segurança ao paciente ${ }^{60,61}$.

Diante do exposto, pode-se considerar que houve apreensão do conhecimento em ambos os grupos, demonstrando que as estratégias utilizadas, a aula simulada e a aula dialogada expositiva, foram eficazes para 
a aprendizagem dos sinais e sintomas do AVC e das condutas assistências preconizados ao paciente com AVC.

\subsection{SATISFAÇÃO DOS ALUNOS EM RELAÇÃO AS ESTRATÉGIAS}

A satisfação do aluno em relação às estratégias adotadas neste estudo foi identificada em ambos os grupos após as intervenções educacionais, onde o aluno atribuiu nota de 0 a 10 para cada afirmação.

Este instrumento foi categorizado em duas dimensões para melhor apresentação dos resultados.

\subsubsection{DIMENSÃO INDIVIDUAL}

As questões do instrumento de coleta de dados referentes à satisfação do aluno quanto às estratégias educacionais, que contemplam a dimensão individual foram:

1. Aprendi os sinais e sintomas do Acidente Vascular Cerebral (AVC).

4. Compreendi as condutas assistenciais preconizadas frente ao paciente com suspeita de Acidente Vascular Cerebral (AVC).

6. Não tive dificuldades para compreender o conteúdo abordado.

8. Sinto-me mais preparado para o exercício profissional.

10. A aula me fez enxergar aspectos que eu não percebia antes sobre o tema AVC.

11. A aula me fez enxergar aspectos que eu não percebia antes sobre o tema AVC.

12. Tenho mais segurança para adotar condutas assistenciais frente ao paciente com suspeita de AVC.

16. Gosto da assistência prestada ao paciente neurológico.

17.Gostaria de atuar na área de neurologia. 


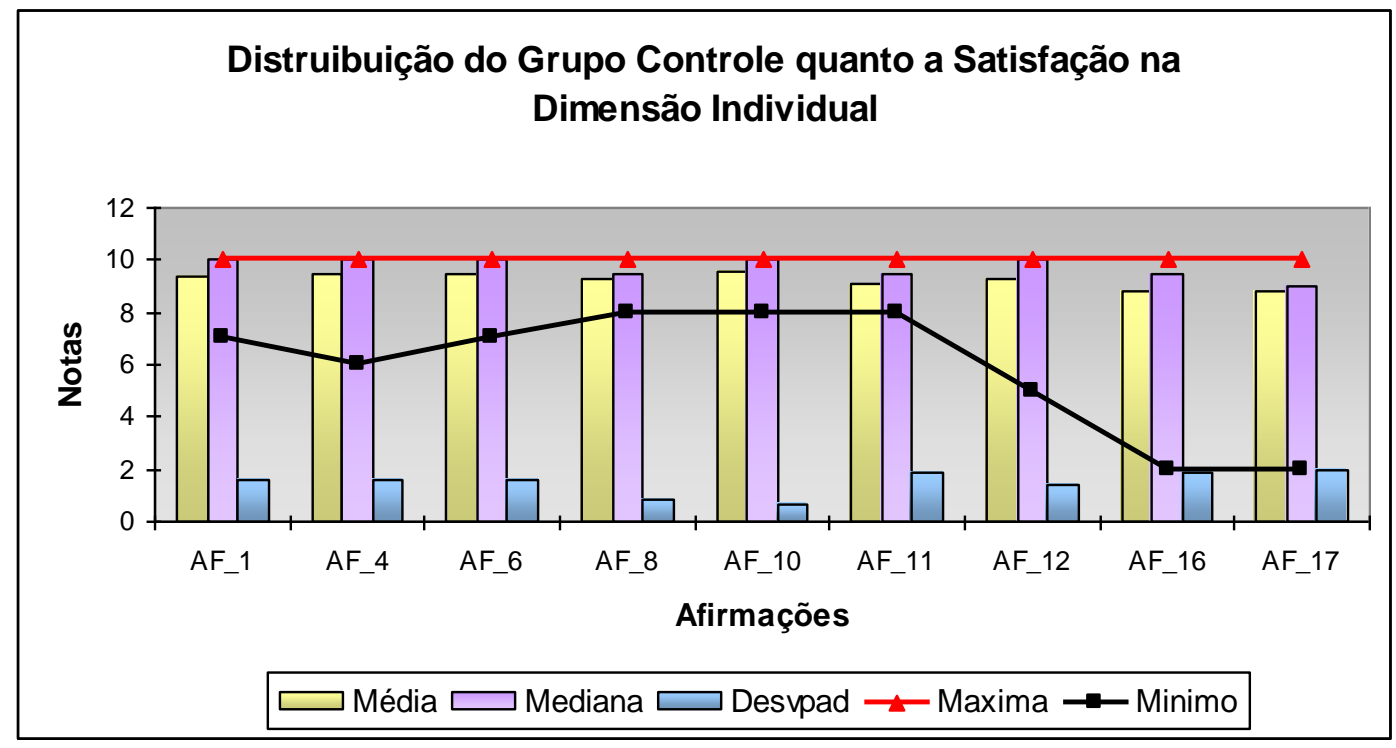

Figura 11 Distribuição do grupo controle quanto à satisfação na dimensão individual. São Paulo- 2011

\section{Distribuição do Grupo Experimental quanto a Satisfação na Dimensão Individual}

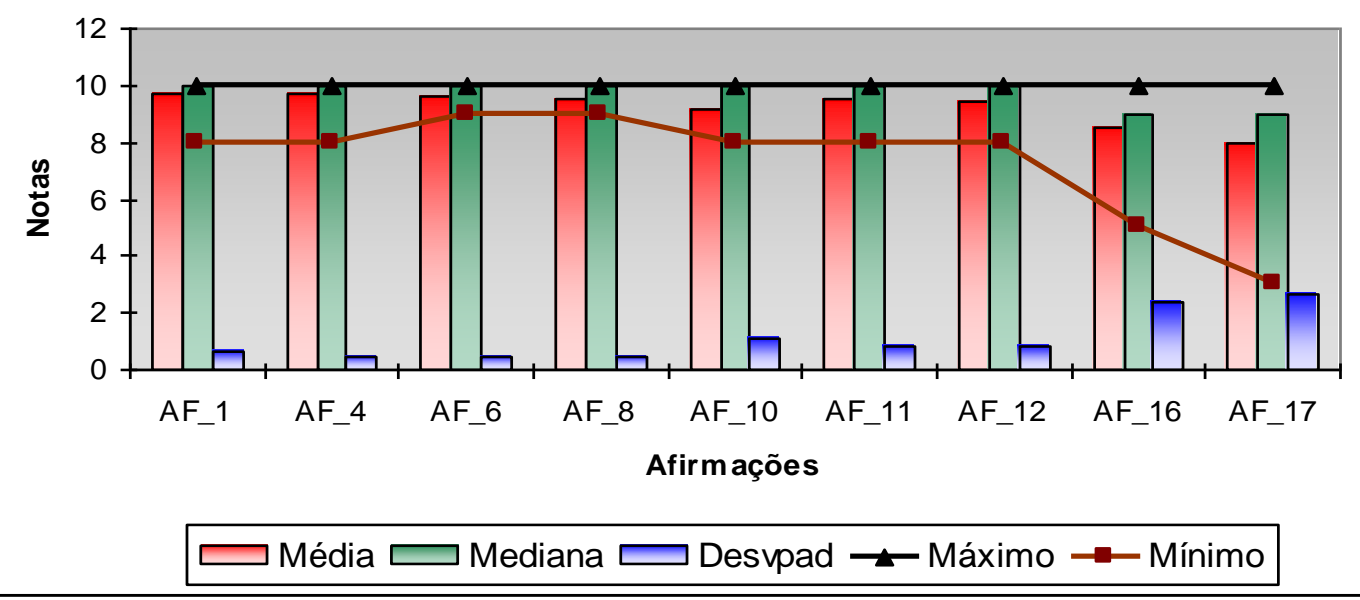

Figura 12 Distribuição do grupo experimental quanto a satisfação na dimensão individual. São Paulo- 2011

Analisando esta dimensão à luz das afirmações, ambos os grupos se comportaram de forma semelhante, porém o grupo experimental atribuiu valores maiores, principalmente nas afirmações 16 e 17 que descrevem a familiaridade ou a motivação do aluno com a temática AVC.

Possivelmente o resultado pode contribuir com as médias deste grupo experimental, imediatamente após a intervenção e ao longo do tempo, após 
15 e 30 dias, destacando que este grupo, pelo fator motivacional e pela temática, pode ter expressado em suas respostas conhecimento sobre o reconhecimento dos sinais e sintomas do AVC e a instituição das condutas assistenciais.

A literatura demonstra que um grupo de discentes pode apresentamr características ou estilos de aprendizagem diferentes, assim como características físicas, estruturas cognitivas, a moral, a cultura, o comportamento e a motivação também o são ${ }^{65}$.

Neste sentido, estes fatores podem influenciar diretamente no processo ensino aprendizagem e, conseqüentemente, na satisfação individual de cada aluno. A motivação é um fator intrínseco do ser humano e está fundamentalmente ligada ao processo ensino-aprendizagem. Desta forma encontramos alunos com motivações em diferentes níveis, desde o apático ao conteúdo apresentado, outros com foco em outros assuntos não relacionados a temática abordada, mas também encontramos estudantes extremamente motivados e preocupados em aprender a temática abordada pelo professor, e espera deste o reconhecimento pelo seu esforço e empenho nas atividades desenvolvidas.

Estudantes mais satisfeitos com o desenvolvimento do processo ensino-aprendizagem apresentam maior motivação para realização das atividades propostas, bem como possuem um alto rendimento metacognitivo na gestão do tempo e de seus esforços para a entrega das atividades designadas durante o curso ${ }^{66}$.

Dessa forma, conclui-se que o professor deve levar em consideração a dimensão individual do aluno, respeitando as suas diferenças motivacionais para a apreensão do conhecimento. 


\subsubsection{DIMENSÃO EDUCACIONAL}

As questões do instrumento de coleta de dados referente à satisfação do aluno quanto às estratégias educacionais, que contemplam a dimensão educacional são:

2. A Aula proporcionou uma visão teórica a respeito do tema.

3. A estratégia foi adequada aos objetivos propostos.

5. O conteúdo abordado correspondeu aos objetivos propostos para a aula.

7. Mantive boa interação com o professor que ministrou a aula.

9. A professora tem domínio do conteúdo da aula.

13. A aula foi dinâmica.

14. Os recursos didáticos utilizados na aula foram adequados.

15. A aula proporcionou relação entre teoria e prática.

18. A professora demonstrou atenção as dúvidas dos participantes.

19. A aula proporcionou uma aprendizagem significativa.

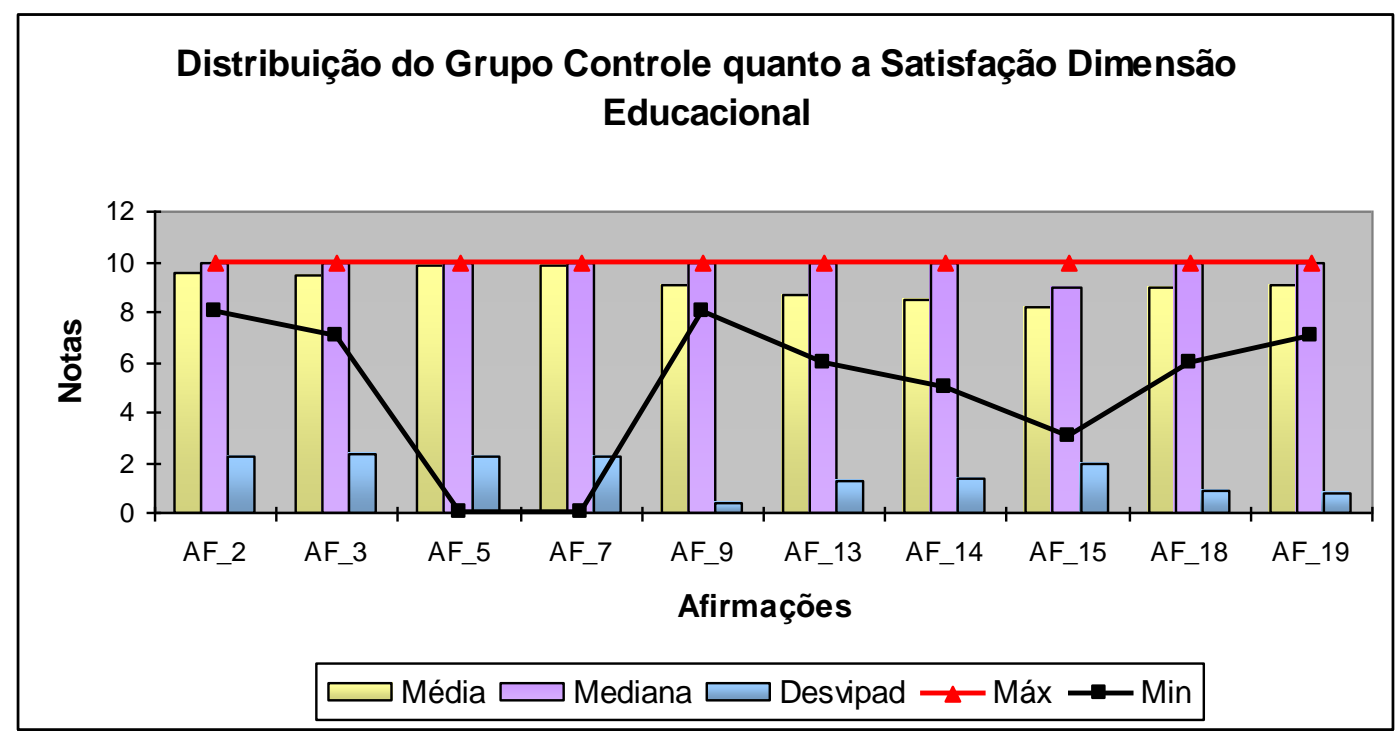

Figura 13 Distribuição do grupo controle quanto à satisfação na dimensão educacional. São Paulo- 2011 


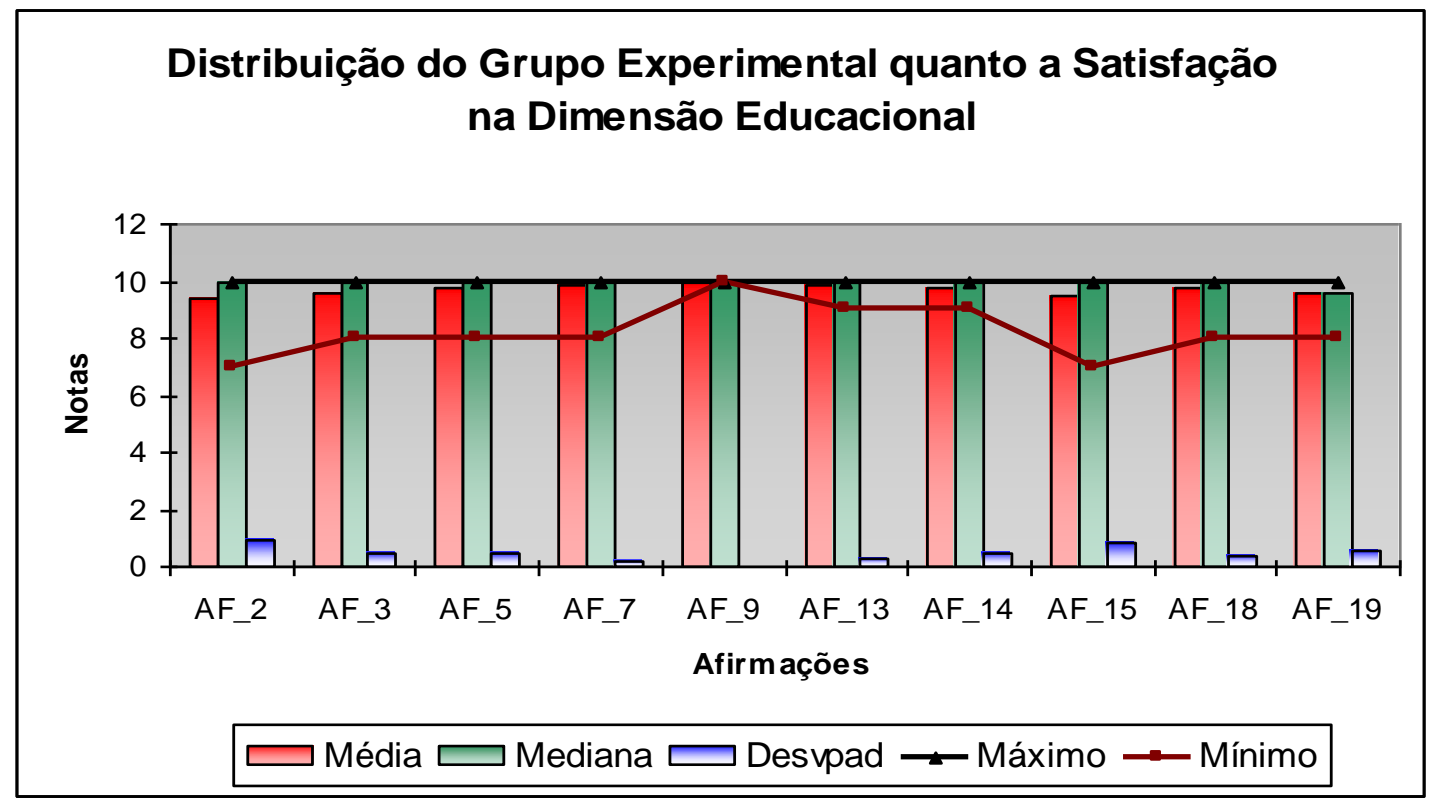

Figura 14

Distribuição do grupo experimental quanto a satisfação na dimensão educacional. São Paulo- 2011

Os resultados encontrados nesta dimensão, demonstram que a média das afirmações do grupo experimental foi superior (entre 9 e 10) à media das afirmações do grupo controle (8 e 10), e a nota mínima foi superior no grupo experimental (entre 7 e 10) enquanto no grupo controle foi inferior (entre 0 e 8).

Observamos que na afirmação cinco e na afirmação sete foi atribuída pelos discentes do grupo controle a nota mínima (0), fato não ocorrido no grupo experimental, onde a nota mínima entre as afirmações analisadas foi sete.

Com estes resultados pode-se entender melhor a questão da importância do processo ensino- aprendizagem na dimensão educacional.

Há muito ainda por conhecer na dimensão educacional, por isso o professor não pode se isolar nos saberes, devendo acompanhar o dinamismo das mudanças e repensar velhos paradigmas, entendendo que o professor é um agente transformador tendo conhecimento do ponto de partida de sua prática educadora, não perdendo de vista a construção dos saberes ${ }^{67}$.

Estes fatores foram expressos na opinião dos alunos tanto no grupo controle como no grupo experimental, conforme as frases descritas a seguir: 
Acredito que aulas que envolvam essa análise de casos clínicos ainda em salas de aula são fundamentais para dar mais segurança e confiança após procedimentos a serem executados pelos alunos (futuros profissionais) na prática clínica. Por mim todas as aulas que envolvam assistência de enfermagem a pacientes poderiam ter essa metodologia (aula aplicação em casos pré selecionados análise crítica, pois os alunos sairiam da faculdade de fato aptos a saber agir na prática com raciocínio clínico adorei a aula). Obrigada.(A)

$A$ aula foi ótima e a professora tb. (B)

$A$ aula foi muito boa. (C)

A professora domina completamente o conteúdo apresentado na aula. (D)

Gostaria de ter mais aulas deste tipo (prática). (A)

Como o AVC é uma doença que causa maior número de morte estando no $3^{a}$ ano é importante estar atento aos sinais e sintomas relatados pelo paciente. A prof $f^{a}$ Tania está de parabéns, pois assim ela contribui para o meu aprendizado. (B)

Acho que a aula foi de grande proveito, pois a dinâmica proporciona uma visão real dos fatos o que melhora a fixação das condutas a serem empregada no caso. (C)

A aula muito construtiva e nada cansativa. Obtive um aprendizado que não vou esquecer na minha vida. (E)

A relação professor-aluno dialógica com respeito às características particulares dos alunos, e à escolha de estratégias inovadoras, como fatores que contribuem para a aprendizagem significativa e apreensão do conhecimento, foram destacadas por vários trabalhos na enfermagem ${ }^{55}$, 58,62,63-66.

Autores abordam que as características particulares de cada aluno são fundamentais para o sucesso de uma aprendizagem significativa, e podem se expressar no processo ensino aprendizagem como a bagagem prévia do conhecimento que implica a ancoragem de novas aquisições, a expectativa do aluno frente a temática proposta pelo professor e a motivação para o aprender, o receio de errar, o medo frente às inovações educacionais 66,67

Colaborando com a questão das particularidades individuais dos alunos, na relação professor aluno, o professor aprende no decorrer do processo educacional como agir para facilitar e promover um ambiente 
dialógico, tornando-se um facilitador real no processo de mudanças internas dos alunos, para que eles alcancem os objetivos propostos no decorrer do processo educacional $^{68,69}$.

Além destas características na aprendizagem do adulto (andragogia), há a necessidade do feedback, pois o aluno adulto almeja um retorno de como está sendo o seu desempenho, ou seja, se ele está ou não no caminho certo ${ }^{66}$.

Neste sentido o planejamento das estratégias educacionais é uma fase importante do processo ensino aprendizagem, desvelando que a aprendizagem do adulto está relacionada à suas experiências prévias e a sua aplicação no cotidiano do tema abordado no novo aprendizado, bem como permite o desenvolvimento reflexivo e a integração mais completa e efetiva com a teoria e prática, rompendo definitivamente com a questão da educação formal centralizadora ${ }^{68,69}$.

A aplicação de estratégias educacionais e o planejamento de simulações em laboratório de enfermagem permitem percepção positiva dos estudantes frente ao uso desta estratégia na enfermagem, por propiciar dinamismo, e facilitar a interação professor-aluno, com o objeto material, reforçando a apreensão do conhecimento e oportunizando para o aluno simular o cuidado que irá futuramente prestar aos pacientes em sua vida profissional $^{70}$.

Corroborando com a idéia do planejamento das estratégias de simulação, um aluno do grupo controle expressou a importância da simulação e da relação teórica-prática na formação do enfermeiro, conforme a frase descrita a seguir:

Período da aula foi curto faltando um tempo para a parte prática. Acredito que a junção do teórico com o prático trás mais absorção da matéria. (D)

Destaca-se que, no processo ensino-aprendizagem, o professor deve levar em consideração a relação professor-aluno e teoria e prática. A promoção do ambiente de respeito e dialógico, assim como a proposta pedagógica devem estar alinhadas com os objetivos de aprendizagem, 
utilizando o planejamento de ensino como uma ferramenta poderosa em sua prática diária. Nessa perspectiva pôde-se evidenciar a importância da adoção da Teoria da Aprendizagem Significativa na promoção da apreensão do conhecimento. 


\section{Conclusões}




\section{CONCLUSÕES}

Pode-se concluir que este trabalho de pesquisa atingiu os objetivos propostos, pois possibilitou a comparação da eficácia entre as duas estratégias de ensino dos grupos controle e experimental.

Destaca-se que ocorreu diferença estatistica significativa na apreensão do conhecimento sobre o reconhecimento dos sinais e sintomas do AVC e as condutas assistenciais com o valor de $p<0,05$ da pré-intervenção para a pós-intervenção inicial no grupo experimental.

Dessa forma, a hipótese do estudo de que a aula simulada no laboratório de enfermagem é mais eficaz do que a aula expositiva dialogada para a apreensão do conhecimento em AVC na enfermagem foi comprovada.

Este estudo possibilitou, ainda, identificar e comparar a eficácia da aprendizagem dos discentes imediatamente, 15 e 30 dias após participarem na aula expositiva dialogada ou aula simulada, demonstrando que ambas são eficazes e favoreceram a retenção do conhecimento de forma significativa pelos discentes de graduação em enfermagem, sobre os sinais e sintomas do AVC e as condutas assistenciais preconizadas ao paciente com AVC.

Quanto a comparação da satisfação dos discentes na aula expositiva dialogada e na aula simulada, o grupo experimental que participou da aula simulada em laboratório de enfermagem evidenciou estar mais satisfeito e motivado para a apreensão do conhecimento sobre AVC.

Este fato pôde ser comprovado por meio da comparação da satisfação dos discentes na aula expositiva dialogada e na aula simulada, bem como dos relatos dos discentes que participaram da aula simulada que expressaram a importância da aula para propiciar uma visão real dos objetos de estudo contribuindo para uma aprendizagem significativa. 


\section{Considerações Finais}




\section{CONSIDERAÇÕES FINAIS}

A importância do estudo justifica-se diante da escassez da literatura, demonstrando a comparação de diferentes metodologias de ensino na área do reconhecimento dos sinais e sintomas do AVC e das condutas assistenciais preconizadas a este paciente.

Observa-se também no desenvolvimento desta pesquisa, o quanto a TAS foi um fator preponderante para a eficácia das estratégias de ensino e contribuiu para a apreensão do conhecimento da temática.

A TAS fundamenta-se em uma visão humanística e enfatiza os aspectos afetivos e relacionais da aprendizagem como os aspectos relacionados à aquisição e organização da consolidação do conhecimento. Nessa perspectiva a adoção da TAS nas duas estratégias de ensino como cenário pedagógico possibilitou estabelecer ambiente dialógico, favoreceu a interação docente-discente e contribuiu para os processos cognitivos dos discentes, propiciando a significação dos objetos de estudo.

Dessa forma as estratégias de ensino que estimulem o ambiente dialógico e a adoção da TAS como cenário pedagógico podem propiciar ao aluno a vivência do cotidiano profissional da enfermagem de forma contextualizada e significativa, oportunizando a segurança e qualidade da assistência que prestará aos seus futuros pacientes.

Acredita-se que este estudo possibilitou identificar e comparar eficácia da aprendizagem, bem como propiciou a compreensão da importância do planejamento educacional e da adoção de estratégias de ensino fundamentadas na Teoria da Aprendizagem Significativa, identificando a necessidade da capacitação pedagógica dos docentes de enfermagem.

Considera-se que as instituições de ensino de enfermagem devem instituir uma política de capacitação pedagógica permanente para os docentes possibilitando dirimir atitudes de resistência e insegurança quanto a utilização de estratégias de ensino fundamentadas no diálogo, no respeito ás característica individuais dos discentes e nas experiências prévias, bem 
como na adoção de atitudes do professor como agente facilitador da construção do conhecimento.

Outro ponto de destaque é a importância de momentos de intervenção educacional que oportunize os alunos a retenção do conhecimento, expondo-os a conceitos e objetos de estudo e as situações como estudo de caso, exercícios, estágio supervisionado e uso do laboratório de enfermagem.

Vislumbra-se assim, que esta pesquisa abre novos caminhos para o desenvolvimento de pesquisas voltadas para as estratégias de ensino em enfermagem amplinado a população do estudo.

Deve-se investir também na utilização de outras estratégias de ensino como o e-learning, simulação realística, ensino baseado em problemas (PBL) que possam favorecer a apreensão do conhecimento dos alunos sobre o tema de AVC, respeitando assim as diferentes estruturas cognitivas e os diversos estilos de aprendizagem dos alunos. 


\section{Referências}




\section{REFERÊNCIAS}

1. Harper B, Ceccon C, de Oliveira MD, de Oliveira RD. Cuidado, escola! desigualdades, domesticação e algumas saídas. 24a ed. Petrópolis: Brasiliense; 1987.

2. Anastasiou LG. Metodologia do ensino superior:da prática docente a uma possível teoria pedagógica. Curitiba: IBPEX;1998.

3. Sancho JM, Hérnandez F. Tecnologias para transformar a educação. São Paulo: Artmed; 2006.

4. Deslandes SF, Mitre RM. Processo comunicativo e humanização em saúde. Interface Comun Saúde Educ [Internet]. 2009 [cited 2010 Feb 9]; 13(Supl 1):641-9.

Disponível em: http:// http://www.scielo.br/pdf/icse/v13s1/a15v13s1.pdf

5. Sakata MC. Globalização e educação: a formação do comunicador social na América Latina. [tese]. São Paulo(SP): Universidade de São Paulo, Escola de Comunicação e Artes; 2009. 314 p.

6. Dutra JS. Competências conceitos e instrumentos para gestão de pessoas na empresa moderna. São Paulo: Atlas; 2004.

7. Peres HHC. O ser docente de enfermagem frente ao mundo da informática: um olhar na perspectiva da fenomenologia social. [tese] . São Paulo: Universidade de São Paulo, Escola de Enfermagem; 2001. 228p.

8. Costa G, Nascimento L. Educação e treinamento a distância mediados por computador:em busca da aprendizagem significativa. RENOTE Rev Novas Tecnol Educ [Internet]. 2004 [citado 2012 Jan 10]; 2(1). Disponível em: 
http://www.faders.rs.gov.br/uploads/1201612842Artigo Lisandra Educacao

e Treinamento a Distancia Mediados por Computador.pdf

9. Anastasiou LG, Alves LP. Processos de enfermagem na universidade: pressupostos para as estratégias de trabalho em aula. $7^{\mathfrak{a}} \mathrm{ed}$. Joinville, SC: UNIVILLE; 2007.

10. Moran JM. Ensino e aprendizagem inovadores com tecnologias audiovisuais e telemáticas. In: Moran JM, Masetto MT, Behrens MA. Novas tecnologias e mediação pedagógica. Campinas: Papirus; 2000. p.11-65.

11. Gil AC. Metodologia do ensino superior. 3ㄹạed. São Paulo: Atlas; 1997. p. 33 a 41.

12. Buchmann M. The priority of knoweledge and understanting in teaching. In: Katz L, Raths J, editors. Advanced in teacher education. Norwood: Ablex;1984. p.29-50.

13. Brasil. Presidência da República. Lei n. 9.394 de 20 de dezembro 1996. Estabelece as diretrizes e bases da educação nacional [Internet]. Diário Oficial da República Federativa do Brasil, Brasília(DF); 1996 Dez 23 [citado 2009 Out 18]. Disponível em: http://portal.mec.gov.br/seed/arquivos/pdf/tvescola/leis/lein9394.pdf

14. Conselho Nacional de Educação. Câmara de Educação Superior. Resolução CNE/CES n.3, de 7 de novembro de 2001. Institui as diretrizes curriculares nacionais do curso de graduação em enfermagem [Internet]. Diário Oficial da república Federativa do Brasil, Brasília(DF); 2001 Nov 7 [citado 2010 Jun 20]. Disponível em: Disponível em: http://portal.mec.gov.br/cne/arquivos/pdf/CES03.pdf 
15. Silva CR. Critérios ergopedagógicos para a avaliação de ambientes virtuais de aprendizagem. Florianópolis: Laboratório de Hipermídia EducacionalUFSC; 2004.

16. Lévy P. A inteligência coletiva: por uma antropologia do ciberespaço. São Paulo: Loyola; 1994

17. Mattos AL. Sumário de didática geral. Rio de Janeiro: Aurora; 1960.

18. Gil AC. Didática do ensino superior. São Paulo: Atlas; 2008. p. 94-107.

19. Libâneo JC. Didática. São Paulo: Cortez; 1994. Capítulo 10, O planejamento escolar. p. 221-47.

20. Gil, AC. Metodologia do ensino superior. 3ed. São Paulo: Atlas; 1997. p. 33-41.

21. Carvalho HM. Introdução a teoria do planejamento. São Paulo: Brasiliense; 1976.

22. Pajares MF. Teachears' beliefs and educational research: cleaning up a messy construct. Rev Educ Res. 1992; 62(3):307-32.

23. Chiesa AM, Nascimento DD, Braccialli LA, Oliveira MA, Ciampone MH. A formação de profissionais da saúde: aprendizagem significativa à luz da promoção da saúde. Cogitare Enferm. 2007; 12(2):236-40.

24. Cooper JB, Taqueti VR. A brief history of the development mannequin simulators for clinical education and training. Qual Saf Health Care. 2004;13 (Suppl 1):i11-8. 
25. Teqtmeyer K, Ibsen L, Goldstein B. Computer-assisted learning in critical care: from ENIAC to HAL. Crit Care Med. 2001; 29 (8 Suppl):N177-82.

26. Levy P. Cibercultura. São Paulo: Editora 34; 1999.

27. Felix CC, Mancussi e Faro AC, Dias CR. Percepção de estudantes de enfermagem sobre o Laboratório de Enfermagem como estratégia de ensino. Rev Esc Enferm USP [Internet]. 2011 Mar [citado 2011 Out 10]; 45(1): 243-9. Disponível em: http://www.scielo.br/pdf/reeusp/v45n1/34.pdf

28. Gomes CO, Germano RM. Processo ensino/aprendizagem no laboratório de enfermagem: visão de estudantes. Rev Gaúch Enferm. 2007;28(3):401-8.

29. Massini EPS, Moreira MA. A aprendizagem significativa:a teoria de David Ausubel. São Paulo: Centauro; 2001

30. Moreira MA, Elcie FS. Aprendizagem significativa: a teoria de David Ausubel. São Paulo: Moraes; 1982.

31. Pontes Neto JA. Teoria da aprendizagem significativa de David Ausubel: perguntas e respostas. Série-Estudos - Periódico do Mestrado em Educação da UCDB. 2006; 21:117-30.

32. Ausubel DP, Novak JD, Hanesian H. Psicologia educacional. Rio de Janeiro: Interamericana; 1980.

33. Leite MM, Prado C, Peres HH. Educação em saúde: desafios e uma prática inovadora. São Caetano do Sul (SP): Difusão; 2010. 
34. Moreira MA. Aprendizagem significativa crítica [Internet]. In: III Encontro Internacional sobre aprendizagem Significativa 2000 Set 11-15; Lisboa (Peniche). [citado 2010 Ago 10] . Disponível em <http://www.if.ufrgs.br/ moreira/ apsigcritport.pdf>.

35. Waal P, Telles M. Aprendizagem significativa (Ausubel). DynamicLab Gazette. Reflexões sobre a aprendizagem on-line [Internet]. 2004; [citado 2010 Ago 20].

Disponível em:

http://www.dynamiclab.com/moodle/mod/forum/discuss.php?d=421

36. Macedo L. Piaget e a nossa inteligência. Rev Pátio. 1997; (1):10-3.

37. Perrenoud P. Construir as competências desde a escola. Porto Alegre: Artmed; 1999.

38. Meirieu P. Aprender...sim, mas como? Porto Alegre: Artmed;1998.

39. Zabala VA. A prática educativa: como ensinar. Porto Alegre: Artmed; 1998.

40. Conselho Federal de Enfermagem. Resolução COFEN-299/2005 Revogada pela Resolução COFEN N.371/2010. Dispõe sobre indicativos para a realização de estágio curricular supervisionado de estudantes de enfermagem de graduação e do nível técnico da educação profissional. Diário Oficial da República Federativa do Brasil, Brasília (DF); 2010.

41. Lobiondo-Wood G, Haber J. Pesquisa em enfermagem: métodos, avaliação crítica e utilização. 4ª̣ed. Rio de Janeiro: Guanabara Koogan; 2001.

42. Polit DF, Hungler B. Fundamentos de pesquisa em enfermagem. $3^{\mathrm{a}} \mathrm{ed}$. Porto Alegre: Artes Médicas; 1995. 
43. Hospital Israelita Albert Einstein. Faculdade de Enfermagem. Plano Ensino de Desenvolvimento Institucional - FEHIAE 2004 a 2008 [Documento institucional]. São Paulo: FEHIAE; 2004

44. Medeiros EB. Provas objetivas discursivas, orais e práticas: técnicas de construção. 7a ed. Rio de Janeiro: Editora. da Fundação Getúlio Vargas; 1983. p.178.

45. Bussad WO, Morettin PA. Estatística básica. $5^{a}$ ed. São Paulo: Saraiva; 2007.

46. Neter J, Kutner MH, Nachtshem CJ, Wasserman W. Applied linear statistical models. 5th ed. Chicago: Homewood; 2005..

47. A trajetória dos cursos de graduação na área da saúde: 1991-2004 [Internet]. Brasília: Instituto Nacional de Estudos e Pesquisas Educacionais Anísio Teixeira; 2006 [citado 2012 Jan 10]. Disponível em: http://bvsms.saude.gov.br/bvs/publicacoes/Texto_de_Referencia.pdf

48. Instituto Nacional e Pesquisas Educacionais Anísio Teixeira (INEP).[Internet]. Brasília: INEP [atualizado 2007] Disponível em: http://www..inep.gov.br/ dowload/ enade/ 2007/ relatório_sintese/20017_REL_SINT_ENFERMAGEM.

49. Nakamae DD, Costa ML. Semelhanças e diferenças do perfil de estudantes em escolas de enfermagem oficiais e particulares da região da grande São Paulo. Rev Paul Enferm 1993; 12(2):72-7.

50. Tavares MS, Rolin EJ, Franco LH, Oliveira FL. O perfil do aluno ingressante nos cursos superiores de enfermagem do Estado de São Paulo: 1993. Rev Paul Enferm 1995;14 (2/3):55-65 
51. Bland AJ, Topping A, Wood B. A concept analysis of simulation as a learning strategy in the education of undergraduate nursing students. Nurse Educ Today. 2011; 31(7):664-70.

52. Sears K, Goldsworthy S, Goodman WM.. The relationship between simulation in nursing education and medication safety. J Nurs Educ. 2010; 49(1):52-5.

53. Scalese RJ, Obeso VT, Issenberg SB. Simulation techonology for skill training and competency assessment in medical education. J Gen Intern Med. 2008; 23 Suppl 1: 46-9.

54. Kaakinen J, Arwood E. Systematic review of nursing simulation literature for use of learning theory. Int J Nurs Educ Scholarsh. 2009; 6(1): Article 16.

55. Hayashida M. Laboratório de enfermagem: histórico organizacional e funcional de uma unidade universitária. [dissertação]. Ribeirão Preto: Universidade de São Paulo, Escola de Enfermagem; 1992.

56. Sociedade Brasileira de Doenças Cerebrovasculares. Primeiro Consenso Brasileiro do Tratamento da Fase Aguda do Acidente Vascular Cerebral. Arq Neuropsquiatr. 2001; 59(4):972-80

57. Hospital Israelita Albert Einstein. Atlas da saúde São Paulo [Internet]. [2008] [cited 2011 Maio 10]. Disponível em: http://apps.einstein.br/atlas/2008_especiais_avc.asp?ano=5\&id1=3\&id2=1

58. André C, Curioni CC, Braga da Cunha C, Veras R. Progressive decline in stroke mortality in Brazil from 1980 to 1982, 1990 to 1992, and 2000 to 2002. Stroke. 2006; 37(11):2784-9. 
59. Murray CJ, Lopez AD. Alternative projections of mortality and disability by cause 1990-2020: Global Burden of Disease Study. Lancet. 1997; 349(9064):1498-504.

60. Kaup AO, Pieri A, Coelho FM. Acidente vascular cerebral protocolos gerenciados do Hospital Israelita Albert Einstein. Barueri: Manole; 2009.

61. Miyadahira AM. Processo de ensino-aprendizagem de habilidades psicomotoras em procedimentos de emergência: avaliação e atendimento primário [livre-docência]. São Paulo: Universidade de São Paulo, Escola de Enfermagem;, 1997

62. Troncon LE, Maffei CM. A incorporação de recursos de simulação no curso de graduação em medicina da Faculdade de Medicina de Ribeirão Preto USP. Medicina (Ribeirão preto). 2007; 40(2):153-61.

63. Benner P, Queirós AA, Lourenço B. De iniciado a perito: excelência e poder na prática clínica de enfermagem. Coimbra: Quarteto; 2001.

64. Sprinthall N. Psicologia educacional. Lisboa: Mc Graw -Hill, 1993.

65. Santos JD. Orientações motivacionais e estratégias de aprendizagem no ensino superior: Contributos para a compreensão da assiduidade ás aulas dos estudantes de enfermagem [dissertação]. Coimbra: Universidade de Coimbra, Faculdade de Psicologia de Ciências da Educação; 2008.

66. Pazin Filho A. Características do aprendizado do adulto. Medicina (Ribeirão Preto) 2007; 40(1):7-16.

67. Hwang SY, Kim MJ. A comparison of problem-based learning and lecturebased learning in an adult health nursing course. Nurse Educ Today. 2006; 26(4):315-21. 
68. Vannuchi MT, Haddad MC, Takahashi OC, Hirazawa AS, Rodrigues IG, Cordeiro BR.. Enfermagem médico-cirúrgica: inovação no processo de ensino. Semina. 1992;13(2):46-51.

69. Mira VL. Avaliação de programas de treinamento e desenvolvimento da equipe de enfermagem de dois hospitais do município de São Paulo [Livredocência]. São Paulo: Universidade de São Paulo, Escola de Enfermagem da; 2010.

70. Paladino Y, Peres HH. E-learning :estudo comparativo da apreensão do conhecimento entre enfermeiros. Rev Latinoam Enferm [Internet]. 2007 [citado 2012 Jan 10]; 15(3): [about 9 p.].

Disponível em: http://www.scielo.br/pdf/rlae/v15n3/pt v15n3a06.pdf 
Apêndices 


\section{APÊNDICES}

\section{APÊNDICE 1 - TERMO DE CONSENTIMENTO LIVRE E ESCLARECIDO}

Pesquisadoras: Enfa Tania Oliveira Lopes (mestranda), Profa Dra Heloísa Helena

Ciqueto Peres (orientadora)

Título da pesquisa: Simulação realística e aula expositiva: comparação entre metodologias educacionais no ensino de graduação em enfermagem

Nome do aluno:

\section{Caro aluno:}

Você está sendo convidado a participar como voluntário da pesquisa intitulada Simulação realística e aula expositiva: comparação entre metodologias educacionais no ensino de graduação em enfermagem, como discente do Curso de Graduação em Enfermagem, devendo cursar a disciplina Práticas Atuais de Enfermagem.

Esta pesquisa se refere ao Trabalho de Conclusão de Curso de PósGraduação Strico Sensu (Mestrado), que tem como objetivos: comparar o grau de apreensão do conhecimento dos discentes antes e após a utilização da estratégia de ensino na aula expositiva e no Centro de Simulação Realística (CSR); comparar o grau de apreensão do conhecimento dos discentes após a utilização da estratégia de ensino no CSR e na aula expositiva semanalmente até quatro semanas; identificar a avaliação de reação dos discentes sobre o uso do CSR na graduação de enfermagem.

Haverá um sorteio (randomização), por meio do qual você poderá participar do grupo controle, cujos alunos terão uma aula expositiva de 60 minutos sobre o reconhecimento dos sinais e sintomas de alerta para 0 paciente com suspeita de Acidente Vascular Cerebral (AVC) ou poderá participar do grupo experimental, cujos alunos serão submetidos a 30 minutos de práticas monitoradas e 30 minutos de simulação sobre o mesmo tema.

Tanto os alunos do grupo controle quanto os do grupo experimental serão convidados a responder um instrumento de coleta de dados antes e após a intervenção educativa, composto por cinco questões e durante as intervenções pedagógicas. Seu nome não será utilizado em qualquer fase da pesquisa, o que garante seu anonimato.

Gostaríamos de deixar claro que sua participação é voluntária e que poderá recusar-se a participar ou retirar seu consentimento ou ainda descontinuar sua participação, se assim o preferir. Entendendo que se trata de um grupo vulnerável, não haverá nenhum prejuízo curricular aos alunos que se recusarem a fazer parte deste estudo, pois as abordagens serão realizadas fora do horário das aulas programadas na disciplina, não tendo, 
assim, nenhum impacto na mesma. Da mesma forma, não haverá benefícios aos alunos que aceitarem participar da pesquisa.

Por não envolver riscos aos participantes, não estão previstos ressarcimentos ou indenizações.

Desde já agradecemos sua atenção e participação e colocamo-nos à disposição para mais informações, a respeito do estudo, a qualquer momento.Em caso de dúvidas e outros esclarecimentos sobre esta pesquisa você poderá entrar em contato com as autoras: Tania Oliveira Lopes telefone (11)2679.4779, e-mail: tlopes1@hotmail.com ou Heloísa Helena Ciqueto Peres telefone (11)3061.7554, e-mail: hhcperes@usp.br e/ou com o Comitê de Ética em Pesquisa do Hospital israelita Albert Einstein (CEP Einstein) no telefone (11)2151.3729.

Eu confirmo que Tania Oliveira Lopes explicou-me os objetivos desta pesquisa, bem como a forma de participação. As alternativas para minha participação também foram discutidas. Eu li e compreendi este Termo de Consentimento Livre e Esclarecido. Portanto, concordo em dar meu consentimento para participar como voluntário desta pesquisa.

São Paulo, $/ 2010$

Assinatura do Aluno

Assinatura da Pesquisadora 


\section{APÊNDICE 2 - PLANILHA DOS ALUNOS COM AS VARIÁVEIS A SER UTILIZADA NO PROCESSO DE RANDOMIZAÇÃO}

\begin{tabular}{|c|c|c|c|c|c|c|c|c|}
\hline \multirow[b]{2}{*}{$\begin{array}{l}\text { ALUNO } \\
\text { FEHIAE }\end{array}$} & \multicolumn{2}{|c|}{ 1'ano 2008} & \multicolumn{2}{|c|}{ 2Ano 2009} & \multicolumn{4}{|c|}{ Dados Pessoais } \\
\hline & $\begin{array}{l}\text { Média } \\
\text { 10S }\end{array}$ & $\begin{array}{l}\text { Média } \\
2 \cong S\end{array}$ & $\begin{array}{c}\text { Média } \\
1 \text { 影 }\end{array}$ & $\begin{array}{l}\text { Média } \\
2^{\circ}\end{array}$ & $\begin{array}{l}\text { APC } \\
2009\end{array}$ & $\begin{array}{l}\text { Trabalha na } \\
\text { Saúde }\end{array}$ & IDADE & Gênero \\
\hline 1 & 7,0 & 7,0 & 7,5 & 7,8 & 5,4 & Não & 20 & Feminino \\
\hline 2 & 9,0 & 9,5 & 8,2 & 9,2 & 7,1 & Não & 20 & Feminino \\
\hline 3 & 8,0 & 9,1 & 8,6 & 8,4 & 4,8 & Não & 22 & Feminino \\
\hline 4 & 8,3 & 8,1 & 8,0 & 8,3 & 4,9 & Não & 20 & Feminino \\
\hline 5 & 7,4 & 7,2 & 8,0 & 7,6 & 6,2 & Não & 21 & Feminino \\
\hline 6 & 8,3 & 8,7 & 8,6 & 8,5 & 6,6 & Não & 22 & Feminino \\
\hline 7 & 9,5 & 9,1 & 9,3 & 8,8 & 7,7 & Sim & 32 & Feminino \\
\hline 8 & 8,3 & 8,5 & 8,3 & 8,6 & 5,1 & Não & 22 & Feminino \\
\hline 9 & 8,5 & 8,4 & 7,9 & 8,5 & 5,9 & Não & 21 & Feminino \\
\hline 10 & 8,8 & 7,6 & 7,5 & 8,2 & 6,3 & Não & 22 & Feminino \\
\hline 11 & 7,6 & 8,9 & 8,7 & 9,2 & 6,0 & Não & 21 & Feminino \\
\hline 12 & 8,3 & 9,0 & 8,0 & 8,4 & 6,9 & Não & 20 & Feminino \\
\hline 13 & 9,3 & 9,6 & 8,2 & 9,1 & 6,3 & Não & 21 & Feminino \\
\hline 14 & 8,5 & 8,5 & 8,2 & 8,7 & 7,4 & Não & 21 & Feminino \\
\hline 15 & 8,0 & 8,5 & 7,4 & 8,1 & 7,7 & Não & 24 & Feminino \\
\hline 16 & 8,3 & 8,8 & 8,3 & 8,3 & 7,4 & Não & 20 & Feminino \\
\hline 17 & 10,0 & 8,1 & 7,6 & 7,8 & 5,9 & Não & 22 & Feminino \\
\hline 18 & 7,0 & 7,9 & 7,2 & 7,1 & 4,5 & Não & 23 & Feminino \\
\hline 19 & 8,2 & 8,7 & 8,3 & 8,8 & 6,0 & Não & 21 & Feminino \\
\hline 20 & 8,4 & 9,4 & 8,6 & 8,9 & 6,5 & Não & 39 & Feminino \\
\hline 21 & 9,3 & 8,6 & 8,6 & 8,8 & 6,3 & Não & 20 & Feminino \\
\hline 22 & 0,0 & 9,3 & 7,7 & 8,3 & 6,2 & Sim & 33 & Feminino \\
\hline 23 & 8,5 & 7,8 & 7,8 & 7,5 & 6,8 & Não & 20 & Masculino \\
\hline 24 & 7,8 & 7,3 & 8,0 & 7,7 & 5,3 & Não & 26 & Feminino \\
\hline 25 & 9,3 & 8,7 & 7,7 & 8,7 & 6,9 & Não & 20 & Feminino \\
\hline 26 & 7,0 & 7,7 & 7,4 & 8,3 & 6,5 & Não & 21 & Feminino \\
\hline 27 & 9,3 & 8,9 & 8,7 & 8,9 & 6,8 & Sim & 29 & Feminino \\
\hline 28 & 8,5 & 7,6 & 8,0 & 8,0 & 7,7 & Sim & 27 & Masculino \\
\hline 29 & 8,8 & 8,4 & 8,4 & 8,0 & 5,9 & Não & 21 & Feminino \\
\hline 30 & 7,8 & 7,5 & 7,5 & 7,4 & 6,3 & Não & 18 & Feminino \\
\hline 31 & 9,3 & 8,6 & 8,1 & 8,5 & 7,7 & Não & 45 & Feminino \\
\hline 32 & 7,0 & 8,5 & 8,3 & 8,5 & 7,8 & $\operatorname{sim}$ & 39 & Feminino \\
\hline 33 & 9,0 & 7,2 & 8,4 & 8,1 & 7,2 & Não & 21 & Feminino \\
\hline 34 & 9,0 & 8,5 & 8,0 & 8,6 & 7,1 & Não & 21 & Feminino \\
\hline 35 & 9,5 & 8,3 & 8,8 & 8,3 & 7,2 & Sim & 24 & Feminino \\
\hline 36 & 7,8 & 7,0 & 7,5 & 7,4 & 4,9 & Não & 20 & Feminino \\
\hline 37 & 8,1 & 8,0 & 8,2 & 8,1 & 6,8 & Não & 21 & Feminino \\
\hline 38 & 8,0 & 8,8 & 7,9 & 8,4 & 5,9 & Não & 20 & Feminino \\
\hline 39 & 8,0 & 7,0 & 7,3 & 7,0 & 0,0 & Não & 38 & Feminino \\
\hline 40 & 7,1 & 7,4 & 7,5 & 7,5 & 7,1 & Não & 20 & Masculino \\
\hline 41 & 8,3 & 6,3 & 7,2 & 6,3 & 3,8 & Não & 20 & Feminino \\
\hline 42 & 7,0 & 7,0 & 8,1 & 7,7 & 6,3 & Não & 20 & Feminino \\
\hline 43 & 7,0 & 7,4 & 6,6 & 7,4 & 5,8 & Não & 20 & Feminino \\
\hline 44 & 7,5 & 8,8 & 8,2 & 7,6 & 0,0 & Não & 24 & Masculino \\
\hline
\end{tabular}




\section{APÊNDICE 3 RELATÓRIO DO LABORATÓRIO DE ESTATÍSTICA - PROCESSO DE RANDOMIZAÇÃO DOS GRUPOS}

\section{EE TSP}

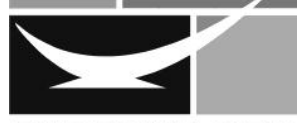

ENFERMAGEM

\author{
LABORATÓRIO DE BIOESTATÍSTICA \\ RELATÓRIO ESTATÍSTICO - No.:01 DATA:25/08/2010 \\ CENTRO DE SIMULAÇÃO REALÍSTICA A \\ TECNOLOGIA EDUCACIONAL UTILIZADO NA \\ GRADUAÇÃO EM ENFERMAGEM \\ TÂNIA OLIVEIRA LOPES
}

01) Após a amostragem dos elementos, foi relizada a comparação das médias das notas entre os dois grupos, para verificar se as médias são iguais. Para comparar as médias, pode-se utilizar o teste-t, mas primeiro é necessário verificar a normalidade dos dados pelo teste de Kolmogorov-Smirnov e a homogeneidade das variâncias.

\begin{tabular}{|ll|r|}
\hline \multicolumn{2}{|c|}{ One-Sample Kolmogorov-Smirnov Test } \\
\hline N & & Nota_2 \\
Normal Parameters ${ }^{\mathrm{a}, \mathrm{b}}$ & Mean & 44 \\
& Std. Deviation & 6,0659 \\
Most Extreme Differences & Absolute & 1,63294 \\
& Positive &, 210 \\
& Negative &, 144 \\
Kolmogorov-Smirnov Z & &,- 210 \\
Asymp. Sig. (2-tailed) & & 1,390 \\
\end{tabular}

a. Test distribution is Normal.

b. Calculated from data.

Os dados não têm distribuição normal $(\mathrm{p}=0,042)$. Isso seria um impedimento para usar o teste-t se as variâncias não fossem homogêneas (verificada pelo teste de Levene abaixo) 
Descritiva da média dos dois grupos:

\section{Group Statistics}

\begin{tabular}{|ll|r|r|r|r|}
\hline & Grupo_2 & $\mathrm{N}$ & Mean & Std. Deviation & Std. Error Mean \\
\hline Nota_2 & Experimental & 22 & 6,1682 & 1,65425 &, 35269 \\
& Controle & 22 & 5,9636 & 1,64362 &, 35042 \\
\hline
\end{tabular}

O teste de Levene indica que as variâncias são homogêneas $(p=0,999)$, então o teste-t pode ser utilizado para comparar as médias dos dois grupos:

\begin{tabular}{|c|c|c|c|c|}
\hline \multicolumn{5}{|c|}{ Independent Samples Test } \\
\hline & & & \multicolumn{2}{|c|}{ Nota_2 } \\
\hline & & & $\begin{array}{c}\text { Equal variances } \\
\text { assumed }\end{array}$ & $\begin{array}{c}\text { Equal variances } \\
\text { not assumed }\end{array}$ \\
\hline Levene's Test for Equality of & $\mathrm{F}$ & &, 000 & \\
\hline Variances & Sig. & & ,999 & \\
\hline \multirow[t]{7}{*}{ t-test for Equality of Means } & $\mathrm{t}$ & & ,411 & ,411 \\
\hline & df & & 42 & 41,998 \\
\hline & Sig. (2-tailed) & & 683 & ,683 \\
\hline & Mean Difference & & ,20455 & ,20455 \\
\hline & Std. Error Difference & & ,49718 & ,49718 \\
\hline & $95 \%$ Confidence Interval of & Lower &,- 79879 &,- 79880 \\
\hline & the Difference & Upper & 1,20789 & 1,20789 \\
\hline
\end{tabular}

O teste-t indica que as médias dos dois grupos não são diferentes $(p=0,683)$. 


\section{APÊNDICE 4 - AMOSTRAGEM DA DIVISÃO DOS ALUNOS PROCESSO DE RANDOMIZAÇÃO PARA MONTAGEM DO GRUPO EXPERIMENTAL E GRUPO CONTROLE}

\begin{tabular}{|c|c|c|c|}
\hline № Alunos & Grupo & № Alunos & Grupo \\
\hline 1 & Controle & 1 & Experimental \\
\hline 2 & Controle & 2 & Experimental \\
\hline 3 & Controle & 3 & Experimental \\
\hline 4 & Controle & 4 & Experimental \\
\hline 5 & Controle & 5 & Experimental \\
\hline 6 & Controle & 6 & Experimental \\
\hline 7 & Controle & 7 & Experimental \\
\hline 8 & Controle & 8 & Experimental \\
\hline 9 & Controle & 9 & Experimental \\
\hline 10 & Controle & 10 & Experimental \\
\hline 11 & Controle & 11 & Experimental \\
\hline 12 & Controle & 12 & Experimental \\
\hline 13 & Controle & 13 & Experimental \\
\hline 14 & Controle & 14 & Experimental \\
\hline 15 & Controle & 15 & Experimental \\
\hline 16 & Controle & 16 & Experimental \\
\hline 17 & Controle & 17 & Experimental \\
\hline 18 & Controle & 18 & Experimental \\
\hline 19 & Controle & 19 & Experimental \\
\hline 20 & Controle & 20 & Experimental \\
\hline 21 & Controle & 21 & Experimental \\
\hline 22 & Controle & 22 & Experimental \\
\hline
\end{tabular}




\section{APÊNDICE 5 - QUESTIONÁRIO PARA COLETA DE DADOS}

\section{Parte I - Caracterização da Amostra.}

\section{Número de Matrícula FEHIAE:}

Data

Favor preencher o questionário, assinalando apenas um item de cada:

1- Qual é a sua idade?

anos

2- Gênero:

( ) masculino

( ) feminino

3- Você trabalha ou trabalhou na área da saúde?
( ) Sim
( ) Não

Se afirmativo responda as questões $A$ e $B$ :

A- Qual a sua função e tempo de Atuação?

( ) Auxiliar de Enfermagem Tempo de atuação

( ) Técnico de Enfermagem Tempo de atuação

( ) Outra atividade__ Tempo de atuação

B- Qual(s)Unidades que você atuou na área da saúde?

( ) Clínica Médica

( )Clínica Cirúrgica

( ) Unidade de Terapia Intensiva ou

( ) Unidade de Pronto Atendimento

( ) Outras Unidades

Parte II- Questionário de Coleta de Dados Pré Intervenção Número de Matrícula FEHIAE

Data 
1-Escreva abaixo os sinais e sintomas clássicos do AVC, que são conhecidos mundialmente

$1-$

2-

3-

4-

$5-$

2- Leia o caso abaixo e escreva as condutas assistenciais imediatas, de acordo com a prioridade de atendimento, que você no papel de uma enfermeira de Clínica Médica deveria implementar:

Sr. JRS, 62 anos, foi admitido em uma Unidade de Clínica Médica com diagnóstico de Pneumonia. Por volta das 08:30h o paciente relatou que sentiu-se estranho pela manhã. Informou que quando chegou a bandeja do café da manhã, ao tentar pegar a xícara do café, não conseguiu erguê-la, pois sentiu a "mão fraca". Relatou, também, alteração na visão e formigamento na perna direita.

Na história clínica o Sr JRS relata fazer tratamento de hipertensão arterial sistêmica (HAS), ser tabagista (fuma 1 maço de cigarros por dia) e ter tido, há 6 meses, um episódio de Ataque Isquêmico Transitório (AIT), fazendo uso de antiagregante plaquetário (AAS).

$1-$

2-

3-

4-

5-

6-

7- 


\section{APÊNDICE 6 - QUESTIONÁRIO PARA COLETA DE DADOS- PÓS INTERVENÇÃO}

Número de Matrícula FEHIAE

Data

1-Escreva abaixo os sinais e sintomas clássicos do AVC, que são conhecidos mundialmente

1 -

2-

3-

4-

$5-$

2- Leia o caso abaixo e escreva as condutas assistenciais imediatas, de acordo com a prioridade de atendimento, que você no papel de uma enfermeira de Clínica Médica deveria implementar:

Sr. JRS, 62 anos, foi admitido em uma Unidade de Clínica Médica com diagnóstico de Pneumonia. Por volta das 08:30h o paciente relatou que sentiu-se estranho pela manhã. Informou que quando chegou a bandeja do café da manhã, ao tentar pegar a xícara do café, não conseguiu erguê-la, pois sentiu a "mão fraca". Relatou, também, alteração na visão e formigamento na perna direita.

Na história clínica o Sr JRS relata fazer tratamento de hipertensão arterial sistêmica (HAS), ser tabagista (fuma 1 maço de cigarros por dia) e ter tido, há 6 meses, um episódio de Ataque Isquêmico Transitório (AIT), fazendo uso de antiagregante plaquetário (AAS).

$1-$

2-

3-

4-

5-

$6-$

7- 


\section{APÊNDICE 7 - INSTRUMENTO DE AVALIAÇÃO DE SATISFAÇÃO PÓS INTERVENÇÃO}

Número de Matrícula FEHIAE

1.Aprendi os sinais e sintomas do Acidente Vascular Cerebral (AVC).

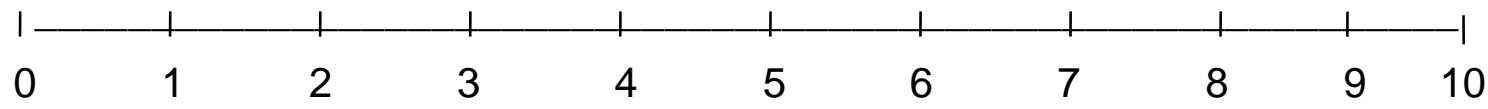

2. Aula proporcionou uma visão teórica a respeito do tema.

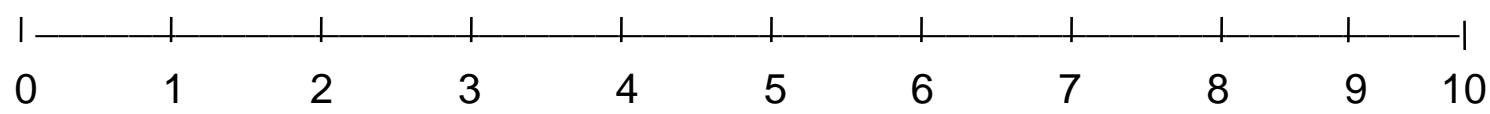

3.A estratégia foi adequada aos objetivos propostos.

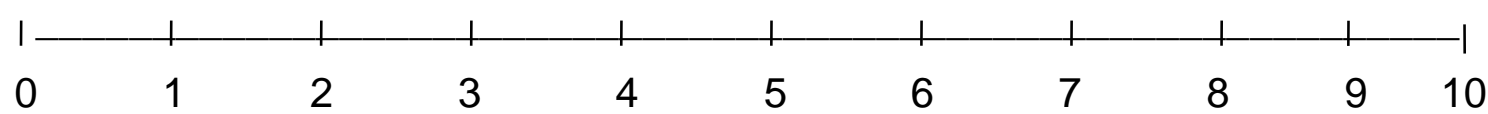

4.Compreendi as condutas assistenciais preconizadas frente ao paciente com suspeita de Acidente Vascular Cerebral (AVC).

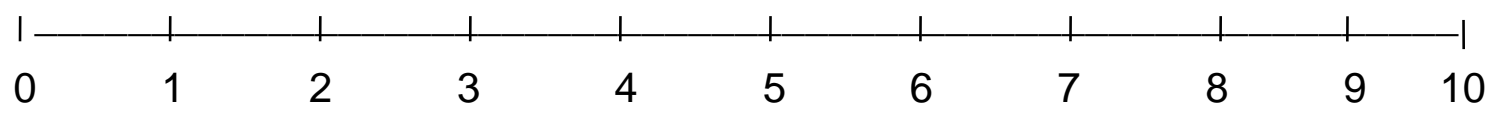

5.O conteúdo obordado correspondeu aos objetivos propostos para a aula.

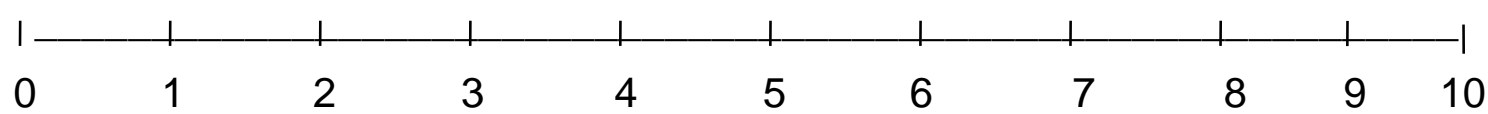

6. Não tive dificuldades para compreender o conteúdo abordado.

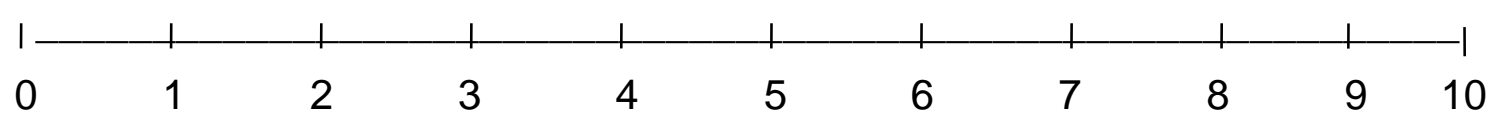

7.Mantive boa interação com o professor que ministrou a aula.

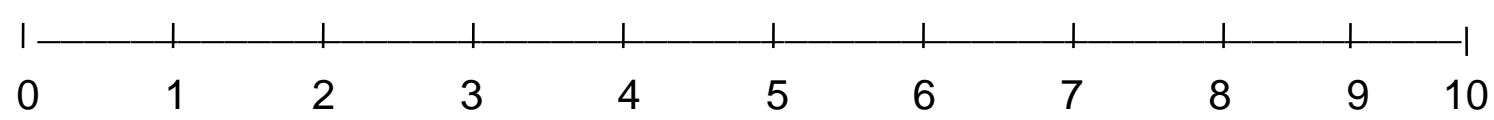

8.Sinto-me mais preparado para o exercício profissional.

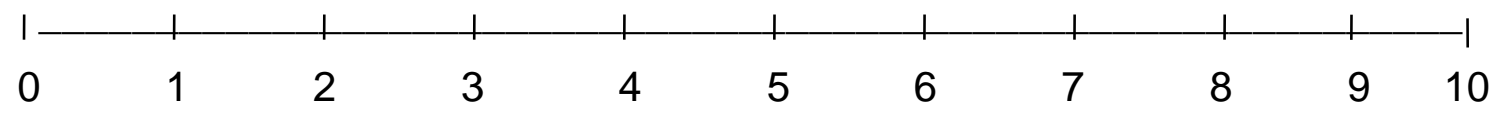

9.A professora tem domínio do conteúdo da aula.

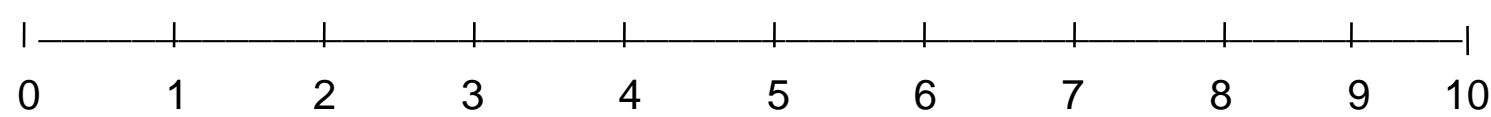


10. A aula me fez enxergar aspectos que eu não percebia antes sober o tema AVC.

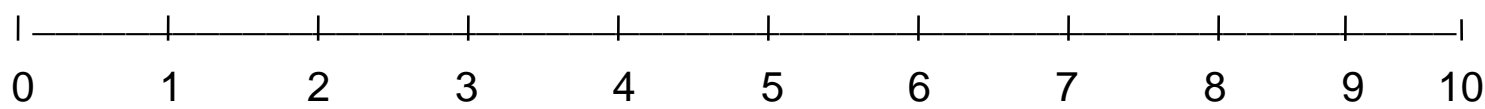

11 A aula fez eu enxergar aspectos que eu não percebia antes sobre o tema AVC.

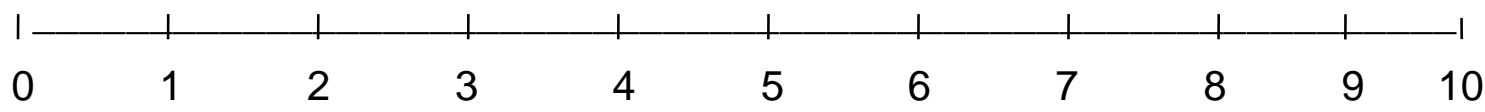

12. Tenho mais segurança para adotar condutas assistenciais frente ao paciente com suspeita de AVC.

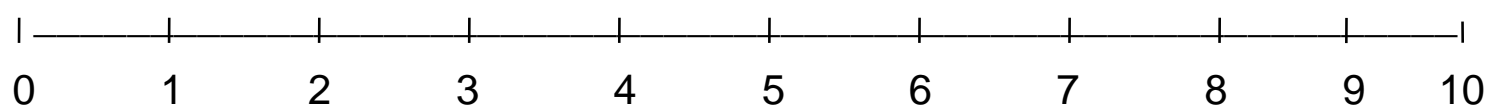

13. A aula foi dinâmica.

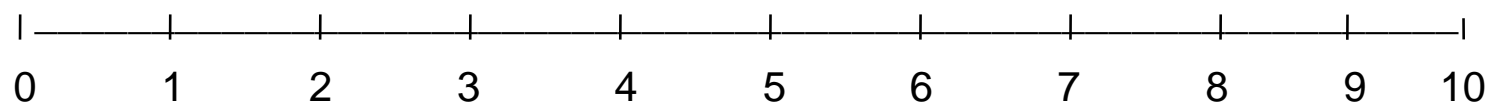

14. Os recursos didáticos utilizados na aula foram adequados.

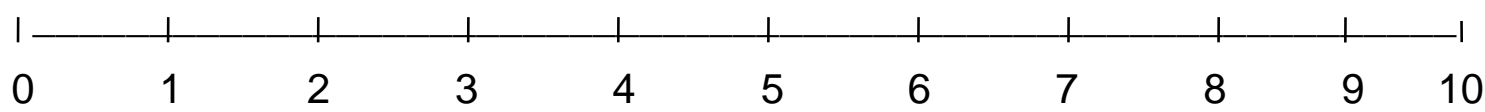

15. A aula proporcionou relação entre teoria e prática.

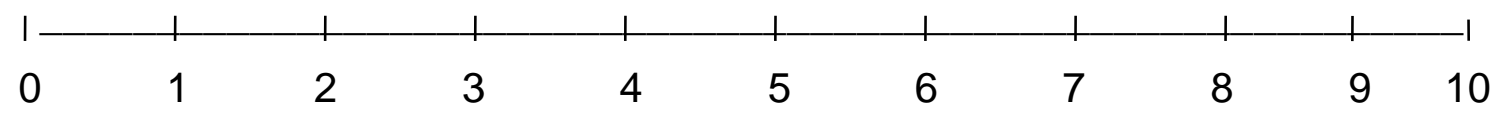

16. Gosto da assistência prestada ao paciente neurológico.

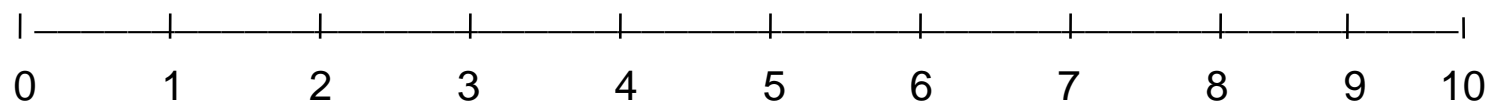

17.Gostaria de atuar na área de neurologia.

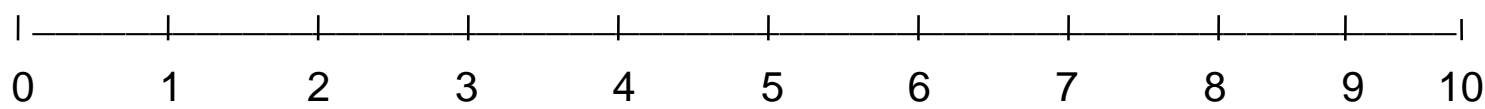

18.A professora demonstrou atenção as dúvidas dos participantes.

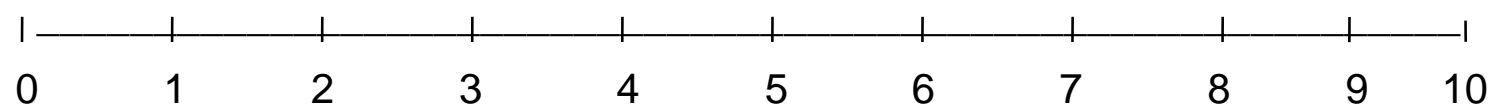

19. A aula proporcionou uma aprendizagem significativa.

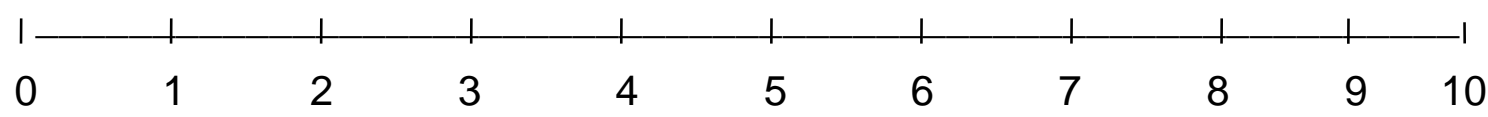

\section{Comentários e Sugestões:}




\section{APÊNDICE 8- GABARITO DO QUESTIONÁRIO DE COLETA DE \\ DADOS- PRÉ E PÓS INTERVENÇÃO}

Cada questão deste Pré e Pós Teste valerá 10 pontos

Parte II- Instrumento de Coleta de Dados Pré e Pós Teste

Número de Matrícula

FEHIAE:

Data

Esta questão vale 10 pontos, sendo atribuídos 2.0 pontos para cada sinal e sintoma citado corretamente.

Escreva abaixo os sinais e sintomas clássicos do AVC, que são conhecidos mundialmente

1- Formigamento ou perda de força de um lado do corpo (2.0)

2-Alteração da visão (2.0)

3- Alteração da fala (2.0)

4- Alteração da marcha (2.0)

5-Cefaléia (2.0)

2- Leia o caso abaixo e escreva as condutas assistenciais imediatas, de acordo com a prioridade de atendimento, que você no papel de uma enfermeira de Clínica Médica deveria implementar:

Sr. JRS, 62 anos, foi admitido em uma Unidade de Clínica Médica com diagnóstico de Pneumonia. Por volta das 08:30h o paciente relatou que sentiu-se estranho pela manhã. Informou que quando chegou a bandeja do café da manhã, ao tentar pegar a xícara do café, não conseguiu erguê-la, pois sentiu a "mão fraca". Relatou, também, alteração na visão e formigamento na perna direita.

$\mathrm{Na}$ história clínica o Sr JRS relata fazer tratamento de hipertensão arterial sistêmica (HAS), ser tabagista (fuma 1 maço de cigarros por dia) e ter tido, há 6 meses, um episódio de Ataque Isquêmico Transitório (AIT), fazendo uso de antiagregante plaquetário (AAS). 
1-Apresentou-se ao paciente e ouviu e coletou a estória clínica do paciente (1.0)

2- Realizou o exame clínico / neurológico (2.0)

3-Iniciou o ABCD (2.0)

4-Puncionou acesso venoso periférico (1.0)

5- Verificou glicemia capilar (2.0)

6-Chamou o médico (1.0)

7-Explicou ao paciente e familiares sobre as condutas tomadas no caso (1.0)

Considerações:

1- A nota final do pré e pós teste valerá 10.0 pontos, calculados pela soma aritmética dos itens 1 e 2 da parte II do Instrumento de Coleta de Dados.

2-A seqüência esperada é a relacionada acima, apenas será considerada a exceção nos itens 4 e 5, onde a ordem não será avaliada. 


\section{APÊNDICE 9-PLANO DE AULA - INTERVENÇÃO DO GRUPO CONTROLE- AULA EXPOSITIVA DIALOGADA}

Curso de Graduação em Enfermagem da FEHIAE

Práticas Atuais de Enfermagem

Profa Tania Oliveira Lopes

27-Setembro - 2010

\section{Plano de Aprendizagem}

Curso: Enfermagem- Nível Superior -Enfermeiro

Disciplina: Práticas Atuais de Enfermagem

Público Alvo: alunos do Curso de Graduação de Enfermagem

Data: 27 de setembro de 2010

Duração: 80 minutos

Horário: das 10:00 às 11:20 horas

Docente: Tania

Título da aula: Reconhecimento dos Sinais e Sintomas do AVC e Condutas Assistenciais ao Pacientes com AVCl em fase Aguda

\section{Objetivo Geral}

1-Instrumentalizar o aluno para que ele possa reconhecer os sinais e sintomas do paciente com Acidente Vascular Cerebral (AVC).

2-Instrumentalizar o aluno para que quando ele se depare com o paciente vítima de AVC em unidade de CMC, instale as condutas assistenciais ao paciente com suspeita de AVC.

\section{Objetivos do professor}

1-Apresentar parâmetros fisiológicos do Acidente Vascular Cerebral.

Apresentar os sinais e sintomas clássico do paciente com Acidente Vascular Cerebral

2-Discorrer sobre as condutas assistenciais imediatas a serem instituídas no paciente com Acidente Vascular Cerebral

\section{Objetivos do aluno}

1-Identificar os sinais e sintomas do Acidente Vascular Cerebral

2-Reconhecer as condutas assistenciais a serem instituídas mediante o paciente com AVC

\section{Conteúdo}

Aspectos fisiológicos do Acidente Vascular Cerebral

Sinais e Sintomas do Acidente Vascular Cerebral

Condutas clínicas a serem instituidas pelo enfermeiro mediante um paciente com você

\section{Estratégias de Ensino}

Aula expositiva dialogada 
APÊNDICE 10- AULA ELABORADA PARA A INTERVENÇÃO DO GRUPO CONTROLE

\section{EE TSSP}

ENFERMAGEM

Aula Dialogada Expositiva

Tema:Reconhecimento dos Sinais e Sintomas de Alerta para o Paciente com Suspeita de Acidente Vascular Cerebral

\section{Prof $^{a}$ Tania Oliveira Lopes}

Faculdade de Enfermagem do Hospital Israelita Albert Einsten

Grupo Controle

27.09.2010

\section{Objetivos da Aula}

1-Instrumentalizar o aluno para que ele possa reconhecer os sinais e sintomas do paciente com Acidente Vascular Cerebral (AVC).

2-Instrumentalizar o aluno para que quando ele se depare com o paciente vítima de AVC, saiba as condutas clínicas imediatas a serem instituídas. 


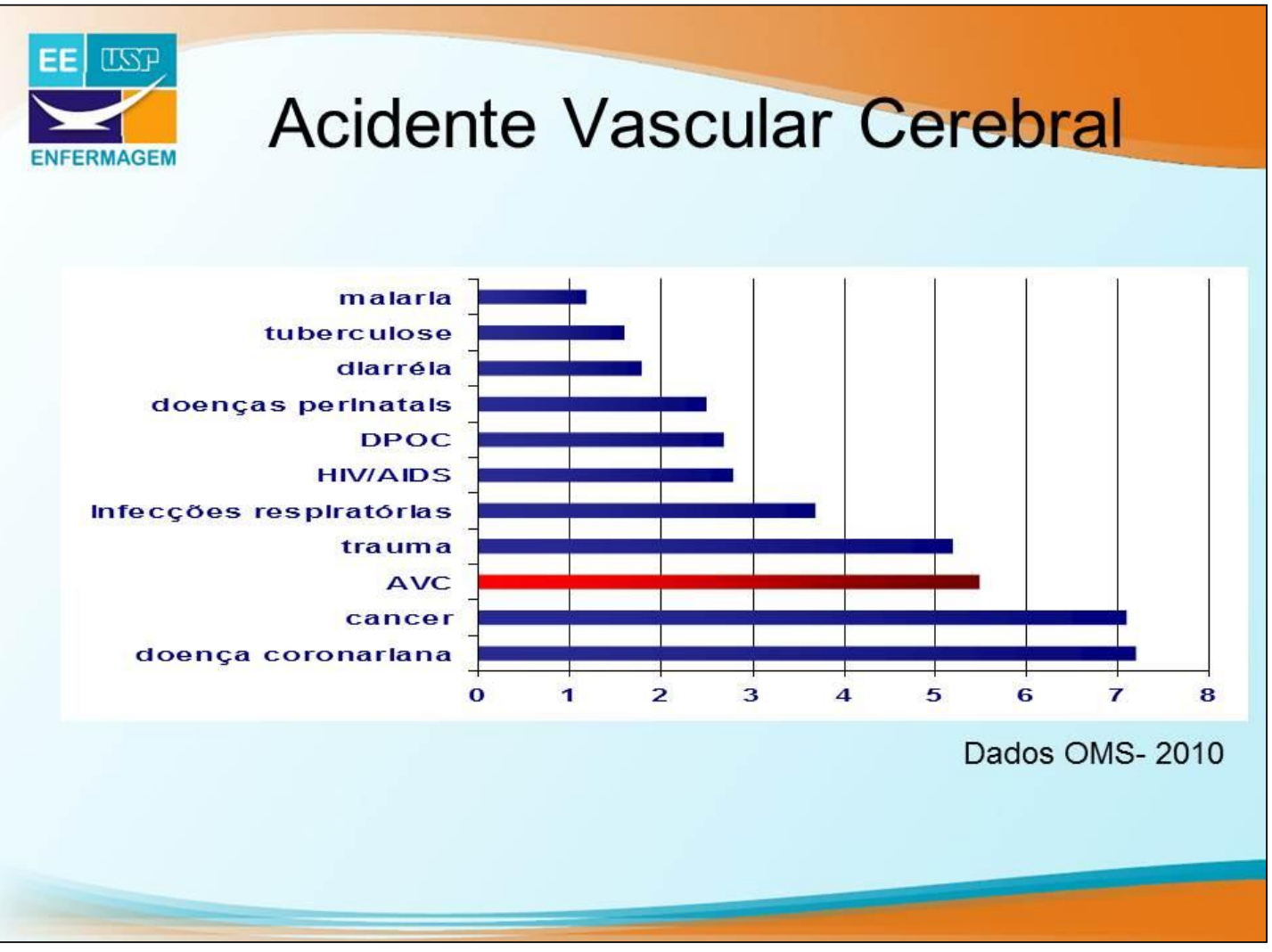

EE एTS

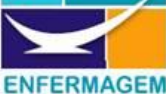

\section{AVC é uma emergência?}

\section{Emergência médica} semelhante com o IAM

- Indicação do tratamento em centros especializados

- CTI ou unidades específicas (Evidência I)

Brainin M. et al, 2004

Unidades de AVC devem coordenar

- > eficiência da equipe interdisciplinar

- Redução do tempo de internação

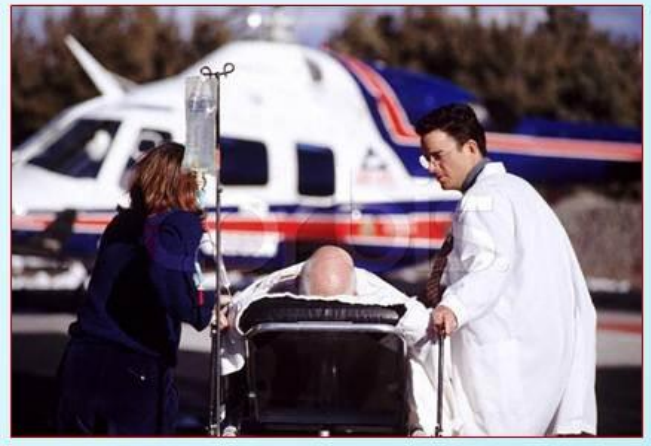

- Redução de mortalidade hospitalar 

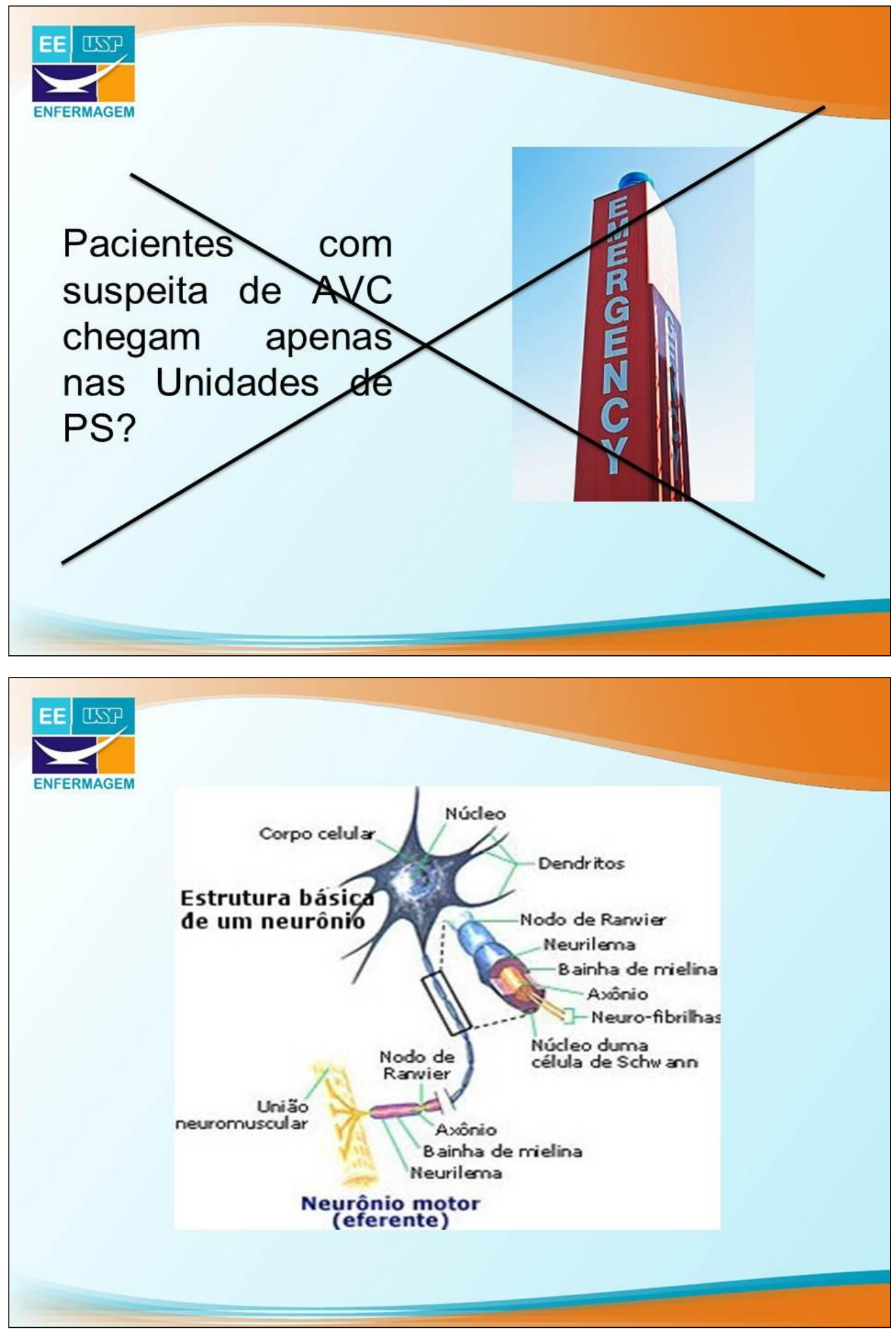


\section{EE TSP \\ ENFERMAGEM}

\section{E porque???}

Temos uma porcentagem de pacientes internados que são portencialmente riscos para desenvolver a

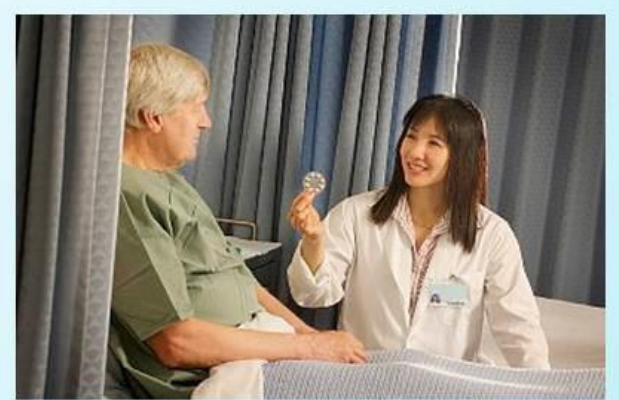
doença durante a internação

\section{A diferença......}

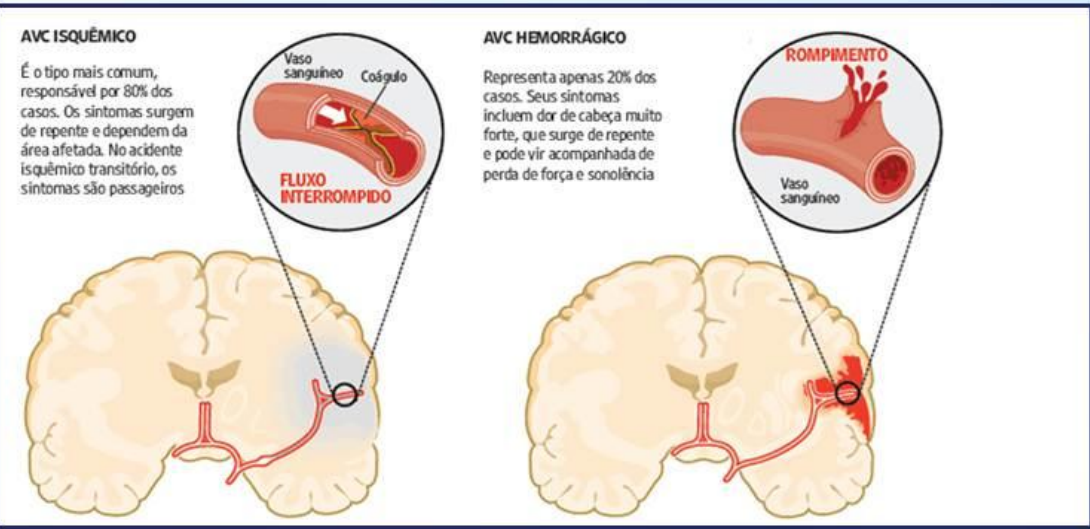



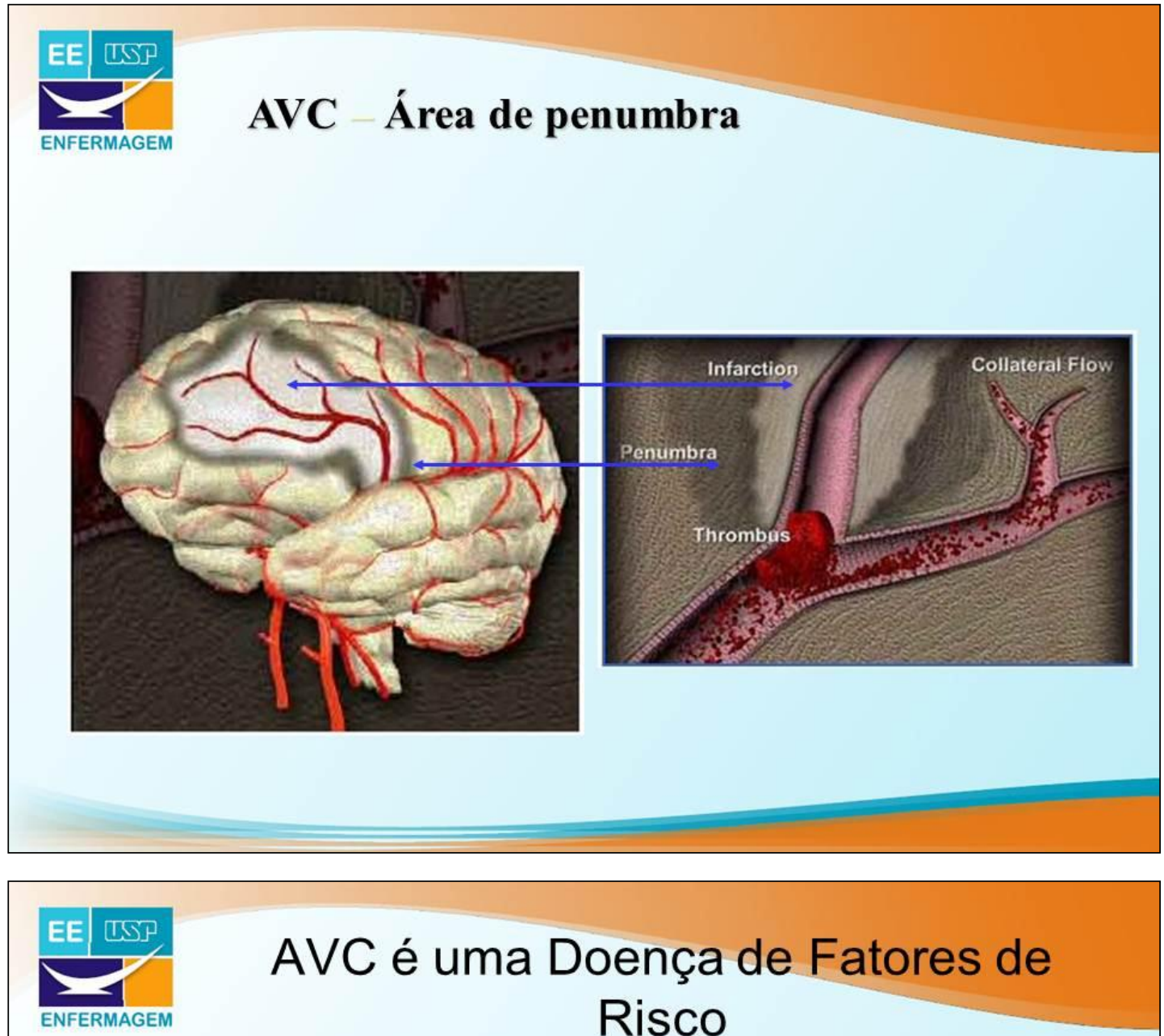

\section{AVC é uma Doença de Fatores de Risco}
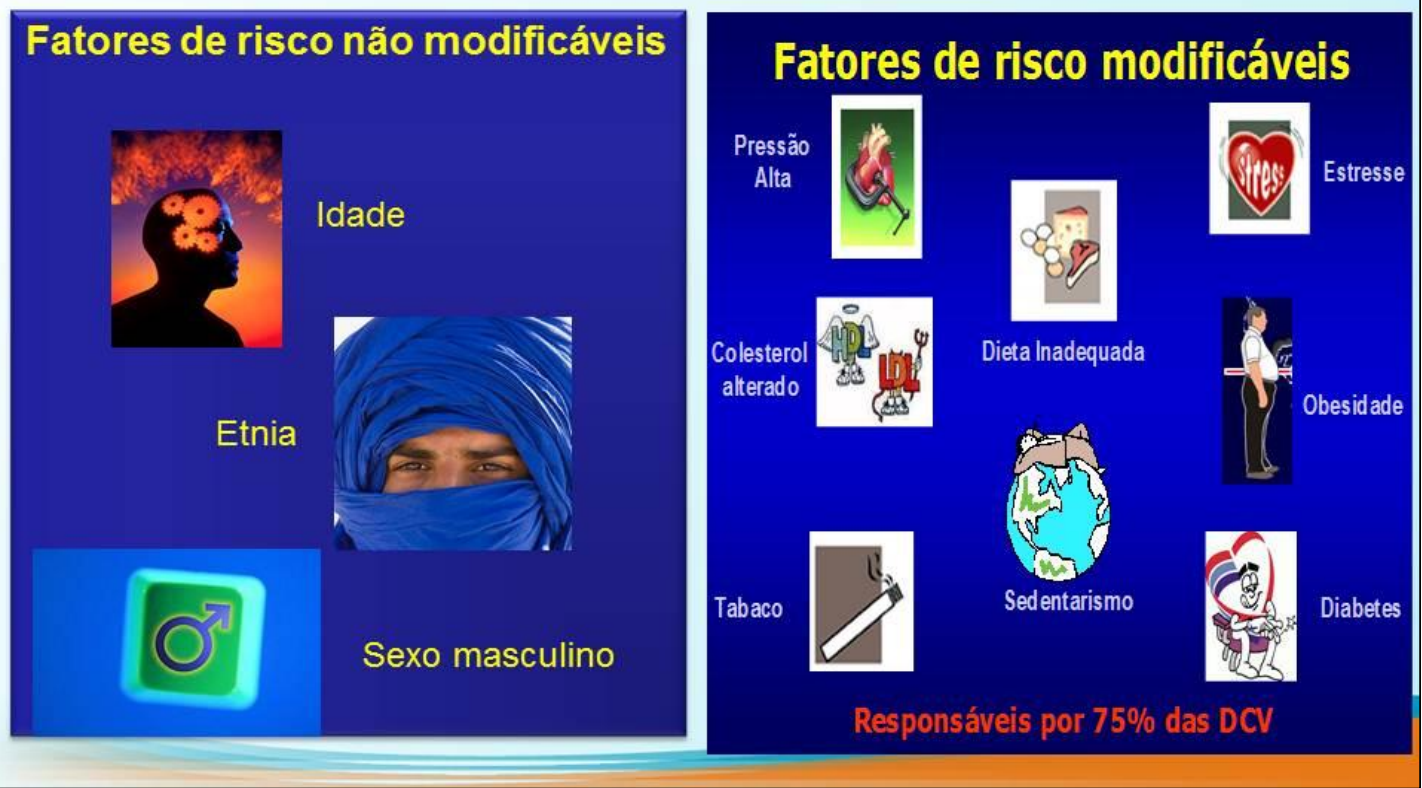


\section{EE एSTP

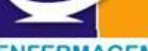

\section{Sinais e Sintomas}
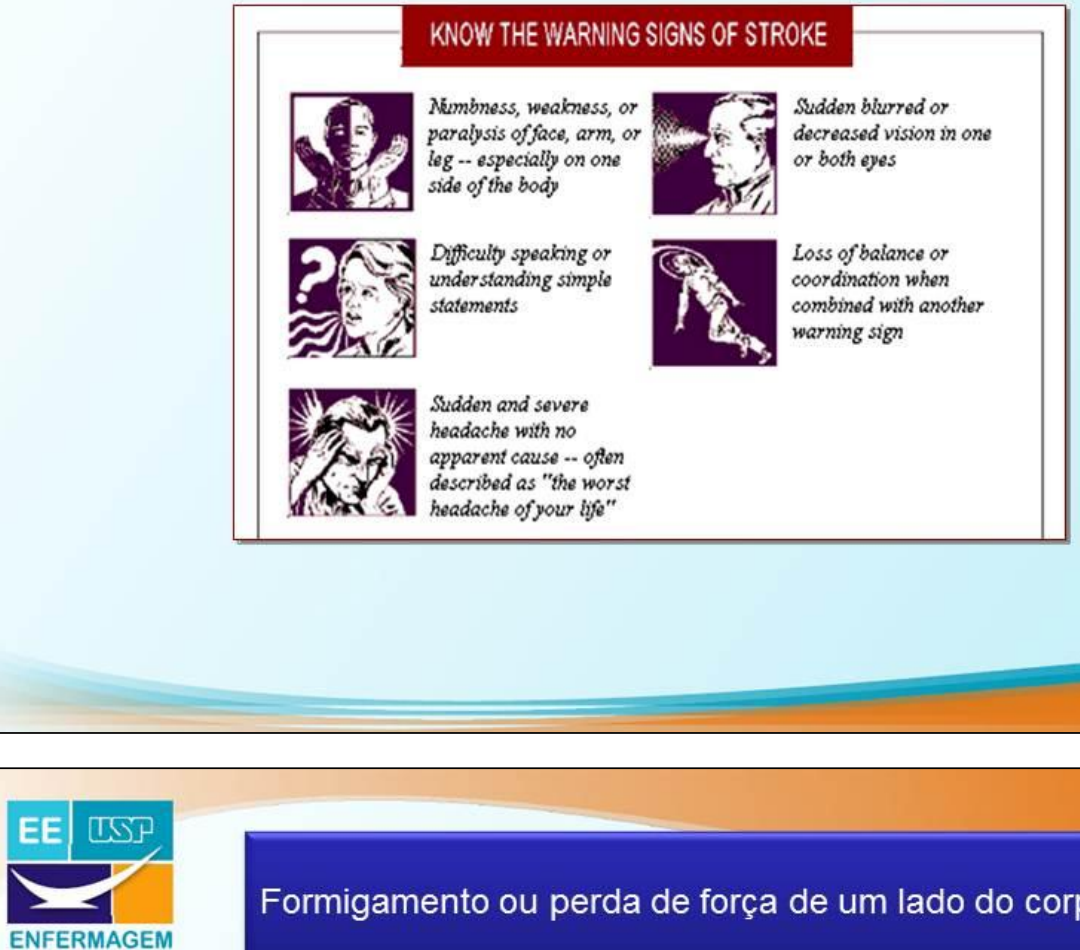

\section{Formigamento ou perda de força de um lado do corpo}
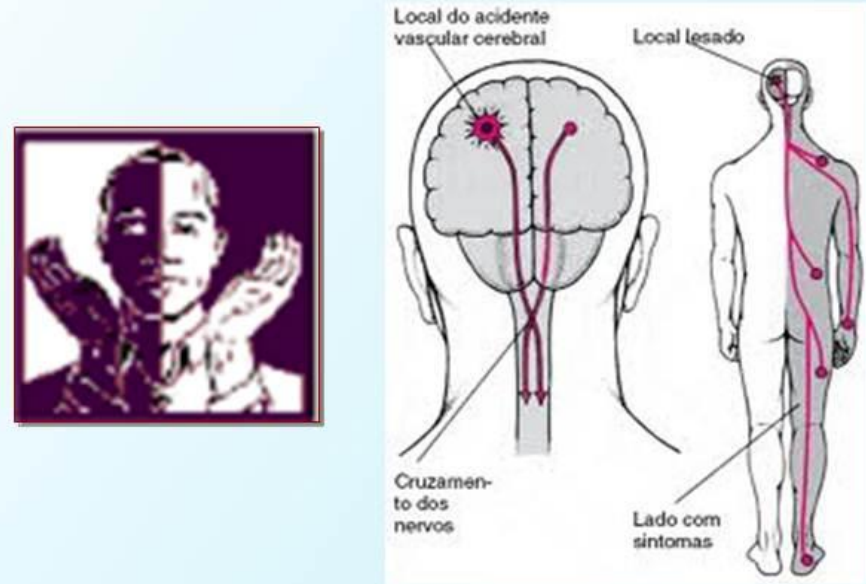


\section{EE WJP}

\section{Alteração na Visão}
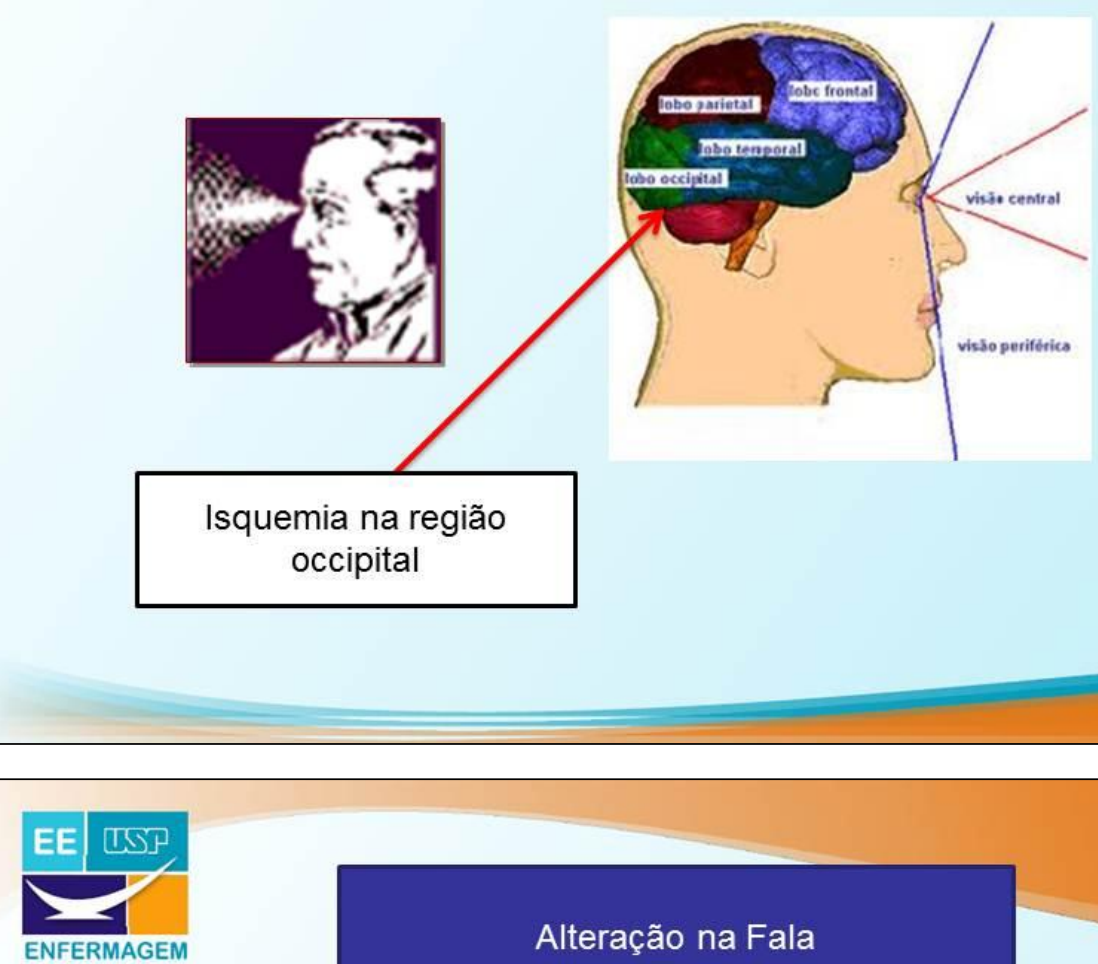

\section{Alteração na Fala}
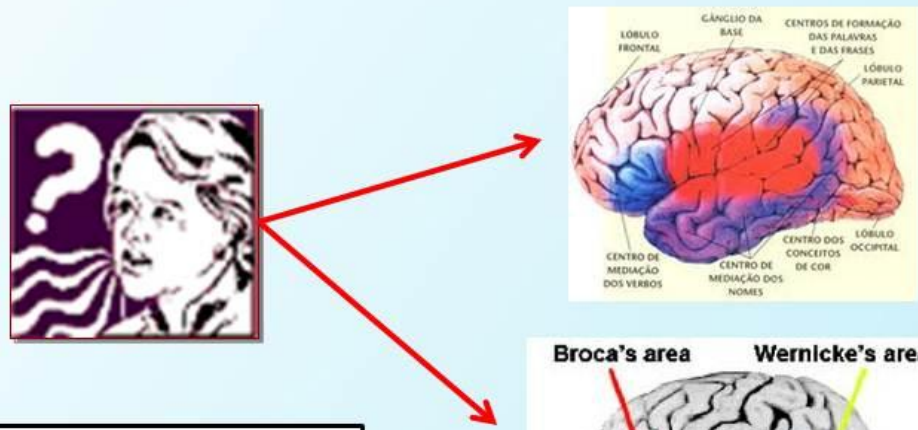

Dificuldade de falar ou Entender frases simples

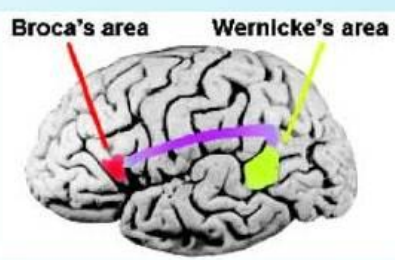



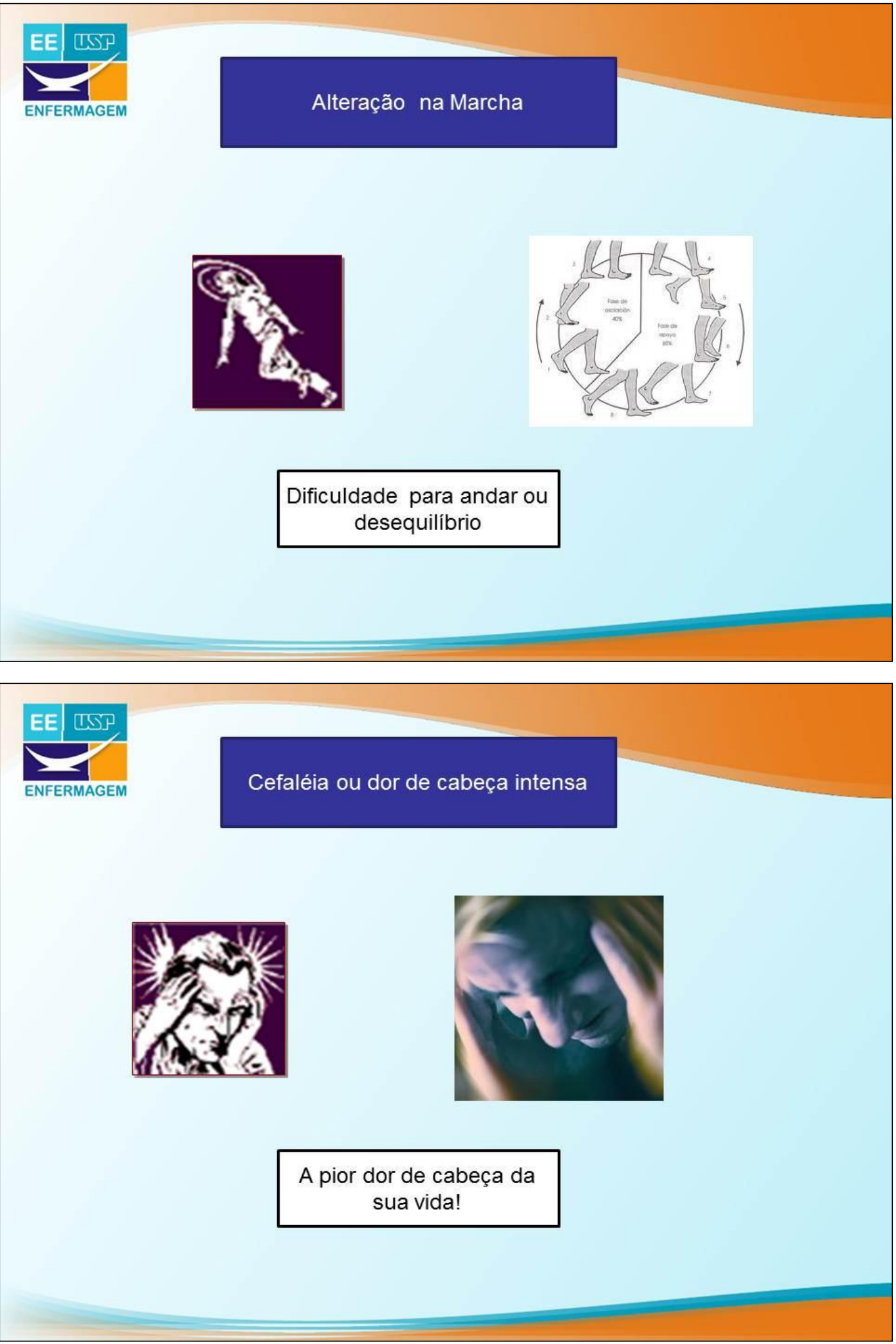


\section{EE एTSP \\ ENFERMAGEM}

O que fazer ???

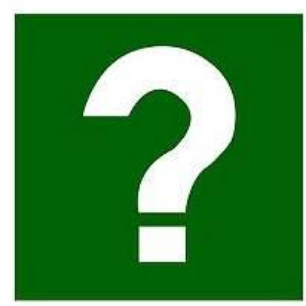

\section{Tomada de Decisão}

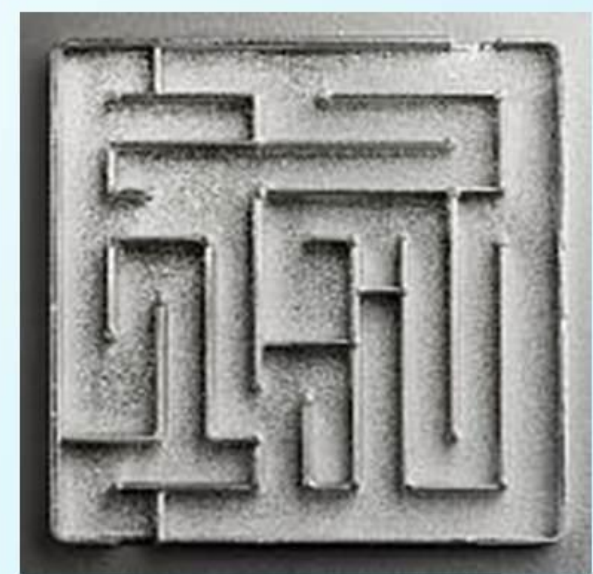




\section{Condutas}
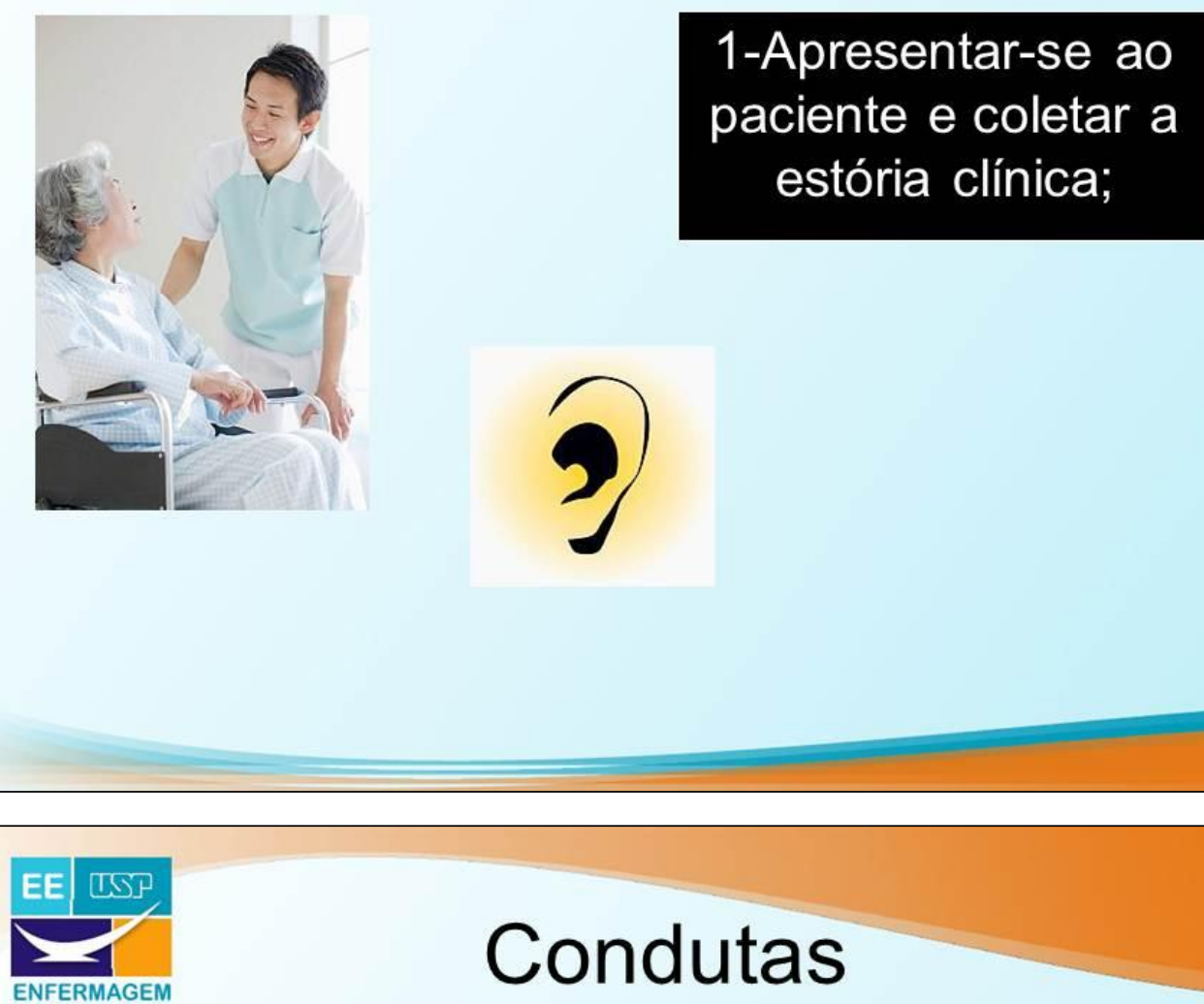

\section{Condutas}

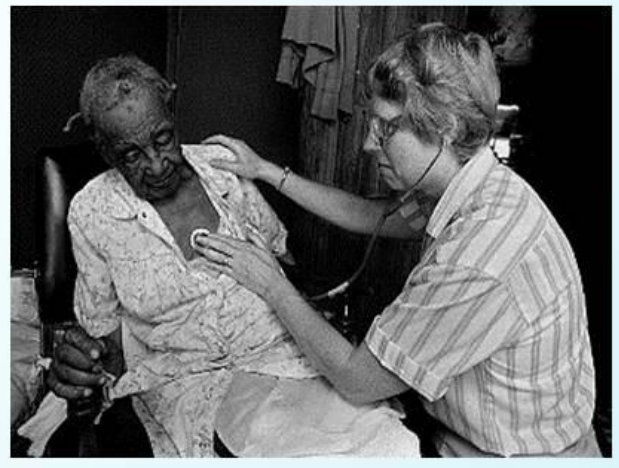

\section{2-Realizar o Exame Físico / Neurológico}




\section{Condutas}
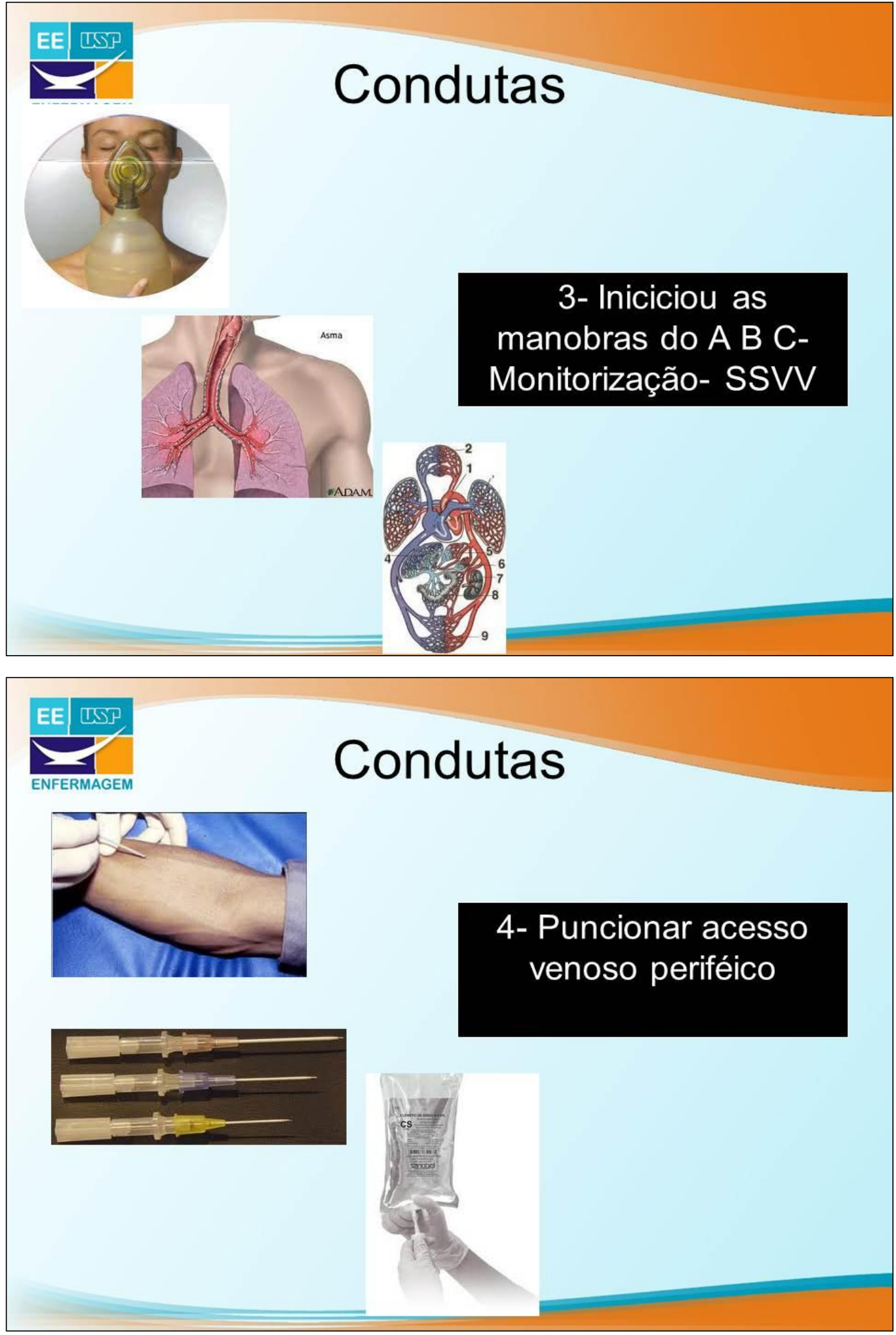


\title{
Condutas
}
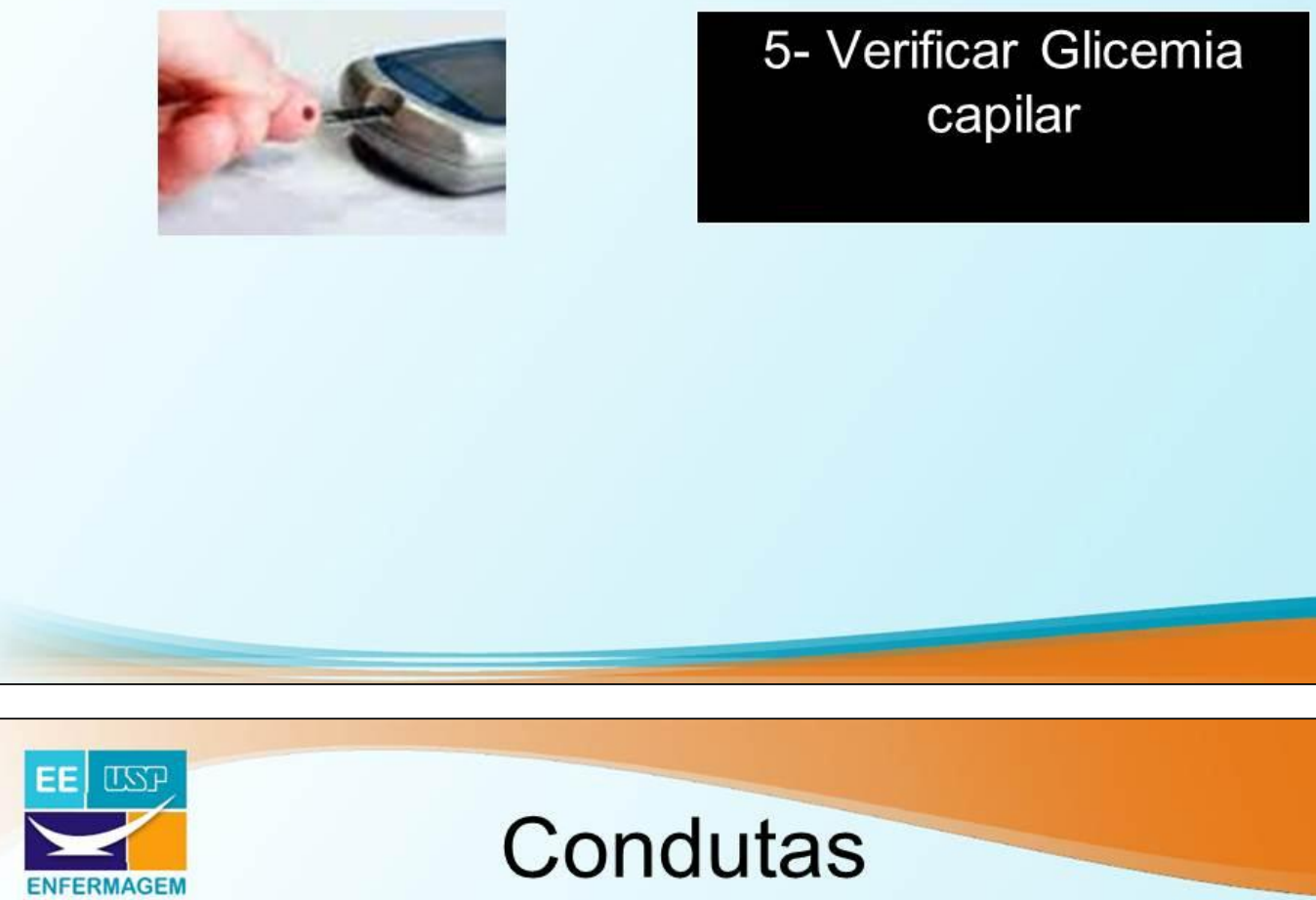

\section{Condutas}

\author{
6- Chamar o médico
}




\section{Condutas}

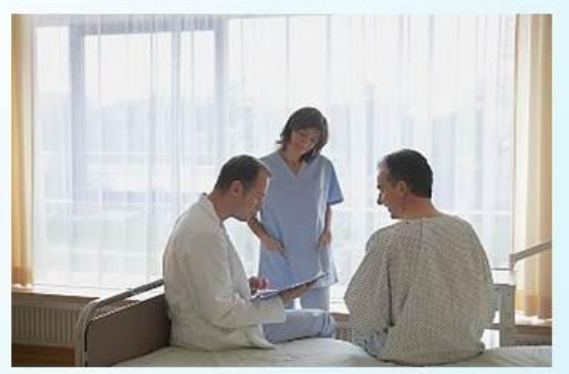

7- Orientar paciente e familia sobre as condutas adotadas.

\section{Discussão em Grupo}

1-Dividir o grupo em dois grupos.

2- O grupo terá que representar graficamente o caso exposto (sinais e sintomas e condutas)- 10 minutos

3- Apresentar para a classe- 5 minutos cada grupo 


\section{Discussão em Grupo}

Sr. JRS, 62 anos, foi admitido em uma Unidade de Clínica Médica com diagnóstico de Pneumonia. Por volta das 08:30h o paciente relatou que sentiu-se estranho pela manhã. Informou que quando chegou a bandeja do café da manhã, ao tentar pegar a xícara do café, não conseguiu erguê-la, pois sentiu a "mão fraca". Relatou, também, alteração na visão e formigamento na perna direita.

- Na história clínica o Sr JRS relata fazer tratamento de hipertensão arterial sistêmica (HAS), ser tabagista (fuma 1 maço de cigarros por dia) e ter tido, há 6 meses, um episódio de Ataque Isquêmico Transitório (AIT), fazendo uso de antiagregante plaquetário (AAS).
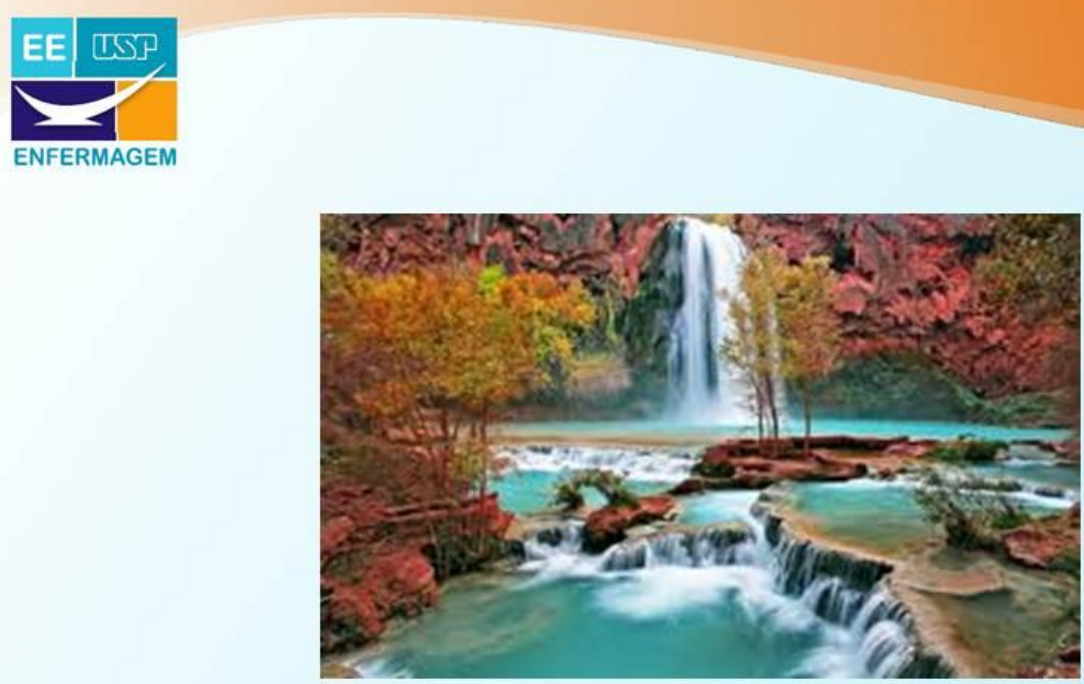

Muito Obrigada! 


\section{Referências}

1. Murray CJL, Lopez AD, Jamison DT. The global burden of disease in 1990: summary results, sensitivity analyses, and future directions. Bulletin of the World Health Organization, 1994, 72:495-508.

2. Murray CJL, Lopez AD. Alternative projections of mortality and disability by cause, 1990-2020: Global Burden of Disease Study. Lancet, 1997, 349:1498-1504.

3. Kaup AO; Pieri A; Coelho FMS. Acidente vascular cerebral protocolos gerenciados do Hospital lsraelita Albert Einstein. Barueri:Manole; 2009.

4. American Stroke Association. Learn to recognize a stroke.[Internet].2009; American Stroke association [citado 2010 Jan 6]. Disponivel em: http://www. strokeassociation.org/presenter. ihtml?identifier $=1020$.

5. Brainin M, et. Al. EUSI Executive Committee and the EUSI Writing Committee

Organization of stroke care: education, referral, emergency management and imaging, stroke units and rehabilitation. Cerebrovasc Dis 2004;17(Suppl.2):1-14 (DOI: 10.1159/000074816)

6. Massant CG, Pieri A, Kuster GW, Morgulis RN. Acidente vascular cerebral protocolos gerenciados do Hospital Israelita Albert Einstein. Barueri: Manole; 2009

7. Almeida ANCF, Neto AC, Coelho FMS, Monzillo P, Silva GS. Acidente vascular cerebral protocolos gerenciados do Hospital Israelita Albert Einstein. Barueri: Manole; 2009.

8. Adams HP Jr, Et al. Guidelines for the early management of adults with ischemic stroke: a guideline from the American Heart Association/American Stroke Association Stroke Council, Clinical Cardiology Council, Cardiovascular Radiology and Intervention Council, and the Atherosclerotic Peripheral Vascular Disease and Quality of Care Outcomes in Research Interdisciplinary Working Groups: the American Academy of Neurology affirms the value of this guideline as an educational tool for neurologists [published corrections appear in Stroke. 2007;38:e38 and 2007;38:e96]. Stroke. 2007; 38: 1655-1711

\section{Imagens}

- Corbis - www.corbis.com.br

- Google Imagewww.google.imagem.com.br 


\title{
APÊNDICE 11-PLANO DE AULA - INTERVENÇÃO DO GRUPO \\ EXPERIMENTAL - AULA SIMULADA
}

\author{
Curso de Graduação em Enfermagem da FEHIAE \\ Práticas Atuais de Enfermagem \\ Profa Tania Oliveira Lopes
}

\section{8-Setembro - 2010}

\section{Plano de Aprendizagem}

Curso: Enfermagem- Nível Superior -Enfermeiro

Disciplina: Práticas Atuais de Enfermagem

Público Alvo: alunos do Curso de Graduação de Enfermagem

Data: 28 de setembro de 2010

Duração: 80 minutos

Horário: Turma $A$ das 08:00 às 9:20 horas e Turma B- das 10:00 ás 11:20

Docente: Tania

Título da aula: Reconhecimento dos Sinais e Sintomas do AVC e Condutas Assistenciais ao Pacientes com AVCl em fase Aguda

\section{Objetivo Geral}

1-Instrumentalizar o aluno para que ele possa reconhecer os sinais e sintomas do paciente com Acidente Vascular Cerebral (AVC).

2-Instrumentalizar o aluno para que quando ele se depare com o paciente vítima de AVC em unidade de CMC, instale as condutas assistenciais ao paciente com suspeita de AVC.

\section{Objetivos do professor}

1-Apresentar parâmetros fisiológicos do Acidente Vascular Cerebral.

Apresentar os sinais e sintomas clássico do paciente com Acidente Vascular Cerebral

2-Discorrer sobre as condutas assistenciais imediatas a serem instituídas no paciente com Acidente Vascular Cerebral

\section{Objetivos do aluno}

Identificar os sinais e sintomas do Acidente Vascular Cerebral

Reconhecer as condutas assistenciais a serem instituídas mediante o paciente com AVC

\section{Conteúdo}

Aspectos fisiológicos do Acidente Vascular Cerebral

Sinais e Sintomas do Acidente Vascular Cerebral

Condutas clínicas a serem instituidas pelo enfermeiro mediante um paciente com você

\section{Estratégias de Ensino}

Aula simulada em laboratório de enfermagem 
Anexos 
ANEXOS

ANEXO 1 - CARTA DE APROVAÇÃO DO PROJETO PELO COMITÊ DE ÉTICA EM PESQUISA

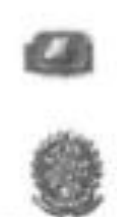

Vinistemo ox saupe

Conaetho Nactonal de Saüs.

Comiseto Naclonal de Etira am Pesouiss - CONE

PROJETO RECEBIDO NO CEP

CAAE - 0137.0.028.000-10

Projeto de Pesquisa

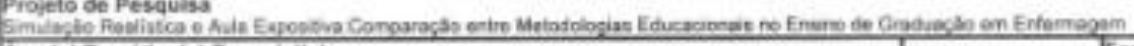

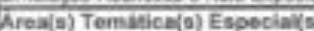

Cono

Fase

teveraic:

CPF

Nas ancalca.

\begin{tabular}{|c|c|}
\hline CPF & Pesquisador Responsivel \\
\hline
\end{tabular}

\begin{tabular}{|c|c|c|}
\hline & & Comine de Eles: \\
\hline \multirow{2}{*}{$\begin{array}{c}\text { Data de Entreg: } \\
270 \text { Dineto }\end{array}$} & Recebimente: & \\
\hline & \multicolumn{2}{|r|}{ Assinutura } \\
\hline
\end{tabular}

Assinutura

Esto documento devera ser, obrigatoriamente, anexado ao Projeto de Pesquisa. 


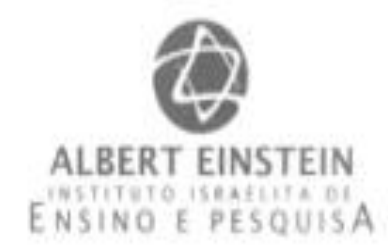

ATENÇÃo

A PARTIR DE SETEMBRO DE 2009 TOOOS OS PROTOCOLOS DE PESQUISA EM DESENVOLVIMENTO NO HIAE PODERAO SER SORTEADOS PARA AUDITORIA. MANTENHA OS SEUS DOCUMENTOS DE PESQUISA ATUALIZADOS E ORGANIZADOS, TERMO DE CONSENTIMENTO LIVRE E ESCLARECIDO (TCLE) DATADO E ASSINADO, ASSIM COMO A LISTA DE SUJETTOS OE PESQUISA INSERIDOS NO PROJETO

OS REL.ATÓRIOS PERIOOICOS DE DESENVOLVMMENTO DA PESOUISA (LINK. hittp ihwww ainsten briPesquisa/ComitesEtica/ComitesEticaPesquisa/Paginas/Principal aspac) DEVEM SER APRESENTADOS A CADA SEIS MESES APOS A APROVACHO

- tCle aPRESENTADO AOS SUJETTOS DA PESQUISA DEVE TER OBRIGATORIAMENTE, O CARIMBO "VERSAOO APROVADA CEPIEINSTEIN". ALEM DISSO, DEVEM SER DATADOS E ASSINADOS PELOS SUJEITOS DE PESQUISA E PELIO RESPONSAVEL PELA SUA OBTENÇĀO, EM DUAS VIAS, UMA DAS QUAIS SERA ENTREGUE AOS SUJETOS DE PESQUISA,

CIENTE

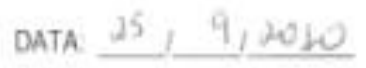
ASSINATURA

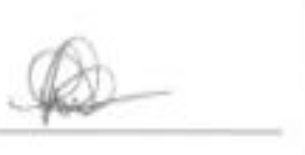




\section{ALBERT EINSTEIN}

ENSINTOOE PRALITADE

Sảo Paula, 22 de setembro de 2010.

Processo CEPiEinstein $n^{\circ}, 10 / 1402$ Projeto de Grupo in

Titulo: "Simulaçbo realistica e aula expositiva: comparaçâo entre mefodologies efucacionais no ensino de graduaças

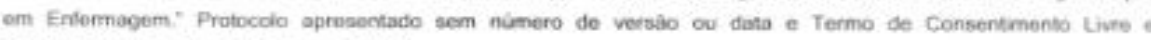
Feclarecido versiolo II da setombro do 2010

Pesquisadora Responsavel. Tána Ctiveira Lopes

Instituiçào: Facuadade de Enfermagem do Hospital laraelita. Albert Einseinir

Instituiçào vinculada Escela de Enfermagem da Universidade de 5 a Paulo - Curso de Pós-graduaçato ant

Enfermagem

Orientadora Hetolsa Hebna Ciqueto Penss (Departanento de Orientaça Profissional da EEUSP)

Entrada no CEP/Einstein: 27 de agosto de 2010

1" Parecer emitido pelo CEPEEinstein em 31 de agosto de 2010

Patrocinador pesquisadora

\section{PARECER}

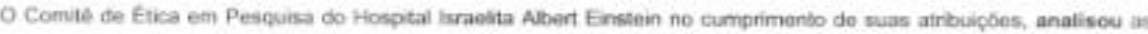
respostas ats peneincias elencades no Parecer CEPEinstein datado de 27 de stembeo de 2010 e considorou que foram tendidas. Assum sendo, aprovou o projeto de pesquisa supracitada, assum come a vernâ if do Termo ofo Consertimento Live e Esclarecido

Agrovetamos a uportunidide pare orientar a pesquisadora score os seguinies fons

- O sujelo da pesquisa tem a liberdade de recusar-se a paniopar ou de peetar seu consentimento em qualquer tase da pesquika, sem peralizache alguma (Res CNS 196596 - Item IV.1.5) e deve receber uma cópia do Tormo do Consentimento Livre Esclarecido, na integra, por ele assinado (tiem IV 2d)

- O pescevisador deve desenvolver a pescuasa conforme dolineada ne protocolo aprovado e desconainuar o estudo somente após analse dass razós da descontinuidade peio CEP que o aprovou (Ros. CNS 196 ltem 1il. 3z)

- O CEP deve ser intomado de iodos os fatos reievantes que atarem o curso narmas do estudo (Ries. CANS lam V.A)

- Evantuais modficaçóes ou emondas ao protocolo devem ser aoresentadas ao CEP de forma clara e sucirta ventificando a parte do peotocob a ser modificado a suas justificativas.

- Rieiatenos parciais o finail devem ser apeesonados ao CEP. inicialmente em 22 de março de 2011, conforme o

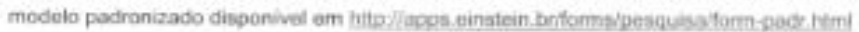

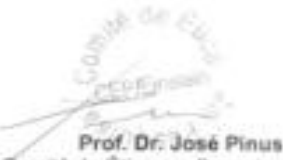




\section{ANEXO 2 - SOLICITAÇÃO AO CEP DA EMENTA I}

Săo Paulo, 31 de janeiro de 2011.

IImo Sr.

Dr. José Pinus

Presidente do Comite de Ética em Pesquisa

do Hospital Israelita Albert Einstein

Informo conforme a ementa I, houve alteraça no projeto de pesquisa sob o $n^{0}$ CAAE 0137.0.028.000-10, onde estiver escrito no projeto Simulaçăo Realistica le-se Aula Simulada.

Esta mudança deu-se em virtude que a responsável pela área da simulaçao realistica, cancelou a viabilidade da coleta de dados, obrigando assim a pesquisadora utlizarem outra estratégia de ensino para a realizaçăo desta pesquisa

Na certeza de contar com sua compreensăo, coloco-me a disposiçăo para possiveis esclarecimentos.

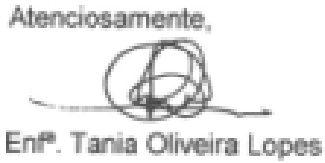




\section{ALBERT EINSTEIN \\ ENSINITUTO ISRAELITA DE}

São Paulo, 15 de fevereiro de 2011.

\section{Processo CEP/Einstein $n^{\circ}, 10 / 1402$ Projeto de Grupo III}

Titulo: "Simulação realistica e aula expositiva: comparaçäo entre metodologias educacionais no ensino de graduaçăo em Enfermagem," Protocolo apresentado sem número de versăo ou data e Termo de Consentimento Livre e Esclarecido versão II de setembro de 2010. Emenda 1, datada de 31 de janeiro de 2011.

Pesquisadora Responsável: Tánia Oliveira Lopes

Instituição: Faculdade de Enfermagem do Hospital Israelita Albert Einstein

Instituição vinculada: Escóla de Enfermagem da Universidade de Sâo Paulo - Curso de Pós-graduaçăo em Enfermagem.

Orientadora: Heloisa Helena Ciqueto Peres (Departamento de Orientaçăo Profissional da EEUSP)

\section{PARECER CEP/EINSTEIN N ${ }^{\circ} 005 / 2011$}

O Comitê de Ética em Pesquisa do Hospital Israelita Albert Einstein analisou e aprovou a Emenda 1 datada de 31 de janeiro de 2010.

Consideramos que a emenda 1 foi apresentada com as justificativas que a motivaram, de forma clara e sucinta, identificando a parte do protocolo modificada, sem alteraçōes importantes de objetivos ou método. No titulo do projeto onde se lê: simulação realistica passa-se a ler aula simulada.

No cumprimento da Resolução 196/96, o Comitê de Ética em Pesquisa (CEP) deverá receber relatórios semestrais sobre o andamento do estudo, bem como a qualquer tempo e a critério do pesquisador nos casos de relevância e o relatório completo ao final do estudo.

Prof. Dr. Jose Pinus

Coordenador do Comitê de Ética em Pesquisa

do Hospital Israelita Albert Einstein

Instituto de Ensine e Ansquisa do Nospital Israelita Albert Einstew

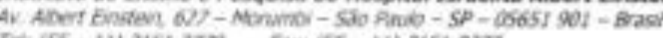

Te; $(55-12) 2151.1729$

Fax: $(55-11) 2151$ a.7?

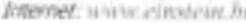

